\title{
NZ Inc: \\ New Zealand's \\ Whole-of-Government Approach \\ to Peace Support Operations
}

\author{
Callum Martin \\ Thesis Submitted in Fulfilment of a \\ Master of Arts \\ in \\ Public Policy \\ Centre for Strategic Studies \\ School of Government \\ Victoria University of Wellington
}

2011 
ABBREVIATIONS

AND ACRONYMS

NZ Inc
MEANING

A term used to refer to the whole of government acting together offshore.

Sometimes also used to include the private sector and other non-government actors.

Figure 1: New Zealand Ministry of Foreign Affairs \& Trade Annual Report 2009/10 


\section{Abstract}

Into the late 1990s the international community began to develop new methods for assisting fragile states. It was recognised that development principles and practice were often insufficient to resolve the 'complex operations' they were entering. This was especially true when engaging states that lacked either the political commitment or the practical capacity to deliver basic social and public services. The defining feature of these operations is that assistance is required across all pillars of civil society - economic, law and justice, governance and public administration. Without effectively addressing each of these pillars there is a significant risk of systemic failure.

A key challenge of engagement across these pillars is coordinating the growing number of contributions - both civilian and military. The whole-ofgovernment approach has been promoted as a method to ameliorate this challenge. It is argued that the approach reduces departmental silos, promotes policy coherence, and provides efficiency while better addressing the complexity of the operating environment. While this may be true, the rhetoric is ill-defined and generates confusion as to what it means at a practical level. In short, it remains unclear how to achieve an efficient and effective whole-of-government approach or what that would actually look like. This thesis examines this dilemma and identifies the factors for successful implementation of New Zealand's whole-of-government approach to peace support operations.

Rather than concentrating on the formerly popular 'machinery of government' changes, this thesis argues that there are three overarching factors when implementing a whole-of-government approach. The first requirement is strategic direction from Government. This should come in the form of a national security statement and subsidiary individual country strategies. The second is culture change across the public sector. This focuses on the 'soft issues' such as organisational cultures, values and routines, professional beliefs, as well as institutional values and preferences. Significantly for peace support operations, this must be extended to promote a culture of education and awareness of host nation history and society. The third factor is accurate and flexible performance indicators and measurement to ensure that success can be identified and achieved. Effective execution of these factors will add value and promote excellence in New Zealand's peace support operations. 
To 'C' 


\section{Acknowledgements}

I would like to thank the people and organisations that enabled this research. It was a thoroughly enjoyable and educating experience. First, I convey my sincere gratitude to my supervisor Professor Robert Ayson. The year has been a voyage of discovery as we both navigated through the workings of the Masters programme at the School of Government. His assistance and direction has been invaluable. This extends to Synonne Rajanayagam who is the backbone of the Centre for Strategic Studies. Her assistance this year, as over the past three years has been very much appreciated. Lyne Todd and the staff at the School of Government have been incredibly helpful and will be missed.

I have been incredibly fortunate to have the financial support of several New Zealand organisations. The Peace and Disarmament Education Trust provided me with a Masters Scholarship to enable me to undertake the thesis. The Asia New Zealand Foundation enabled me to conduct field research by awarding me with the 2010 International Relations Grant. I am extremely grateful to both organisations. Asia:NZ provided further opportunities over the year after bringing me on as a Young Leader. The staff at the Foundation have been brilliant and I look forward to working with them over the next few years.

I would like to offer my appreciation and gratitude to the many people that took time out of their schedules to speak to me - in Wellington, Canberra and Dili. Specifically, I would like to mention the excellent work of the Asia Pacific Civil-Military Centre of Excellence and the National Security College (ANU). These organisations are international leaders in their field. The support they extend to New Zealand practitioners and academics is appreciated and should be applauded.

Finally, I thank Associate Professor Jim Veitch for his guidance and instruction over the past several years. With the submission of this thesis it draws to an end a journey that I began as his researcher at the Centre for Strategic Studies early 2008. I hope the future holds further opportunities for us to work together. 


\section{Table of Contents}

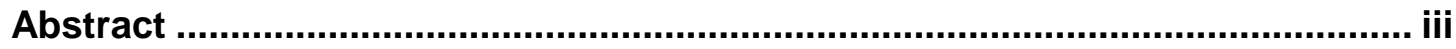

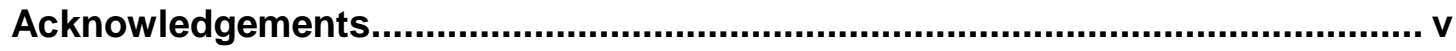

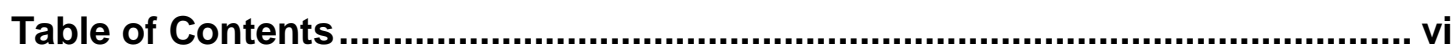

List of Figures and Tables ................................................................................ vii

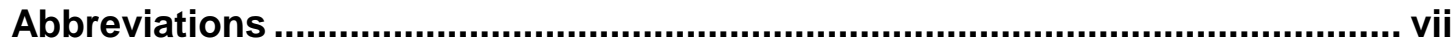

Chapter 1: Introduction and Methodology..................................................... 1

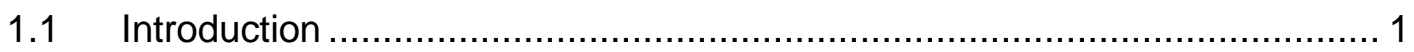

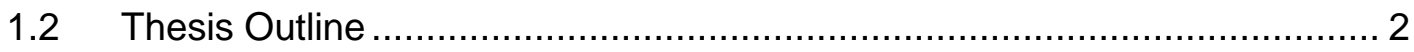

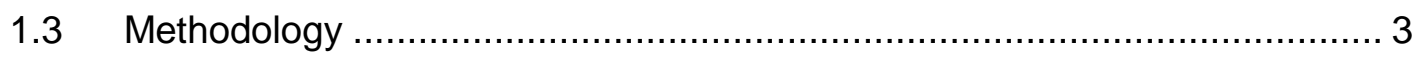

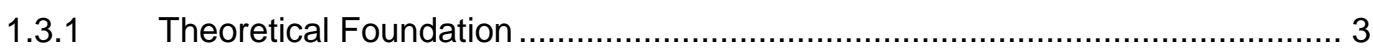

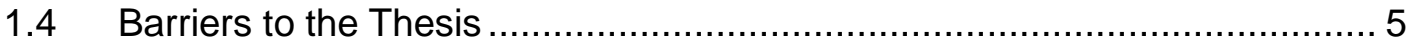

Chapter 2: The Whole-of-Government Approach........................................... 7

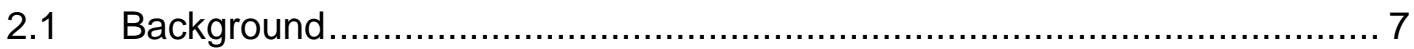

2.2 Motivations for Whole-of-Government ............................................ 10

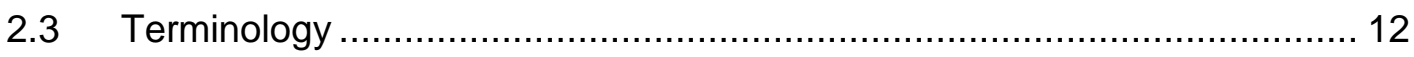

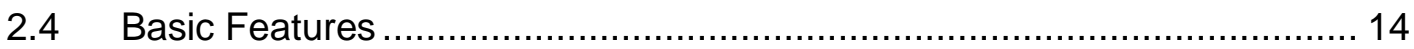

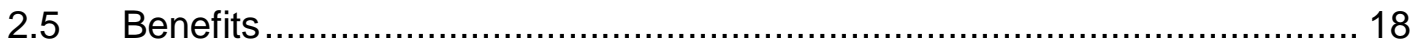

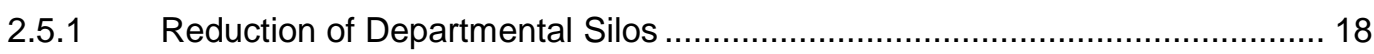

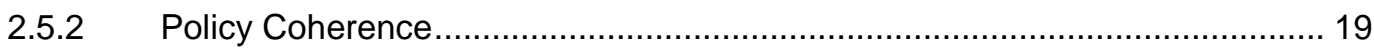

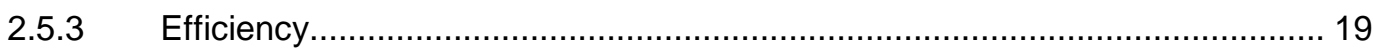

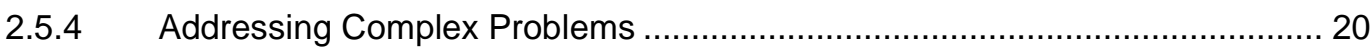

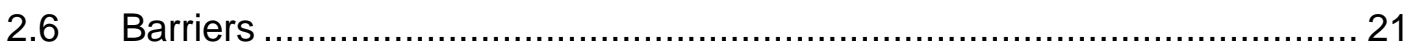

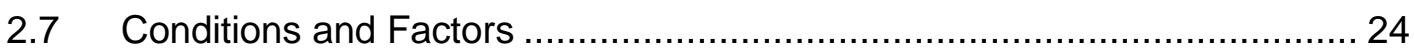

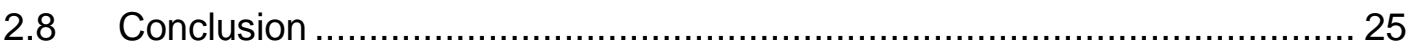

Chapter 3: Whole of Government Approaches to Peace Support Operations.. 26

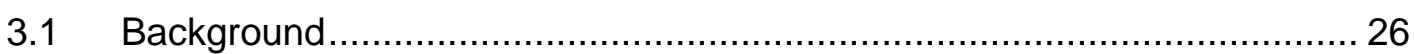

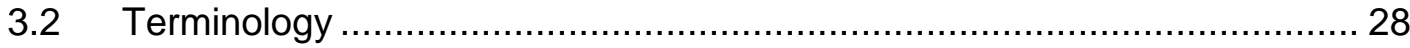

3.3 International Whole of Government Approaches .................................. 32

3.3.1 The United Kingdom, Canada \& the United States ....................................... 32

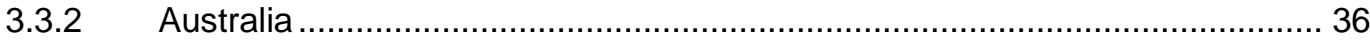

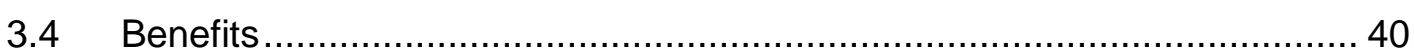

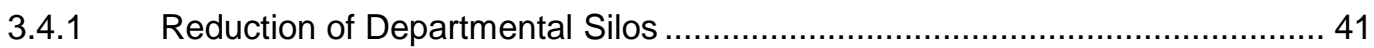

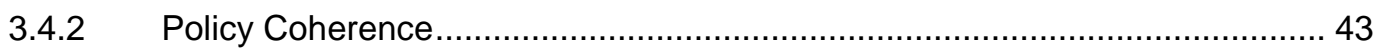

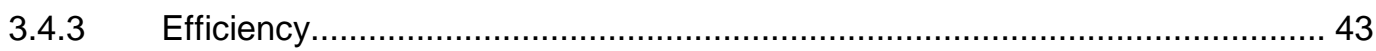

3.4.4 Addressing Complexity in Peace Support Operations .................................. 44

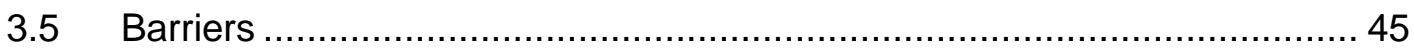

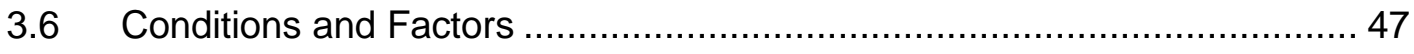

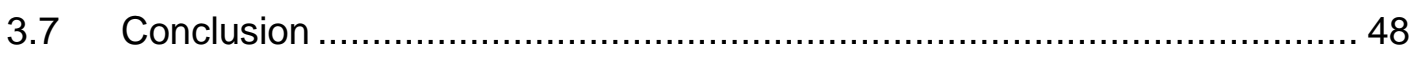

Chapter 4: The Whole-of-Government Approach in New Zealand ..................... 50 
4.1 New Zealand Public Sector Reform...................................................... 50

4.2 Implementation of the Approach in New Zealand ................................... 54

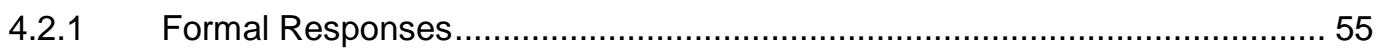

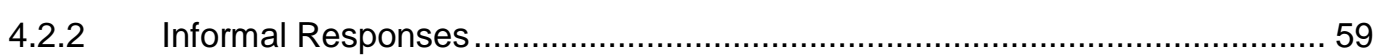

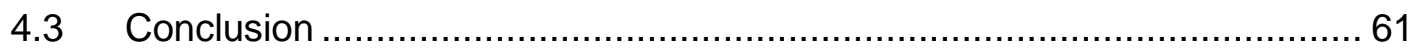

Chapter 5: New Zealand's Whole-of-Government Approach to Peace Support

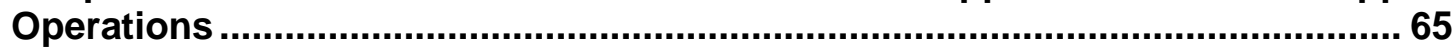

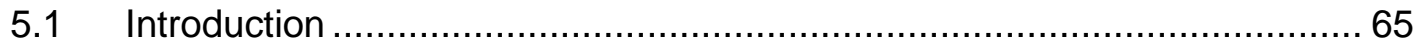

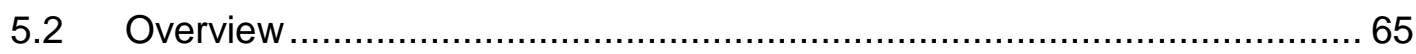

5.3 Whole-of-Government Approach to External Security .............................66 66

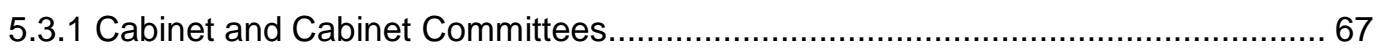

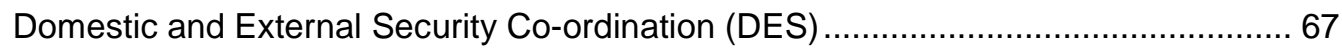

External Relations and Defence Committee (ERD) ................................................. 68

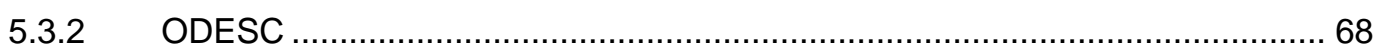

5.3.3 The Department of the Prime Minister and Cabinet ....................................... 69

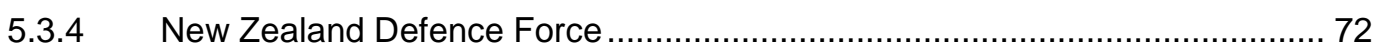

5.3.5 The New Zealand Ministry of Foreign Affairs and Trade ................................ 76

5.3.6 The Requirement for a Whole-of-Government National Security Statement .. 80

5.4 Complex Peace Support Operations .................................................... 83

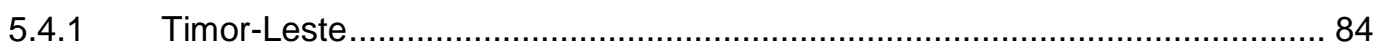

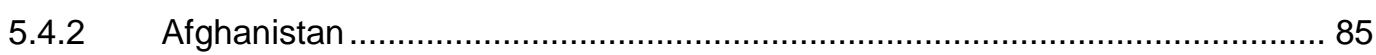

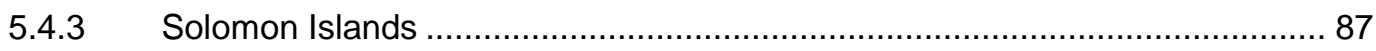

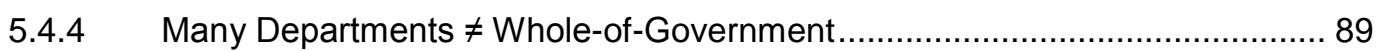

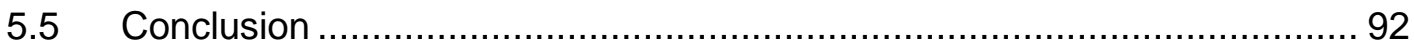

Chapter 6: Findings and Conclusions .......................................................... 94

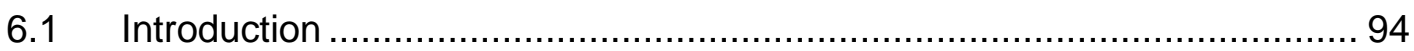

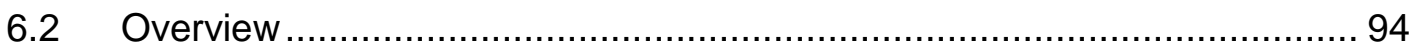

6.3 What Should Whole-of-Government Look Like? .................................. 95

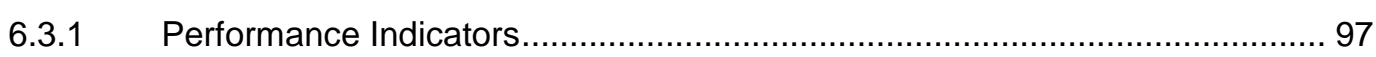

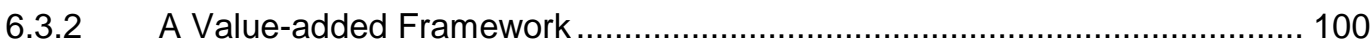

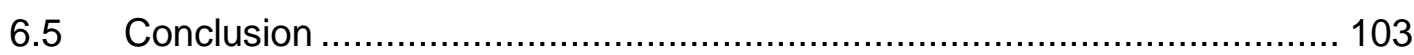

\section{List of Figures and Tables}

Figure 1: New Zealand Ministry of Foreign Affairs \& Trade Annual Report 2009/10 ...ii Figure 3: The nature of the changes we think are needed is as follows: ................. 54 Figure 4: An Overview of New Zealand's Security and Intelligence Arrangements .. 72

Table 1: Advantages and Disadvantages of a Whole-of-Government Approach...... 21

\section{Abbreviations}




\begin{tabular}{|c|c|}
\hline CA & Comprehensive Approach \\
\hline DAC & Development Assistance Committee (OECD) \\
\hline DES & Domestic and External Security Committee (Cabinet) \\
\hline DESC & Domestic and External Security Coordination \\
\hline DFAT & Department of Foreign Affairs and Trade (Australia) \\
\hline DPF & Defence Policy Framework \\
\hline DPMC & Department of the Prime Minister and Cabinet \\
\hline EBO & Effects Based Operations \\
\hline ERD & External Relations and Defence Committee (Cabinet) \\
\hline FSG & Fragile States Group (OECD) \\
\hline INTERFET & The International Force for East Timor \\
\hline IPS & Institute of Policy Studies \\
\hline JUG & Joined-up government \\
\hline MFAT & The New Zealand Ministry of Foreign Affairs and Trade \\
\hline MoU & Memorandum of Understanding \\
\hline NGO & Non-Governmental Organisation \\
\hline NPM & New Public Management \\
\hline NSC & National Security College (Australia) \\
\hline NZDDP-D & Foundations of New Zealand Military Doctrine \\
\hline NZDF & The New Zealand Defence Force \\
\hline NZ Inc & $\begin{array}{l}\text { A term coined by MFAT used to denote the whole of government working } \\
\text { together offshore towards collective outcomes. }\end{array}$ \\
\hline ODESC & Officials Committee for Domestic and External Security Coordination \\
\hline OECD & Organisation for Economic Co-operation and Development \\
\hline OPRES & Operational Preparedness Reporting System \\
\hline PCRU & Post-Conflict Reconstruction Unit (United Kingdom) \\
\hline PKO & Peacekeeping operation \\
\hline PRT & Provincial Reconstruction Team \\
\hline QDDR & Quadrennial Diplomacy and Development Review (USA) \\
\hline R2P & Responsibility to protect \\
\hline RAMSI & Regional Assistance Mission to Solomon Islands \\
\hline SOI & Statement of Intent \\
\hline SRG & Security Risk Group (DPMC) \\
\hline S/CRS & Office of the Coordinator for Reconstruction and Stabilization \\
\hline UNMISET & United Nations Mission of Support in East Timor \\
\hline UNMIT & United Nations Integrated Mission In Timor-Leste \\
\hline UNOTIL & United Nations Office in East Timor \\
\hline UNTAET & The United Nations Transitional Administration in East Timor \\
\hline WGA & Whole-of-government approach \\
\hline
\end{tabular}




\section{Chapter 1: Introduction and Methodology}

What are the conditions and factors for, and the barriers to, successful implementation of New Zealand's whole-of-government approach to peace support operations?

\subsection{Introduction}

One of New Zealand's leading contributions to international security and the rule of law is a continuing commitment to peace support operations (PSOs). PSOs led or endorsed by the United Nations have expanded in response to the increase in conflict, post-conflict and fragile states that require international assistance. A core role for New Zealand has been the contribution to the integrated state-building operations in Solomon Islands, Timor-Leste and Afghanistan. These "complex operations" require both civilian and military components from New Zealand to work alongside those of international and host nation partners.

In 2005, the OECD Development Assistance Committee's (DAC) Fragile States Group (FSG) drafted a set of Principles for Good International Engagement in Fragile States. The Principles established that successful development in fragile environments largely depends on "well-sequenced and coherent progress across the political, security, economic and administrative domains."1 These domains were held to be interdependent: "failure in one risks failure in all others". ${ }^{2}$ They determined that working effectively across these domains "requires donor countries to adopt a 'wholeof-government' approach (WGA), involving departments responsible for security, and political and economic affairs, as well as those responsible for development aid and humanitarian assistance." The benefit of this approach, the FSG outlined, is that it promotes long-term development and stability in fragile states at a lower overall fiscal cost. Additionally, coherent policies and activities will likely generate greater legitimacy in the recipient country and are therefore more likely to receive a positive response.

With New Zealand's involvement in these complex operations, a growing number of ministries and agencies are taking on international responsibilities in addition to their domestic portfolios. An analysis of New Zealand official information

\footnotetext{
${ }^{1}$ OECD Whole of Government Approaches to Fragile States (Development Assistance Committee (DAC) Fragile States Group (FSG), 2006) available at http://www.oecd.org/dataoecd/15/24/37826256.pdf (accessed 22 March 2011.) 13.

${ }^{2}$ Ibid. 7.
} 
over this period illustrates that the whole-of-government approach is being applied to manage these interrelated commitments. However, policy making for whole-ofgovernment is a complex system with multiple sectors and levels of decision making. Policy researchers have shown that this has generated confusion as to what the rhetoric actually means at a practical level.

This research will critically review the international literature on the whole of government approach as a service delivery strategy in peace support operations. The thesis will look at the background and terminology as well as whole of government approaches internationally. Attention will then turn to identifying the conditions and factors for, and the barriers to, successful implementation of New Zealand's whole-of-government approach to peace support operations.

\subsection{Thesis Outline}

To examine New Zealand's whole-of-government approach to peace support operations I believe it is necessary to provide a detailed history and background of the whole-of-government concept. This will provide building blocks on which to look at the subsequent development of the concept in different jurisdictions and sectors. It will also extract from each stage a set of conditions, factors and barriers to the successful implementation of the concept.

The natural starting point into an examination of the whole-of-government is to provide a literature review and analysis of the development of the concept internationally. Chapter Two provides this analysis by drawing on international literature, defining the terminology and outlining the basic features. It then draws out of the literature the barriers, conditions and factors that are salient in efficient and effective implementation. Chapter Three applies this framework to international use of the concept in peace support operations. After this the thesis moves towards a survey of the concept in New Zealand domestic governance. It examines how the concept is a central component of public sector reform in the period after the socalled 'new public management' era. It also looks towards the formal and informal responses by government to attempt to drive this change across the public sector.

It is at this point that the thesis is adequately prepared to analyse how the whole-of-government approach has been implemented in New Zealand's peace support operations. Chapter Five provides a review of the origins of the interest in the 
concept, and outlines where it fits into the structures of New Zealand's external security policy. With this performed, the final chapter is able to draw on the complete research and provide a detailed picture of what the concept should look like when implemented appropriately. Of specific significance is the provision of a performance indicator framework to add value to New Zealand's whole-of-government operations.

\subsection{Methodology}

This research draws on methodology that is qualitative in nature. It provides a detailed literature review that analyses the broader policy environment then narrowing to concentrate on the specific subject of this thesis - New Zealand's whole-of-government approach to peace support operations. It addresses the research questions by applying a comparative approach. Implementation of the whole-of-government approach in several countries will be contrasted with the implementation in New Zealand. Countries have been selected that have historically close political and cultural ties to New Zealand. It is these nations that New Zealand most often collaborates with in peace support operations. Within New Zealand, state agencies at the central level form the main object of the study. They will be studied in a broader context but also with respect to their own governance structure, their internal management, their organisational culture, and their performance. The data basis of the chapters is a comprehensive comparative survey approach. Data is drawn from the literature through a comprehensive comparative survey approach in different countries, as well as document studies and media coverage.

\subsubsection{Theoretical Foundation}

Policy analysis targets what governments intend to do, what they actually do, why they do it and what differences it makes. ${ }^{3}$ Studies of public policy are generally preoccupied with the underlying question in political science: "Who gets what, when and why?" ${ }^{4}$ The objective of the analysis of existing policy is to identify how future political problems may be more efficiently and effectively addressed. Policy analysis

\footnotetext{
${ }^{3}$ See: Rannveig Røste Innovation in the Public Sector: Studies of Innovation in the Public Sector, a Theoretical Framework (Publin Report No. D16, 2005) available at http://www.step.no/publin/reports/d16litteraturesurvey.pdf (accessed 27 February 2011) 15, S. Z. and Cahn Theodoulou, M. A., Public Policy. The Essential Readings (Englewood Cliffs, NJ: Prentice Hall, 1995).

${ }^{4}$ See: H D Laswell, Politics: Who Gets What, When and How (Cleveland: Meridan, 1936).
} 
is often biased, and it is therefore advantageous to use several different theoretical perspectives in the study of existing policy and political processes. ${ }^{5}$

The theoretical basis for the study of public sector organisations is drawn from different schools. It is useful to avoid single-factor explanations and instead aim to gain a healthier understanding of change in public sector organisations and its effects by combining different theoretical approaches. ${ }^{6}$ Additionally, with the wide variety of theoretical approaches, come rival vocabularies and terminologies. ${ }^{7}$ This is certainly seen in the attempt to define the whole-of-government approach in Chapter Two of this thesis.

This thesis draws on a variety of theoretical models. Principal agent theory is one of these. As outlined by Per Lægreid and Koen Verhoest, this theory deals with the design and control problem a principal has when delegating a task to a specialised and autonomous agent. It refers to the agency problem a government faces when dealing with autonomous public bodies. The theory advocates the use of result based management tools and incentives, in order to counterbalance agencies' autonomy and to increase their performance. Explored in more detail in Chapter Four, this theory argues that change will be best driven if results are linked to tangible rewards - such as pecuniary incentives.

The research draws intuitively from a constructivist standpoint. As stressed by Brewer and Selden Colman, organisational performance is a socially constructed phenomenon that is subjective, complex, and particularly hard to measure in the public sector. ${ }^{8}$ This research follows this conviction and holds that the real essence of the nascent whole-of-government reforms has been an awareness of the social complexity of the operating environment. My thesis will argue that rather than continue the formerly popular 'machinery of government' changes - a central requirement to reach an effective and efficient whole-of-government approach is culture change. In effect, institutional norms need to be transformed to promote more joined up working. This needs to be supported by a dedicated culture of learning especially about the nuances of the individual countries requiring assistance. While

\footnotetext{
${ }^{5}$ Røste Innovation in the Public Sector: Studies of Innovation in the Public Sector, a Theoretical Framework 15.

${ }^{6}$ Per Lægreid and Koen Verhoest, ed., Governance of Public Sector Organizations: Proliferation, Autonomy and Performance (Palgrave Macmillan 2010), 6.

${ }^{7}$ Røste Innovation in the Public Sector: Studies of Innovation in the Public Sector, a Theoretical Framework 15.

${ }^{8}$ Gene A Brewer and Sally Coleman Selden, 'Why Elephants Gallop: Assessing and Predicting Organizational Performance in Federal Agencies,' Journal of Public Administration Research and Theory 10, no. 4 (2000): 688. 
there has been awareness that 'militaries cannot go it alone' and require civilian assistance, this must be complemented by enhanced education into the host nation their culture, their history and their way of doing business. This is an iterative process that will benefit from recognition that working together in these environments requires a socialisation of ideas and actions.

Lastly, I argue that context is related to cultural processes. As Philip Selznick identified in 1957, public organisations evolve gradually by adapting to internal and external pressure. ${ }^{9}$ In a process of institutionalisation they develop distinct cultural features represented by their informal norms and values. ${ }^{10}$ In specific relation to this research, in the security sector this process develops distinct and entrenched raisons d'être in which equally distinct and entrenched departmental esprit de corps are developed. When attempting to 'join-up' government departments this constructive process needs to be fully understood. This requires agencies and departments to better educate their peers in the New Zealand Government about their unique methods and values. This would enhance empathy across the public sector thus promoting better understanding of why other agencies act in certain ways and to leverage the most value out of any collaboration.

\subsection{Barriers to the Thesis}

One of the challenges in performing this research was the difficulty faced in locating comprehensive information about New Zealand's commitments to peace support operations. The New Zealand Defence Force (NZDF) provides valuable information in its annual reports and on their website about current operations. Apart from NZDF however, there is little public information available about these commitments. The New Zealand Ministry of Foreign Affairs and Trade (MFAT) provides a broad outline of its involvement and leadership of 'NZ Inc' - though NZ Inc is not specifically focused towards peace support operations (and to date has had little impact on them). Several other government departments refer to their involvement in peace support operations in their annual reports, though apart from those meagre references, there is a real dearth of information about the size of New

\footnotetext{
${ }^{9}$ See: P Selznick, Leadership in Administration (New York: Harper \& Row, 1957).

${ }^{10}$ Tom Christensen \& Per Lægreid, "Democracy and Administrative Policy: Contrasting Elements of NPM and Post-NPM" (paper presented at the EGPA Annual Conference 'The Public Service: Public Service Delivery in the Information Age', Study Group VI: Governance of Public Sector Organizations, Malta, 2-5 September 2009) available at 2011) 9.
} 
Zealand's combined presence in these operations. A significant weakness is that there is no centralised source providing comprehensive information about New Zealand's whole-of-government contributions. ${ }^{11}$ As a result, the public (especially media and academia) cannot easily obtain accurate information on the use of the whole-of-government approach to these operations.

A further challenge with this type of research is securing formal, recorded interviews. I met with resistance from interviewees when conducting field research for the thesis in Timor-Leste when I asked whether they would sign the university ethics forms and go 'on the record'. I found that they were very prepared to talk 'off the record' and did not mind me taking notes, but were reluctant to be formally recorded. My university approved ethics requirements enabled full anonymity, though in a small environment such as Dili, people believed it was possible for comments to be traced to a source. I adapted my research to this development. This was certainly not fatal to the Master's thesis - in contrast, it enabled me to gather better material with which to shape the thesis. However, if I were to undertake doctoral research I would design the field work differently. One change would be to spend several lengthy periods incountry to build relationships. ${ }^{12}$

\footnotetext{
${ }^{11}$ See recommendations from Australian Senate: Australian Government Australia's Involvement in Peacekeeping Operations (The Senate: Standing Committee on Foreign Affairs, Defence and Trade, 2008).

${ }^{12}$ I note that a PhD student from Monash University who was staying for a short time in the same Dili guesthouse as I was had identical problems gaining formal permission to record his interviews. 


\section{Chapter 2: The Whole-of-Government Approach}

This chapter aims to critically review the international literature on the whole of government approach. ${ }^{13}$ The section will outline the historical development of the concept and discuss the difficulties with the definitions of this idea. It will then summarise the basic features, conditions for and barriers to successful implementation. This examination will be used in the following chapters as a benchmark to analyse the approach in New Zealand's peace support operations. This will form the basis of an argument that an efficient and effective whole-ofgovernment approach requires more than structural changes. Indeed, to extract the most value out of the concept, culture change at multiple levels of decision making and action is required.

The research questions that guided this section are:

- What is the background of the WGA?

- What is meant by a WGA?

- What are the motivations for a WGA?

- What are the perceived benefits of a WGA?

- What are the basic features of a WGA?

- What are the conditions for the success of a WGA?

- What are the barriers to successful implementation of a WGA?

\subsection{Background}

Tom Christensen and Per Lægreid's research found that the concept of "whole-of-government" was initially termed "joined-up government" (JUG). ${ }^{14}$ Supporting this evaluation, a 2008 literature survey compiled by Elizabeth Eppel showed that there was "no lingua franca for the variegated multi party arrangements that have become common in the last decade." 15 In explanation, Eppel pointed to differing conceptual and theoretical perspectives that permeate the literature. ${ }^{16}$ Christopher Hood had found the same about the historical underpinnings, noting that,

\footnotetext{
${ }^{13}$ See for previous analysis into the related concept of collaboration: Debiprosad Majumdar, 'Collaboration among Government Agencies with Special Reference to New Zealand: A Literature Review,' Social Policy Journal of New Zealand, no. 27 (2006).

${ }^{14}$ Tom Christensen and Per Lægreid, 'The Whole-of-Government Approach to Public Sector Reform,' Public Administration Review 67, no. 6 (2007).

${ }^{15}$ Elizabeth Eppel Better Connected Services for Kiwis: Achieving Outcomes by Joining Up: A Liturature Review (School of Government, Victoria University of Wellington, 2008) available at http://ips.ac.nz/events/completed-

activities/joiningup/Integrated\%20Government\%20Services\%20lit\%20review\%20outline\%20\%20v4\%20 revised\%20May2008.doc 3 .

16 Ibid.
} 
"it is difficult to trace the history of ideas about coordination because the subject is a nebulous one, appearing in several different disciplinary literatures and spanning many institutional and policy domains." 17

The concept of JUG has developed under various guises. Traditionally referred to as coordination, Oxford University Professor of Government Christopher Hood outlined that at its most general level "the doctrine holds that all or many parts of executive government should interconnect, complement one another, and pool related information." ${ }^{18}$ Hood has elsewhere observed that while JUG is a new term it is in fact an old administrative doctrine. In fact, the doctrine of coordination can be traced back at least as far as Jeremy Bentham's Constitutional Code, published in 1820. ${ }^{19}$ Christensen and Lægreid argue a similar point, asking whether it was really a new development, as it advanced the "old question of coordination". ${ }^{20}$ They stressed that, "elements of it have been observable in the United kingdom and Canada for sometime." ${ }^{21}$ Despite this, they believed it was fair to say that the approach "has been revitalized and become more comprehensive."22

While the historical development may be somewhat opaque, the impetus for the recent development of the whole-of-government approach is not. It is widely agreed that what is now termed the 'whole of government approach' was launched in direct response to the New Public Management (NPM) reforms of the 1980s and 1990s. ${ }^{23}$ Those reforms applied Chicago School economic theory to public management. This was built on the presumption that public servants were motivated by the same factors as their private sector counterparts, namely economic incentives and disincentives. ${ }^{24}$ However, as James Q Wilson illustrated in his seminal 1989 work Bureaucracy, public agencies necessarily operate under vastly different conditions from private enterprise. ${ }^{25}$

\footnotetext{
${ }^{17}$ Christopher Hood, "The Idea of Joined-up Government: A Historical Perspective," in Joined-up Government, (ed). Vernon Bogdanor (Oxford: Oxford University Press, 2005), 20.

18 Ibid., 19

${ }^{19}$ Vernon Bogdanor, "Introduction," in Joined-up Government, (ed). Vernon Bogdanor (Oxford: Oxford University Press, 2005), 2.

${ }^{20}$ Lægreid, 'The Whole-of-Government Approach to Public Sector Reform,' 1059.

21 Ibid.

22 Ibid.

${ }^{23}$ See: Ibid, Bogdanor, "Introduction.", Getting Better at Managing for Shared Outcomes: A Resource for Agency Leaders (Prepared by the Managing for Shared Outcomes Development Group for the Managing for Outcomes Programme Office, 2004) available at http://www.ssc.govt.nz/upload/downloadable_files/mfso-resource.pdf, Jonathan Davies, 'The Limits of Joined up Government: Towards a Political Analysis,' Public Administration 87, no. 1 (2009).

${ }^{24}$ Bogdanor, "Introduction," 9.

${ }^{25}$ James Q. Wilson, Bureaucracy: What Government Agencies Do and Why They Do It (New York: Basic Books, 1989), chapter 17. 
Wilson argued that economists evaluate enterprise, whether public or private, by the efficiency criterion - that is by "obtaining the most output for a given level of resources." ${ }^{26}$ In contrast, Wilson held that the outputs of governments are always complex and often controversial. ${ }^{27}$ Moreover, they have distributional effects that are required to fit an equitable social contract - taxes in return for equal and fair distribution of outputs. Citizens also expect government departments to be accountable in a way that businesses are not. Reinforcing this is a political system that provides "one vote to each person and one district to each legislator". ${ }^{28}$ Wilson eloquently described, "The currency of the marketplace may be wealth, which is divided unequally, but the currency of politics is votes, which are distributed equally." ${ }^{29}$ An overarching theme of Wilson's text was that while there is little doubt that in pure economical terms private enterprise is more efficient than public bureaucracies, governments are required to take a more holistic approach to building and maintaining societies.

Wilson's argument proved to be somewhat prescient. By the mid to late 1990s, cracks began to form between the ideology and the practice of the rational choice economic reforms. Bob Gregory claimed that: ${ }^{30}$

The [NPM] reforms had focused on issues of accountability and efficiency at the operational level of government, but in creating an 'arms length' relationship between the political executive and government agencies, and their concern for structural disaggregation, they diminished strategic capability.

Gregory concluded that the NPM reforms had caused "structural problems that were unintended - though by no means unpredictable". ${ }^{31}$ One of these unintended effects was that it "deprived the political and administrative leadership of levers of control and influence and information." ${ }^{32}$ This subsequently raised serious questions of accountability and control.

\footnotetext{
${ }^{26}$ Ibid., 347-8.

27 lbid.

28 Ibid.

29 Ibid.

${ }^{30}$ Robert Gregory, "Theoretical Faith and Practical Works: De-Autonomizing and Joining-up in the New Zealand State Sector," in Autonomy and Regulation: Coping with Agencies in the Modern State (ed). Tom Christensen and Per Lægreid (Cheltenham: Edward Elgar, 2006), 138.

31 Ibid.

32 Tom Christensen and Per Lægreid The Whole-of-Government Approach - Regulation, Performance, and Public-Sector Reform (Working Paper 6, Stein Rokkan Centre for Social Studies, 2006) available at https://bora.uib.no/bitstream/1956/1893/1/N06-06\%20Christensen-L\%C3\%A6greid.pdf (accessed 9 September 2010) 7.
} 


\subsection{Motivations for Whole-of-Government}

According to Geoff Mulgan, the highly departmentalised Westminster systems of government developed since the late nineteenth century were often very efficient. They prevented corruption and waste, ensured clear lines of accountability and generally "helped to get things done". ${ }^{33}$ With the NPM reforms of those systems in the 1980s and 1990s a number of weaknesses were exposed in the evolved model. The 'tubes' or 'silos' which filtered money from government to the public became a key inhibitor to efficient government action. Many issues did not fit neatly into departmental slots. By their very nature, vertical organisations disincentivise certain activities, such as prevention, as the benefits of preventative action often flow to other departments. It can also lead to government being less sensitive to certain groups who cut across departmental lines. Mulgan indicated that at worst it incentivised departments and agencies to dump problems onto each other. ${ }^{34} \mathrm{He}$ critiqued that schools expelled unmanageable children onto the streets where they become an issue for police; prisons released parolees into the community without sufficient job training or housing where they become a burden for social services. ${ }^{35}$

Mulgan listed six prominent factors that contributed to the development of the whole-of-government approach in the 1990s. ${ }^{36}$ Firstly, the "wicked issues" that could not be easily resolved with existing tools or structures. Secondly, there was mounting evidence that the NPM reforms prevented effective knowledge sharing and were not geared to the integrative potential of the internet. Thirdly, there was a growing literature by social scientists on the interconnectedness of problems. Fourthly, the rapid advancement in technology and organisational techniques, especially communication and coordination, meant that horizontal networks were becoming integral in achieving outcomes. Fifthly, the influence in consumerism had led to the public demanding services that better met their needs. The public also increasingly expects services to be easily accessible such as in 'one stop shops' - as Patrick Dunleavy questioned, why can't the government "be more like Marks and Spencer or John Lewis?". ${ }^{37}$ Finally, Mulgan highlighted that there was a broad shift in the late

\footnotetext{
${ }^{33}$ Geoff Mulgan, "Joined-up Government: Past, Present, and Future," in Joined-up Government, (ed). Vernon Bogdanor (Oxford: Oxford University Press, 2005), 177.

${ }^{34}$ Ibid.

${ }^{35}$ Ibid.

${ }^{36}$ lbid., 179.

${ }^{37}$ Professor Dunleavy raised the question: “...why aren't public services easily accessible, all in one place, in a location everyone goes to on a regular basis? Why do citizens have to make several phone calls and visits to different government agencies over several days, weeks or even months to solve a problem?". Patrick Dunleavy The Future of Joined-up Public Services (2020 Public Services Trust, 2010) available at http://clients.squareeye.com/uploads/2020/documents/esrc_dunleavy.pdf 6. 
twentieth century away from atomistic models of thinking towards a greater emphasis on systems thinking. ${ }^{38}$

Christensen and Lægreid added an additional set of factors for the development of whole-of-government approaches. One of those factors was that for number of reasons the world is perceived as increasingly insecure and dangerous. ${ }^{39}$ They highlight that concerns raised by terrorist attacks have had significant repercussions for public-sector reforms in the US, the UK, and Australia. ${ }^{40} \mathrm{~A}$ growing number of countries were becoming concerned about crises and natural disasters, like tsunamis or pandemics such as SARS or bird flu. This has resulted in a tightening-up of government, which includes whole-of-government measures. Of particular importance for this thesis, Christensen and Lægreid stress that the contemporary threat of terrorism has "underlined the importance of governments' avoiding contradictory outcomes and ensuring that information is shared between agencies." ${ }^{41}$ Their argument is directly applicable to New Zealand's recent security and intelligence sector reforms where a concentration was placed on aligning the roles of the agencies involved in national security. ${ }^{42}$

A further factor for Christensen and Lægreid is that the whole-of-government approach has been seen as an efficiency measure and an answer to budgetary pressure. ${ }^{43}$ They note that this may sound contradictory following the introduction of organised fragmentation in the name of efficiency under the NPM reforms. It is argued that a "vertical tightening of the system combined with increased horizontal collaboration" is now being seen as more efficient than a more fragmented system, with a focus mainly on efficiency in service delivery. ${ }^{44}$ This will be particularly salient when analysising the New Zealand National Government's motivation and public reasoning for their dedication to the whole-of-government approach.

In response to these developments, the UK was the first to begin to move away from exclusive adherence to the rational choice instrumentalism of NPM. Tony Blair's New Labour government in 1997 was credited with the initial move, which was

\footnotetext{
${ }^{38}$ Mulgan, "Joined-up Government: Past, Present, and Future," 180.

${ }^{39}$ Lægreid The Whole-of-Government Approach - Regulation, Performance, and Public-Sector Reform 7. 40 Ibid.

41 Ibid.

${ }^{42}$ NZSIS Annual Report for the Year Ended 30 June 2010 (New Zealand Security Intelligence Service, 2009) available at http://www.security.govt.nz/reports/ar10/nzsis-ar10.pdf (accessed 10 January 2011) 5 .

${ }^{43}$ Lægreid The Whole-of-Government Approach - Regulation, Performance, and Public-Sector Reform. 44 Ibid.
} 
closely followed by several other commonwealth nations. ${ }^{45}$ Christensen and Lægreid asserted that the Anglo-Saxon countries "once seen as the trail-blazers of NPM" are now leading the way in whole of government reforms. ${ }^{46}$ The new package, initially labelled 'Joined-Up Government', proposed a change in emphasis away from the "structural devolution, dissagregation, and single-purpose organizations" of NPM. ${ }^{47}$ Vernon Bogdanor described a move towards a "more holistic approach" that sought to "apply not only the logic of economics, but also the insights of the other social sciences ... to the reform of the public services." ${ }^{48}$

\subsection{Terminology}

In the public policy literature, the broad notion of integrated service delivery encompasses a number of inter-related concepts. These include, but are not limited to, coordination, collaboration, whole of government, joined-up government, horizontal government, policy coherence, networked government, inter-sectoral collaboration, inter-agency co-operation as well as partnership. ${ }^{49}$ The literature varies as to accepted definitions and the differences between these concepts. As argued above, this is in large part because the rhetoric and language of policy has evolved differently subject to the field, research or theories on which it is based. ${ }^{50}$

One imprecise development has been a movement from the use of the term 'joined-up government' towards using 'whole of government'. The relationship between these two terms has been debated. Alison Gray's literature survey on integrated service delivery in 2002 argued with compelling evidence that there were distinct differences between JUG and WGA. Gray stated that, "While references to 'whole of government' activity often refer to policy development, references to 'joint working' and 'joined-up' government typically emphasise structures and contractual or organisational arrangements for service delivery, rather than shared involvement

\footnotetext{
${ }^{45}$ Lægreid, 'The Whole-of-Government Approach to Public Sector Reform,' 1060.

${ }^{46}$ Lægreid The Whole-of-Government Approach - Regulation, Performance, and Public-Sector Reform 6.

${ }^{47}$ Lægreid, 'The Whole-of-Government Approach to Public Sector Reform,' 1.

${ }^{48}$ Bogdanor, "Introduction."

${ }^{49}$ For useful surveys of these terms see: Alison Gray Integrated Service Delivery and Regional CoOrdination: A Literature Review (Review of the Centre - Regional Co-ordination Workstream, 2002) available at http://www.msd.govt.nz/documents/about-msd-and-our-work/publicationsresources/archive/2003-integrated-service-delivery-regional-coordination-literature-review.pdf 1 , and, Perri 6, 'Joined-up Government in the Western World in Comparative Perspective: A Preliminary Literature Review and Exploration,' Journal of Public Administration Research and Theory 14, no. 1 (2004).

${ }^{50}$ See: Jim Hyde, 'How to Make the Rhetoric of Joined-up Government Really Work,' Australia New Zealand Health Policy 5 (2008): 5. 
in policy-making." ${ }^{51}$ With the development and implementation of the whole-ofgovernment approach in various countries it is now less certain that Gray's argument is as persuasive as it was in 2002.

According to Christensen and Lægreid, the overlap between JUG and WGA is semantic. While they accept that the scope of the whole-of-government approach is "pretty broad", they point to the Australian Management Advisory Committee's Connecting Government Report (2004) which provided this definition of the WGA in the Australian Public Service: ${ }^{52}$

\begin{abstract}
Whole-of-government denotes public services agencies working across portfolio boundaries to achieve a shared goal and an integrated government response to particular issues. Approaches can be formal or informal. They can focus on policy development, program management, and service delivery.
\end{abstract}

This definition demonstrates that in the Australian context, the whole-of-government approach is wider than Gray's narrow interpretation that focused on policy formulation. In another attempt at deciphering the rhetoric in 2005, Sue Hunt observed that: ${ }^{53}$

The term 'joined-up' government tends to be used in the United Kingdom, while 'horizontal' management' or horizontal government' is used in Canada. In Australia, integrated or collaborative government are corresponding terms ... while 'whole-ofgovernment' tends to refer to the set of processes that are intended to result in more integrated policy and service delivery outcomes for government.

Hunt's account confirms that there is no consistent definition of the concepts. This conclusion was reached by the Connecting Government Report, which outlined: ${ }^{54}$

\begin{abstract}
There are various models, frameworks and concepts outlined in the literature which attempt to classify whole of government approaches. However, there is no overriding theory that captures all key aspects. This is an evolving field of investigation, both at the practice and theoretical level.
\end{abstract}

\footnotetext{
${ }^{51}$ Gray Integrated Service Delivery and Regional Co-Ordination: A Literature Review 5.

52 Lægreid, 'The Whole-of-Government Approach to Public Sector Reform,' 1060, Connecting Government: Whole of Government Responses to Australia's Priority Challenges (Management Advisory Committee, Commonwealth of Australia, 2004) available at http://www.apsc.gov.au/mac/connectinggovernment.htm (accessed 04 January 2011) 4.

${ }^{53}$ Sue Hunt Whole-of-Government: Does Working Together Work? (Policy and Governance Discussion Paper 05-01, Australian National University, Asia Pacific School of Economics and Government, 2005) 7. 
Christensen and Lægreid argued that rather than become tied down by conceptual terminology it is more beneficial to accept that the WGA "does not represent a coherent set of ideas and tools." 55 They believed that it could be "best be seen as an umbrella term describing a group of responses to the problem of increased fragmentation of the public sector and public services and a wish to increase integration, coordination, and capacity."

\subsection{Basic Features}

Conceptually, the whole-of-government approach represents a desire to achieve horizontal and vertical coordination to reduce situations where related policies undermine each other. ${ }^{57}$ This, it is thought, will enhance the value of resources and create synergies by drawing together various stakeholders in a particular policy area. ${ }^{58}$ It also seeks to offer clients seamless rather than fragmented access to and delivery of services.

Alice Mosley has reduced the framing of whole-of-government into two distinct strands of public administration theory one of which can be termed a 'rational administrative' and the other a 'bureaucratic politics' perspective. ${ }^{59}$ The former is regarded as the dominant framework within which "policy prescriptions surrounding joined-up government are articulated, and has dominated the coordination and inter organisational relations literature." 60 The latter emphasises the "competing interests and power dynamics at play in the context of joined-up government." ${ }^{61}$ Moseley argues that the key aspects dominating collaborative decision-making include: ${ }^{62}$

... prioritisation of, and a desire to protect resources for, agencies' and departments' own client groups; the greater ability of the most powerful actors to gain the cooperation of other bodies in order to advance their own organisational agendas; and the adoption of coordination mechanisms to reduce risk and maintain organisational survival.

\footnotetext{
${ }^{55}$ Lægreid, 'The Whole-of-Government Approach to Public Sector Reform,' 1059.

56 Ibid.

${ }^{57}$ Lægreid The Whole-of-Government Approach - Regulation, Performance, and Public-Sector Reform 6.

${ }^{58}$ Lægreid, 'The Whole-of-Government Approach to Public Sector Reform.', Christopher Pollitt, 'Joinedup Government: A Survey,' Political Studies Review 1, no. 1 (2003).

${ }_{59}$ Alice Moseley, "Joined-up Government: Rational Administration or Bureaucratic Politics?" (paper presented at the Public Administration Committee Annual Conference, University of Glamorgan, 7th-9th September 2009) available at http://hass.glam.ac.uk/media/files/documents/2009-0805/AMoseley_PAC_09.pdf (accessed 24 January 2011) 2.

60 lbid.

61 Ibid.

62 Ibid. 1. 
Christensen and Lægreid indicate that they also do not believe in single-factor explanations and provide structural and cultural perspectives. ${ }^{63}$ They note that from a structural or instrumental perspective the whole-of-government approach can be seen as conscious organisational design or reorganisation. The assumption is that political and administrative leaders use the structural design of public entities as instruments to fulfil public goals. In the case of whole-of-government this requires government organisations to work better together. ${ }^{64}$ The significant precondition for this is that leaders have a relatively large degree of control over change or reform processes and that they rely highly on rational calculation.

On the other hand, a cultural-institutional explanation sees the development of public organisations more as evolution than 'revolution' and redesign. With much in common with the international relations notion of constructivism, culturalinstitutional explanations are useful when analysing the whole-of-government approach. Christensen and Lægreid write that, "while structure receives significant attention, even more emphasis is given to the importance of cultural change for successful WOG systems." ${ }^{15}$ A key theme is that structure is not enough to fulfil the goals of whole-of-government initiatives - cultural change is necessary. Processes and attitudes need to be addressed in order to drive collaboration across departments. An overall characteristic is that the post-NPM reforms are less preoccupied with structural changes and more concerned with evolutionary change resulting from conscious policy choices. ${ }^{66}$ The focus is more on building a "unified sense of values, teambuilding, the collective involvement of participating organisations, trust, value-based management, collaboration, and improving the training and self-development of public servants." 67 The Australian Management Advisory Committee Connecting Government Report stressed the need to build a supportive Australian public sector culture that encouraged whole-of-government

\footnotetext{
${ }^{63}$ Lægreid The Whole-of-Government Approach - Regulation, Performance, and Public-Sector Reform 9. 64 Ibid. 
solutions by formulating value guidelines and codes of conduct, where the slogan is 'working together'. ${ }^{68}$

One distinguishing feature of a whole of government approach is that there is a focus on sharing objectives across organisational boundaries in contrast to working solely within an organisation. ${ }^{69}$ Geoff Mulgan highlighted two primary concerns that the whole-of-government approach seeks to resolve: ${ }^{70}$

1. A problem of coordination: how to cajole and encourage an often huge flotilla of agencies, departments, units and professions to point in broadly the same broad direction, and not to undermine each other's work.

2. A problem of organization and integration: how to align incentives, cultures, and structures of authority to fit critical tasks that cut across organizational boundaries.

In light of these issues, a range of measures has been implemented across the countries that are taking on whole of government approaches. A theme of these measures is that there is 'no one size fits all' whole of government approach. ${ }^{71}$ The 2004 Australian Report argued that, "There needs to be a range of organisational options available to deliver policies, programs and services across organisational boundaries successfully. The structure should be matched to the task."72

Debiprosad Majumdar's literature survey on collaboration across government agencies found several writers expressing similar views about the basic features of collaboration. ${ }^{73}$ Gray characterised it by interdependence and participative decisionmaking and Sussman believed that mutually agreed outcomes and a willingness to share resources as critical to successful collaboration. ${ }^{74}$ Majumdar showed that O'Looney and Wilson established the ultimate objective of collaboration: O'Looney claimed that, "collaboration refers to partnership formation that is believed to bring about change", while Wilson found collaboration to be the most effective tool to "create something entirely new". ${ }^{75}$

\footnotetext{
${ }^{68}$ See: Connecting Government: Whole of Government Responses to Australia's Priority Challenges. ${ }^{69}$ Ibid. 4.

${ }^{70}$ Mulgan, "Joined-up Government: Past, Present, and Future," 176.

${ }^{71}$ Connecting Government: Whole of Government Responses to Australia's Priority Challenges 12.

${ }^{72}$ Ibid.

${ }^{73}$ Majumdar, 'Collaboration among Government Agencies with Special Reference to New Zealand: A Literature Review.' Majumdar defined that "collaboration" denotes government agencies (also referred to as "participating organisations" or "parties", "partners" or "stakeholders") working across sectoral boundaries to achieve common goals."

${ }^{74}$ Ibid.

75 Ibid. 
An early indication of the variety of activities that might be involved were summarised in the UK Cabinet's 2000 Wiring it up: Whitehall's Management of Cross-cutting Policies and Services Report. ${ }^{76}$ The Report placed the activities into the following broad categories: ${ }^{77}$

- Organisational change;

- Merged structures and budgets;

- Joint teams (virtual or real);

- Shared budgets;

- Joint customer inter-face arrangements;

- Shared objectives and policy indicators;

- Consultation to enhance synergies and manage trade-offs;

- Sharing information to increase mutual awareness.

Mulgan demonstrated that measures in the UK did not take shape in a single 'blueprint', but that there was a deliberate decision to experiment with many forms. ${ }^{78}$ These included: ${ }^{79}$

- Taking a cross-cutting approach to policy making.

- Managing joined up working through seminars, reports ... networks such as the New Local Government Network and the role and implementation of the Prime Minister's Strategy Unit in the Cabinet Office.

- Activities to join up implementation of policies, through tools such as training and support in project management and implementation...

Australian examples of whole of government approaches include the integrated response to the Bali bombings and Council of Australian Governments activities, such as the Australian Better Health Initiative or the whole of government indigenous trials. ${ }^{80}$ Centrelink, Australia Post and Rural Transaction Centres are also examples of integrated service delivery arrangements. ${ }^{81}$ In Canada, under the label

\footnotetext{
${ }^{76}$ Wiring It Up: Whitehall's Management of Cross-Cutting Policies and Services (UK Cabinet Office, A Performance and Innovation Unit Report, 2000) (accessed 22 March 2011).

77 Tom Ling, 'Delivering Joined-up Government in the UK: Dimensions, Issues and Problems,' Public Administration 80 (2002): 625.

${ }^{78}$ Mulgan, "Joined-up Government: Past, Present, and Future," 183.

${ }^{79}$ Ibid, Joined up Government: A Review of National and International Experiences (State Government of Victoria State Services Authority, 2007) available at http://www.ssa.vic.gov.au/CA2571410025903D/WebObj/OccPaper_JoinedupGovernment/\$File/OccPap er_JoinedupGovernment.pdf 8.

${ }^{80}$ Joined up Government: A Review of National and International Experiences 9.

81 Ibid.
} 
of horizontal management, the government launched a set of initiatives in the mid1990s in areas such as poverty, innovation and climate change. ${ }^{82}$

\subsection{Benefits}

A number of potential benefits can be drawn out of the literature on whole-ofgovernment approaches. The New Zealand State Services Commission's Factors for Successful Coordination - A Framework to Help State Agencies Coordinate Effectively listed a number of these benefits. The report illustrates several key themes on why public agencies should coordinate: ${ }^{83}$

- Because the challenges facing New Zealand are bigger than one agency can solve alone

- Because by pooling the best of our resources we provide better solutions

- Because coordination can reduce duplication and provide New Zealanders with the best services at the right cost

- New Zealanders are increasingly expecting government policies and services to be tailored for particular communities or client groups.

This research reduces the benefits into four main areas: the reduction of departmental silos, an increase in policy coherence, maximising efficiency, and to more adequately address complex social problems. As will be seen later in the thesis, the same benefits have been applied to argue for the approach in peace support operations.

\subsubsection{Reduction of Departmental Silos}

Joined-up government is often understood to be an administrative solution to the problem of departmentalism. It can provide incentives for departments to look beyond their own narrow departmental interests. ${ }^{84}$ The Review of the Centre in New Zealand highlighted the 'fragmentation' and 'siloisation' of the public sector, resulting largely from the separation of policy and operational agencies and from the

\footnotetext{
${ }^{82}$ Lægreid The Whole-of-Government Approach - Regulation, Performance, and Public-Sector Reform 11, see, Herman Bakvis and Luc Juillet The Horizontal Challenge: Line Departments, Central Agencies and Leadership (Canada School of Public Service, 2004) available at http://www.cspsefpc.gc.ca/pbp/pub/pdfs/P124_e.pdf (accessed 04 January 2011).

${ }^{83}$ Summarised from the original: SSC Factors for Successful Coordination - a Framework to Help State Agencies Coordinate Effectively (State Services Commission: New Zealand Government, 2008) available at http://www.ssc.govt.nz/state-services-coordination 8.

${ }^{84}$ Moseley, "Joined-up Government: Rational Administration or Bureaucratic Politics?" 2. 
proliferation of core government agencies. ${ }^{85}$ Whole-of-government initiatives attempt to break through these vertical silos and encourage officials to work 'horizontally'. This has been aided by a rapid growth in technology that enables faster and more secure communication between agencies. The natural result of a break down in silos is an increased awareness of collective social outcomes and the workings of partner agencies.

\subsubsection{Policy Coherence}

The reduction of silos within a whole-of-government approach will arguably lead to a greater level of policy coherence. The drive to eliminate contradictions and tensions between different policies will predominately have a positive impact on the effectiveness of those policies. Christopher Pollitt describes an example in the 1990s where a well-intentioned intensification of performance management in schools "led to a dramatic rise in the exclusion of difficult pupils from school and a rise in criminality among young people". ${ }^{86}$ In essence, it reduces the negative externalities or spillover effects that may occur when one department or agency fails to take account of the impact of its actions on other parts of government. ${ }^{87}$

\subsubsection{Efficiency}

It is argued that a whole-of-government approach creates efficiencies by reducing duplication across the departments and agencies of government. The Factors for Successful Coordination report held that coordination is widely seen as a solution to the fragmentation of the State sector. The argument was made that fragmentation made coordinated service delivery more complicated, added to the costs of doing business by duplicating services, effort and expenses, and blured accountability for some issues. ${ }^{88}$ The Report highlighted that: ${ }^{89}$

\footnotetext{
${ }^{85}$ See: Report of the Advisory Group on the Review of the Centre (Presented to the Ministers of State Services and Finance, November 2001) available at

http://www.ssc.govt.nz/display/document.asp?DocID=2776 (accessed 31 October 2010).

${ }^{86}$ Pollitt, 'Joined-up Government: A Survey,' 35.

${ }^{87}$ Ibid.

${ }^{88}$ SSC Factors for Successful Coordination - a Framework to Help State Agencies Coordinate Effectively 8.

${ }^{89}$ Ibid.
} 
When the right agencies coordinate over a complex issue, they can develop targeted solutions based on a better understanding of the full scope of the issue, resulting in more effective interventions.

The whole-of-government approach will also improve the information flow of ideas and cooperation between stakeholders in a particular policy sector, thus producing synergies or smarter ways of working. ${ }^{90}$

\subsubsection{Addressing Complex Problems}

It is argued that further value is gained from a whole-of-government approach due to the potential to more adequately address complex social problems. Alice Moseley asserted that another common argument is that working in a joined-up way should deliver more holistic responses to policy problems, particularly problems that transcend departmental boundaries. ${ }^{91}$ Lynne Dovey contends that a systems approach is required to achieve better social policy outcomes. ${ }^{92}$ When the full spectrum of agencies coordinate over a complex issue, they can develop targeted solutions based on a better understanding of the full scope of the issue, resulting in more effective interventions. ${ }^{93}$ The New Zealand literature argued that this will achieve "more and better outputs and outcomes for individuals and their families, empowering communities to be more self-reliant, and creating a more inclusive and co-ordinated public sector." ${ }^{94}$ The following table, extracted from the Factors for Successful Coordination report, provides a summary of the advantages and disadvantages of a whole-of-government approach.

\footnotetext{
${ }_{91}^{90}$ Pollitt, 'Joined-up Government: A Survey,' 35.

${ }^{91}$ Moseley, "Joined-up Government: Rational Administration or Bureaucratic Politics?" 2.

92 Lyne Dovey Achieving Better Social Outcomes in New Zealand through Collaboration: Perspectives from the United States (Working Paper No.16, State Services Commission, 2003) available at http://www.ssc.govt.nz/upload/downloadable_files/Working_Paper_16.pdf (accessed 24 January 2011) 3.

${ }^{93}$ SSC Factors for Successful Coordination - a Framework to Help State Agencies Coordinate Effectively.

${ }^{94}$ Majumdar, 'Collaboration among Government Agencies with Special Reference to New Zealand: A Literature Review,' 7, Report of the Advisory Group on the Review of the Centre. 
Table 1: Advantages and Disadvantages of a Whole-of-Government Approach ${ }^{95}$

\begin{tabular}{|c|c|}
\hline Benefits/Advantages & Costs/Disadvantages \\
\hline 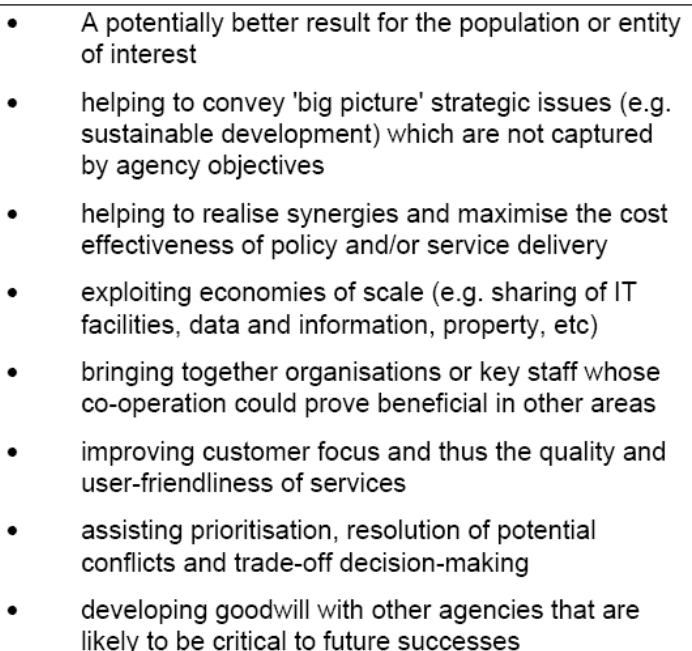 & 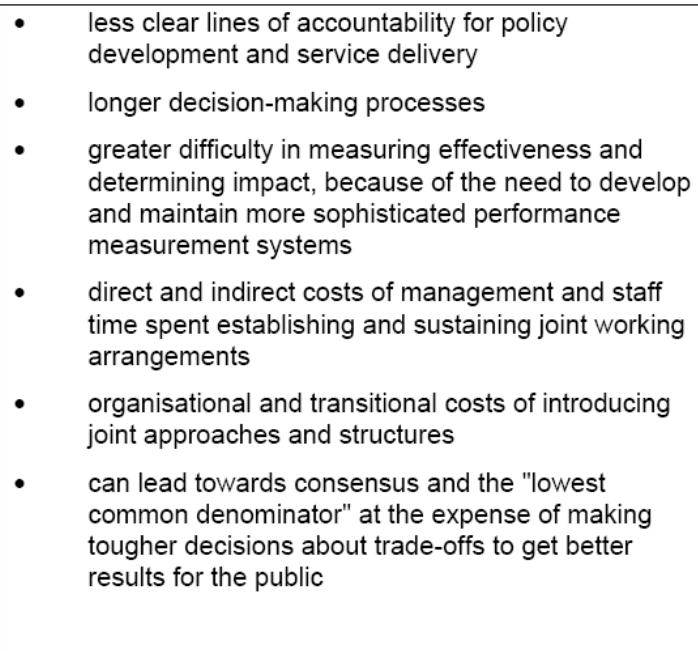 \\
\hline
\end{tabular}

\subsection{Barriers}

The literature indicates that there are a number of barriers to successful implementation of whole-of-government working. Christopher Pollitt contended that such efforts were no panacea; he described, "Efforts at [joined-up government] tend to be more fragile than 'normal', single silo policymaking." ${ }^{96}$ The UK Cabinet Office's initial review of cross-cutting issues in 2000 conceded that, "By their nature, crosscutting policies tend to have more stake-holders; be harder to monitor and evaluate; and run greater risks of failure and communications breakdown." ${ }^{97}$

An outcome of the 2001 New Zealand Review of the Centre was the formation of a research project termed the Integrated Service Delivery: Regional Coordination workstream. This undertook a "review of the New Zealand and international literature on collaboration, carried out fieldwork in three regions in New Zealand, and drew on a range of relevant government reports." ${ }^{98}$ The workstream established several further barriers to successful implementation of a whole-ofgovernment approach, including: ${ }^{99}$

\footnotetext{
${ }^{95}$ SSC Factors for Successful Coordination - a Framework to Help State Agencies Coordinate Effectively 10.

${ }_{96}^{96}$ Pollitt, 'Joined-up Government: A Survey,' 38.

${ }_{97}$ Wiring It Up: Whitehall's Management of Cross-Cutting Policies and Services 10.

${ }^{98}$ Review of the Centre Integrated Service Delivery: Regional Co-Ordination - Final Workstream Report (State Services Commission, Ministry of Social Development, 2003) available at http://www.ssc.govt.nz/upload/downloadable_files/integrated-service-delivery-final-workstreamreport.pdf (accessed 29 January 2011) 4.

99 lbid. 13.
} 
- $\quad$ no one agency at the centre with an overview

- no government agency at the regional level with a clear mandate to lead regional initiatives

- $\quad$ an increase in competition for resources between agencies

- the nature of the funder/provider contracting regime

- overall funding pressures limiting the level of resource that is allocated to co-ordination and collaboration

- a tendency for some agencies to shift responsibilities to other agencies, withdraw from collaboration

- $\quad$ differences between agencies priorities and national policy drivers which make it complicated to identify common interests

- $\quad$ use of the Privacy legislation to limit the exchange of information across agencies.

Christopher Pollitt's research found three primary obstacles to joined-up working. The first is the tension between whole-of-government and the past and continuing success of performance management. ${ }^{100}$ Pollitt argues that individuals and organisations have become increasingly focused on achieving their own (individual, unit and departmental) performance targets. Due to this, unless cross-cutting targets can be given equal status, whole-of-government is unlikely to succeed.

The second obstacle is accountability. Pollitt asserted that public sector modernisation has unsettled traditional models of ministerial and political accountability. ${ }^{101} \mathrm{He}$ contended that the accountability literature holds several lessons for whole-of-government. The first is the importance of making a formal agreement. This is required at the establishment of any co-ordinated effort or partnership. It would outline the respective responsibilities of the different parties and institutions involved. Pollitt stressed that it would also be wise to agree what the procedure should be for revising that agreement, in the event that becomes necessary in light of later experiences. ${ }^{102}$

A second requirement would be for a formal agreement, though by itself this is seldom sufficient. Those in partnership should look to maintain a culture that supports and promotes a sense of individual responsibility on the part of staff. ${ }^{103}$ Vertical accountability necessarily remains, although horizontal accountability grows in importance. A third requirement is the need to amend procedures for external oversight. Audit bodies, inspectorates and even legislatures themselves will need to adapt to the reality of whole-of-government operations. ${ }^{104}$

\footnotetext{
100 Pollitt, 'Joined-up Government: A Survey,' 42.

101 Ibid.

102 Ibid.: 43

103 Ibid.

104 Ibid. 
The final issue for Pollitt is the risk of unintentionally creating a new set of organisational enclaves. Pollitt argues that it would not be difficult to slide into the worst of both worlds. He stressed that this is made from a combination of traditional, 'vertical' organisations, with the principal legal responsibilities and means of delivery, and an overlay of fashionable new units or teams, which poach the most talented staff but lack either clear lines of accountability or the implementation capacity to get things done. ${ }^{105}$

A further aspect that has taken on added importance in the midst of a global financial crisis is that of the expense of joined-up working. The financial investment in working horizontally is substantial. The costs include increased meeting time, the challenge of creating a shared vision and framework, the need to compromise, more complex accountability arrangements, increased volumes in paper work, the development of shared performance indicators, and more complex reporting requirements. These impact noticeably on the strained budgets of line managers and their seniors - in order for these officials to support whole-of-government approaches there is a real requirement for them to be supported and to see tangible benefits. In acute awareness of this, the Integrated Service Delivery: Regional Co-ordination workstream suggested that the key issues that would require a policy response from Ministers and central government included the need to: ${ }^{106}$

- $\quad$ remove structural barriers to collaboration eg by addressing service boundaries and funding mechanisms

- $\quad$ emphasise ways to ensure that government systems and processes support and incentivise collaboration eg by addressing departmental accountabilities, managerial delegation at local level and evaluation arrangements

- $\quad$ undertake further policy work to support collaborative working with stakeholder groups eg by addressing ... whole of government approaches to working with local authorities

- develop better monitoring and evaluation mechanisms to determine where collaboration is effective.

The main themes of the barriers to whole-of-government working in the literature can therefore be reduced into three areas - structural, procedural and cultural. These factors need to be addressed if an efficient and successful whole-ofgovernment approach is to be implemented. These will be specifically important when assessing whole-of-government approaches to peace support operations.

\footnotetext{
105 Ibid.: 43.

${ }^{106}$ Review of the Centre Integrated Service Delivery: Regional Co-Ordination - Final Workstream Report 4.
} 


\title{
2.7 Conditions and Factors
}

Flowing from the main barriers are the conditions and factors that must be present in order to implement a successful whole-of-government approach. In 2005, the Australian Public Service Commissioner Lynelle Briggs made a critical observation that whole-of-government outcomes were overwhelmingly reliant on driving culture change in government departments. Elaborating on this, Briggs argued that: ${ }^{107}$

\begin{abstract}
In the past, the outcomes we are now looking to achieve from whole of government activity were mostly pursued through organisational restructuring and machinery of government changes. What is new is that today's whole of government approaches tend to look primarily to the development of organisational cultures, capabilities and relationships that support, model, understand and aspire to whole of government solutions.
\end{abstract}

A central message is that "structure alone cannot drive cultural change, as processes and attitudes also need addressing". ${ }^{108}$ As was suggested by the UK Cabinet Office in 2000, "Simply removing barriers to cross-cutting working is not enough: more needs to be done if cross-cutting policy initiatives are to hold their own against purely departmental objectives". ${ }^{109}$

The 2008 Factors for Successful Coordination Framework (New Zealand) highlighted nine success factors consistently identified in the literature. The report grouped those under three dimensions: mandate, systems and behaviours. ${ }^{110}$ The mandate dimension consisted of a leadership commitment, Ministers' and stakeholders' buy-in, and defined and agreed joint outcomes. ${ }^{111}$ The systems dimension requires appropriate and documented governance and accountability frameworks, sufficient and appropriate resources, and process to measure performance from established baselines. The Behaviours Dimension requires the right representation, skills and team leadership, organisational cultures that support

\footnotetext{
107 Lynelle Briggs, "A Passion for Policy," in A Passion for Policy: Essays in Public Sector Reform, (ed). John Wanna (Canberra: ANU E Press, 2007), 9.

${ }_{108}$ Majumdar, 'Collaboration among Government Agencies with Special Reference to New Zealand: A Literature Review.'

${ }^{109}$ Wiring It Up: Whitehall's Management of Cross-Cutting Policies and Services 5.

110 SSC Factors for Successful Coordination - a Framework to Help State Agencies Coordinate Effectively 11.

111 Ibid. 
coordination, and a shared culture, language and values. ${ }^{112}$ These are aimed at addressing the primary barriers to whole-of-government working and as will be seen, are specifically relevant to peace support operations.

The literature demonstrates that there is almost universal awareness of the factors required for joined-up working. There is a multitude of methods suggested to address these factors - though much is theoretical and there has been little empirical research undertaken. ${ }^{113}$ This is not unexpected as successful whole-of-government working is necessarily an extended process and does not naturally lend itself to short-term outcomes.

\subsection{Conclusion}

The whole-of-government approach has gained widespread appeal in the past decade. Initially it was a reaction to the rational economic reforms of the $1980 \mathrm{~s}$ and 1990s, though it has also played a central role in the evolution of public management. Whole-of-government is not a panacea however; it comes with entrenched barriers that will take more than eloquent rhetoric to overcome. As Christopher Pollitt conveyed, it would be wise for proponents to regard it as "a long term project, a selective project, and a cooperative project - not something that central government can just decide to 'have'." ${ }^{114}$ A central feature that can be drawn from the literature is that successful whole-of-government approach requires a concentrated effort at driving culture change across levels and sectors of government. The following chapter will demonstrate that this is equally as significant in adapting the concept to peace support operations. As will be seen, there are significant hurdles in these environments where disciplined forces are increasingly working collaboratively with civilian agencies to reach collective outcomes.

\footnotetext{
112 Ibid.

${ }^{113}$ See for example: Pollitt, 'Joined-up Government: A Survey.', Ling, 'Delivering Joined-up Government in the UK: Dimensions, Issues and Problems.'

${ }^{114}$ Pollitt, 'Joined-up Government: A Survey,' 46.
} 


\section{Chapter 3: Whole of Government Approaches to Peace Support Operations}

This chapter draws on the concepts established in the first chapter and aims to critically review the international literature on the whole of government approach in peace support operations. The first section will look at the background and terminology as well as whole of government approaches internationally. Attention will then turn to drawing out the benefits and challenges of the whole of government approach in peace support operations. This literature in this chapter will be later used to evaluate how New Zealand is operating its whole-of-government approach in such operations.

The research questions that guided this section are:

- What is the background to whole of government approaches in peace support operations?

- What are the basic features of a WGA in PSOs?

- What are the perceived benefits and challenges of a WGA in PSOs?

\subsection{Background}

In 2005, the OECD Development Assistance Committee's (DAC) Fragile States Group (FSG) drafted a set of Principles for Good International Engagement in Fragile States. ${ }^{115}$ The Principles established that successful development in fragile environments largely depends on "well-sequenced and coherent progress across the political, security, economic and administrative domains."116 These domains were held to be interdependent: "failure in one risks failure in all others". ${ }^{117}$ They determined that working effectively across these domains "requires donor countries to adopt a 'whole-of-government' approach (WGA), involving departments responsible for security, and political and economic affairs, as well as those responsible for development aid and humanitarian assistance." ${ }^{118}$ The benefit of this approach, the FSG outlined, is that it promotes long-term development and stability in fragile states at a lower overall fiscal cost. ${ }^{119}$ Additionally, coherent policies and activities will likely generate greater legitimacy in the recipient country and are therefore more likely to receive a positive response. ${ }^{120}$

\footnotetext{
115 OECD Whole of Government Approaches to Fragile States 7.

116 Ibid. 13.

117 Ibid. 7.

118 Ibid.

119 Ibid.

120 Ibid.
} 
After the perceived failures of the 1990s interventions such as in Somalia, Kosovo and Rwanda, the international community resolved to develop new methods for assisting fragile states. ${ }^{121}$ Stewart Patrick and Kaysie Brown held that the motivation for this was twofold. First, the international development community, including the bilateral donors of the OECD, the World Bank, and UN agencies, recognised that existing development principles and practice were often insufficient to resolve the 'complex missions' they were entering. This was especially true when engaging states that lacked either the political commitment or the practical capacity to deliver basic social services. States such as Afghanistan, Haiti, Somalia and Yemen suffered from low or negative levels of development and poor governance, and were often caught up in intractable conflicts. Due to these issues, donors struggled to find effective ways to engage such "difficult partners."122

Patrick and Brown noted that a further factor was that security officials in donor states began to recognise the threats posed by weak and failing states. ${ }^{123}$ The 'spillover' effects, such as transnational crime, terrorism, weapons proliferation, global pandemics, and environmental degradation strongly contributed to the realpolitik motives of donor states. UK Foreign Secretary Jack Straw highlighted this in 2003 stating that these, "constitute a global agenda affecting all countries; they are linked to each other; and we need to address them before they lead to crises." ${ }^{124}$

One of the key international responses to these issues was the September 2005 ratification at the UN World Summit of the Secretary General's In Larger Freedom. ${ }^{125}$ In this document, the Secretary-General claimed that there is a "gaping hole" in the UN institutional machinery: "No part of the United Nations system

\footnotetext{
${ }^{121}$ For a discussion of the concept of "fragile states" see: Stewart Patrick and Kaysie Brown Greater Than the Sum of Its Parts?: Assessing "Whole of Government" Approaches to Fragile States (International Peace Academy, 2007) available at http://www.cgdev.org/content/publications/detail/13893/ 4, and, OECD Whole of Government Approaches to Fragile States 21.

${ }^{122}$ World Bank Engaging with Fragile States: An leg Review of World Bank Support to Low-Income Countries under Stress (Independent Evaluation Group, 2006) available at http://www.worldbank.org/ieg/licus/docs/licus_ce.pdf, Brown Greater Than the Sum of Its Parts?: Assessing "Whole of Government" Approaches to Fragile States, Lisa Chauvet and Paul Collier Development Effectiveness in Fragile States: Spillovers and Turnarounds (Centre for the Study of African Economies, Department of Economics, Oxford University, 2004) available at http://www.jica.go.jp/cdstudy/library/pdf/20071101_09.pdf.

${ }^{123}$ Brown Greater Than the Sum of Its Parts?: Assessing "Whole of Government" Approaches to Fragile States 2.

${ }^{124}$ Jack Straw UK International Priorities: A Strategy for the FCo (UK Foreign and Commonwealth Office, December 2003) available at http://www.sovereignty.org.uk/siteinfo/newsround/FCOStrategyFullFinal.pdf 1.

${ }_{125}$ In Larger Freedom: Towards Development, Security and Human Rights for All (Report of the Secretary-General of the United Nations for Decision by Heads of State and Government, September 2005) available at http://www.un-ngls.org/orf/UNreform/UBUNTU-1.pdf.
} 
effectively addresses the challenge of helping countries with the transition from war to lasting peace." ${ }^{126}$ The document was designed to strengthen both the sovereign capacities and the multilateral architecture of all states to address contemporary global threats. It entrenched the notions of freedom from fear and freedom from want, which are manifestations of the modern concepts of human security and the Responsibility to Protect (R2P). Speaking on this issue, the New Zealand Minister of Foreign Affairs, Phil Goff stated that: ${ }^{127}$

\begin{abstract}
In a post 9/11 environment we have been mesmerised, not unreasonably, by global security issues. Terrorism is an important issue but addressing its causes is as important as suppressing its symptoms. One cause is the alienation of those deprived of decent living standards and of hope. Meeting the poverty gap and development challenges are complimentary to meeting the challenges of political security.
\end{abstract}

This statement was in line with the realisation in the international community that in order to resolve these issues, sustainable models of development and security assistance needed to be designed. It was acknowledged that these issues cut across government departments and so it was of critical importance that governments were able to implement integrated, cross-departmental responses. The crux of the argument was that the individual activities of departments, whether military, diplomatic or defence could not succeed in isolation; instead they had to be conducted as a part of a comprehensive plan so that they supported and reinforced one another. ${ }^{128}$

\title{
3.2 Terminology
}

In international peace operations, the terminology for coordination is far less convoluted than domestic coordination. Unlike the variegated terms used to denote the models of coordination in domestic governance, the literature shows that coordination in international peace missions has been limited to several main concepts. These include:

\footnotetext{
126 Ibid. Addendum 2.2.

127 Phil Goff, "Meeting the Challenges of Security and Development" (27 June, 2005), available at http://www. beehive.govt.nz/release/meeting+challenges+security+and+development, (accessed 21 September 2010).

${ }^{128}$ Peter Viggo Jakobsen A Work in Slow Progress: Nato's Comprehensive Approach to Crisis Response Operations (DIIS Report 2008:15, Danish Institute for International Studies, 2008) available at http://www.diis.dk/graphics/Publications/Reports\%202008/Report_200815_NATO_Comprehensive_Approach_Crisis_Response_Operations.pdf 3. 
- the Integrated Approach and Integrated Missions concepts developed by the United Nations in the late 1990s and early 2000s, ${ }^{129}$

- NATO's effects based approach to operations (EBO), ${ }^{130}$

- the Comprehensive Approach by the European Union and NATO, ${ }^{131}$ and,

- the Whole-of-Government approach. ${ }^{132}$

An analysis of the literature suggests that by 2010 the whole of government approach had become the most widely used definition for intra-governmental coordination of peace missions. Cedric Coning and Karsten Friis explained that WGA "takes place within a specific country. The purpose is to harmonise the efforts of the various government agencies, for more rational use of resources and to contribute to multinational-level efforts." ${ }^{\text {"133 }}$

Cedric Coning argued that the UN's Integrated Approach defined a wider multilateral context. He stressed that it "is an effort to achieve whole-of-government coherence among the members of the UN family." ${ }^{134}$ He claimed that it serves as a

${ }_{129}$ See: Espen Barth Eide et al. Report on Integrated Missions: Practical Perspectives and
Recommendations (Independent Study for the Expanded UN ECHA Core Group, May 2005) a
at http://www.isn.ethz.ch/isn/Digital-Library/Publications/Detail/?ots591=0C54E3B3-1E9C-BE1E-2
A6A8C7060233\&Ing=en\&id=28276, Cedric de Coning The United Nations and the Comprehens
Approach (DIIS Report 2008:14, Danish Institute for International Studies, 2008) available at
http://www.diis.dk/graphics/Publications/Reports\%202008/Report-2008-
14 _The_United_Nations_and_the_Comprehensive_Approach.pdf.
${ }_{130}$ Ståle Ulriksen Niels Nagelhus Schia Multidimensional and Integrated Peace Operations (A Discussion paper for MNE5, A Publication in the NUPI Series on Security in Practice, 2007) available at http://www.humansecuritygateway.com/documents/NUPI_multidimensionalandintegratedpeaceops.pdf (accessed 23 January 2011).

${ }^{131}$ Eva Gross The Eu and the Comprehensive Approach (DIIS Report 2008:13, Danish Institute for International Studies, 2008) available at http://www.diis.dk/graphics/Publications/Reports\%202008/R2008-

13_EU_and_the_Comprehensive_Approach.pdf, Jakobsen A Work in Slow Progress: Nato's Comprehensive Approach to Crisis Response Operations. The New Zealand Defence Force also refers to the 'Comprehensive Approach', see: Foundations of New Zealand Military Doctrine (NZDDP-D) (Development Branch, Headquarters New Zealand Defence Force, November 2008) available at http://www.nzdf.mil.nz/downloads/pdf/public-docs/2008/nzddp-d-2008-ed-2.pdf.

${ }_{132}$ For a survey of global whole of government approaches see: David Lanz (swisspeace) Simon J A

Mason (CSS) Towards a Swiss "Whole of Government" Approach in Sudan: 2005-2008 (Swiss

Background Paper 3C Conference 2009, Center for Security Studies (ETH Zurich) and Swisspeace, 2009) available at

http://www.swisspeace.ch/typo3/fileadmin/user_upload/pdf/publications_by_staff/Swiss-WGA-in-Sudan18Mar09.pdf, Helge Lurås Cedric de Coning, Niels Nagelhus Schia and Stăle Ulriksen Norway's Wholeof-Government Approach and Its Engagement with Afghanistan (Security in Practice 8 - 2009 [NUPI Report], Norwegian Institute of International Affairs, Department of Security and Conflict Management, 2009) available at http://english.nupi.no/Publications/Books-and-reports/2009/Norway-s-Whole-ofGovernment-Approach-and-its-Engagement-with-Afghanistan, US Department of State A Whole-ofGovernment Approach to Prevent, Resolve, and Transform Conflict, Fact Sheet: Office of the Coordinator for Reconstruction and Stabilization, available at http://merln.ndu.edu/archivepdf/nss/state/71036.pdf, (accessed 21 September), Colonel M.P. Jorgensen, "A Strategy for Effective Peace-Building: Canada's Whole-of-Government Approach in Afghanistan" (Canadian Forces College, 2008).

${ }^{133}$ Cedric de Coning and Karsten Friis, "How to Conceptualise 'Comprehensive Approach'?," in Comprehensive Approach: Challenges and Opportunities in Complex Crisis Management, (ed). Karsten Friis and Pia Jarmyr (Oslo: Norsk Utenrikspolitisk Institutt (NUPI), 2008), 2.

${ }^{134}$ Coning The United Nations and the Comprehensive Approach 10. 
"catalyst for agency coherence among the individual members of the UN system" and provides a "focal point for the facilitation of external coherence among the various agencies". ${ }^{135}$ The Integrated Mission concept is the physical manifestation of the integrated approach. ${ }^{136}$ An example is the United Nations Integrated Mission in Timor-Leste (UNMIT), which was established in 2006.

The term comprehensive approach (CA) has much in common with the UN's Integrated Approach. It is a wider notion encapsulating the various models and mechanisms aimed at enhancing overall coherence, cooperation and coordination across various agencies, governments and organisations. Coning posited that the 'term 'comprehensive approach' is used ... as an umbrella concept for all such initiatives." ${ }^{137}$ Exemplifying the difficulty in pinning down one authoritative definition, the New Zealand Defence Force's (NZDF) 2008 Foundations of New Zealand Military Doctrine (NZDDP-D) provided the following definition: ${ }^{138}$

\footnotetext{
The Comprehensive Approach is an extension of the Whole of Government Approach. It is a conceptual framework that recognises that solutions to most crises involve the application of more than one element of national power. However, the Comprehensive Approach also embraces the fact than in the current complex security environment relevant non-governmental organisations also have a part to play in achieving lasting solutions.
}

Critically, and possibly somewhat contrary to common perceptions, it was the military in New Zealand which reinforced the importance of the inclusion of nongovernmental organisations into the coordination spectrum. Their interpretation provides that the comprehensive approach is effectively a whole-of-government approach incorporating non-government organisations. However, the NZDF fail to define whether their interpretation stretches to include the relationships with other governments and foreign NGOs. If it does not, then it is somewhat narrower than Coning's definition.

However, as of 2011, this definition of the comprehensive approach is yet to take hold in New Zealand outside of defence circles - which in-itself demonstrates the difficulty in developing effective cross-government coordination. ${ }^{139}$ This is salient,

\footnotetext{
135 Ibid.

136 See: Ibid. 3.

${ }^{137}$ Friis, "How to Conceptualise 'Comprehensive Approach'?."

${ }^{138}$ Foundations of New Zealand Military Doctrine (NZDDP-D) 2-7, footnote 6.

139 Several speeches in 2004 and 2007, one from the Prime Minister and the others from Minister's of Defence (Phil Goff and Mark Burton) refer to the 'Comprehensive approach'. Phil Goff has also used the term in a 2010 speech. It appears that there was no wider use of the term by Foreign Affairs or NZAID 
as the use of whole of government terminology significantly fails to incorporate nongovernment entities into the policy and service delivery cycle. In Australia, this gap has been recognised and is being addressed by incorporating experienced nongovernment practitioners into quasi-government departments - such as the AsiaPacific Civil-Military Centre of Excellence in Queanbeyan, NSW. ${ }^{140}$

The effects-based operations concept, which began in the 1990s, is an offshoot of network-centric warfare and is a purely military concept. With EBO the military looks to exploit the asymmetric advantages in knowledge, precision and mobility. ${ }^{141}$ Military activities, for example, could include use of kinetic force, but also may include a number of non-kinetic military actions. Actions encompass operations "in peace, crisis, and war," not just combat. ${ }^{142}$ This approach helps conceptualise the enemy as a system, which is characterised as being complex and adaptive. ${ }^{143}$ In a literature survey on the subject, Major Z. Jobbagy has observed that: ${ }^{144}$

\begin{abstract}
Since the successful 1991 Gulf War the US Air Force in every military operation has been applied under an effects-based operating concept that emphasises the accomplishment of strategic goals. Warfare in the context of EBO allows us to think about ways other than just simple destroy the enemy's forces. EBO is about accomplishing the objective via effects we want to achieve. This difference in mind-set frees up resources and minimises damage and loss of life. EBO is the definite springboard to accomplish security goals and objectives in an integrated, unified fashion by better linking all security pillars together.
\end{abstract}

The concept takes a systems thinking approach, as does the whole-of-government approach. However, the concept is military centric and would not naturally stretch to incorporate civilian organisations.

\footnotetext{
officials and in the NZDF 2010-2013 Statement of Intent reference to the CA had been removed completely. See: (Minister of Defence) Phil Goff, "New Zealand's Defence Policy" (30 August, 2007), available at http://www.beehive.govt.nz/node/30478, (Minister of Defence) Mark Burton, "New Zealand's Role in the Global Defence Community" (16 June, 2004), available at http://www.beehive.govt.nz/node/20017, (Prime Minister) Helen Clark, "Clark: NZ and Peaceful Conflict Resolution" (29 November, 2007), available at http://www.scoop.co.nz/stories/PA0711/S00588.htm, (Leader of the Opposition) Phil Goff, "New Zealand's Contribution to a World Free of Nuclear Weapons" (May 31, 2010), available at http://www.labour.org.nz/news/new-zealand\%E2\%80\%99s-contributionworld-free-nuclear-weapons, (Minister of Defence) Phil Goff, "Meeting Contemporary Security Challenges" (12 July, 2007), available at http://www.beehive.govt.nz/node/30047.

140 The Asia Pacific Civil-Military Centre of Excellence [Website], The Asia Pacific Civil-Military Centre of Excellence, available at http://civmilcoe.gov.au/, (accessed 23 January 2011).

${ }^{141}$ Z Jobbagy, "A Literature Survey on Effects-Based Operations" (TNO Physics and Electronics Labratory, 2003).

${ }^{142}$ See: Edward A Smith Effects Based Operations Applying Network Centric Warfare in Peace, Crisis, and War (Information Age Transformation Series) available at http://www.iwar.org.uk/rma/resources/ebo/Literature_survey_on_Effects-Based_Operations.pdf (accessed 23 January).

143 Jobbagy, "A Literature Survey on Effects-Based Operations".

144 lbid., 13.
} 


\subsection{International Whole of Government Approaches}

To examine coordination in these operational environments it is useful to focus on individual national efforts. Several governments have been working on increased coordination among departments involved in international operations. The United Kingdom and Canada led the way in the development of integrated approaches to peace support operations. Many other nations have since begun to develop iterations of these approaches, with an expanding literature hard on their heels in attempting to analyse their relevant weaknesses and strengths. The following briefly outlines the basic whole of government approaches of New Zealand's closer security partners: the United Kingdom, Canada, and the United States of America. It will then turn to a closer look at Australia's enhanced focus on civil-military relations amongst an energised whole-of-government approach to peace operations.

\subsubsection{The United Kingdom, Canada \& the United States}

Of the main actors implementing these approaches, the UK has been at the "forefront of conceiving and adopting integrated policy responses to weak and failing states." ${ }^{145}$ The UK began developing this approach in the late 1990s. However, the first institutional manifestation was the creation of the Post-Conflict Reconstruction Unit (PCRU) in 2004, which was later re-named the Stabilisation Unit. ${ }^{146}$ The Stabilisation Unit was set up to respond to the complex challenges of "fragile and conflict-afflicted states", and to help countries enhance their capacity for selfgovernance. ${ }^{147}$ The Unit reports to the Ministry of Defence, the Foreign and Commonwealth Office and the Department for International Development and includes staff from each of the Departments. It was set up to ensure that decisions and policies were developed and collectively agreed upon by the three

\footnotetext{
145 See: Brown Greater Than the Sum of Its Parts?: Assessing "Whole of Government" Approaches to Fragile States 9, Major Will Anderson, 'Wiring up Whitehall: Ensuring Effective Cross -Departmental Activity,' Journal of Security Sector Management 3, no. 3 (2005), Finn Stepputat Integrated National Approaches to International Operations: The Cases of Denmark, UK, and the Netherlands (DIIS Report 2009:14, Danish Institute for International Studies, 2009) available at http://www.isn.ethz.ch/isn/DigitalLibrary/Publications/Detail/?ots591=EB06339B-2726-928E-0216-1B3F15392DD8\&Ing=en\&id=99492.

${ }_{146}$ Friis, "How to Conceptualise 'Comprehensive Approach'?," 4.

147 The Stabilisation Unit About Us, The Stabilisation Unit available at http://www.stabilisationunit.gov.uk/index.php/about-us, (accessed 23 September 2010). 
departments. ${ }^{148}$ Finn Stepputat praised the creation of this unit, stating that it "fills a critical gap between the departments." ${ }^{149}$ However, Stepputat notes that one of its main challenges is the limit of its power at director level, "which has the consequence 'that it has nobody to impress or depress'". 150

In addition to the Stabilisation Unit, the UK House of Commons announced on 15 December 2009 that a "1,000-strong civilian capability (of whom 200 can be deployed at any one time) has been developed ahead of schedule." ${ }^{151}$ Called the 'UK Civilian Stabilisation Group', their stated Mission is to co-ordinate and support crossgovernment stabilisation planning and execution; to ensure the rapid and integrated delivery of targeted expertise in a cross-government approach; and, to lead on stabilisation lesson-learning and assist with implementation. ${ }^{152}$ This is a firm step forward in recognising the requirement for civilian expertise in peace operations and actively building the capability to deploy them.

The Canadians are regarded as the first to develop the '3D' concept (diplomacy, development and defence). The rationale for this approach was voiced in Canada's 2005 International Policy Statement. ${ }^{153}$ While all departments involved never officially adopted the statement, it demonstrated the initial political will to move towards more integrated responses to PSOs. ${ }^{154}$ Like the UK, Canada also mandated the development of a civilian deployment pool in the form of the Canadian Stabilization and Reconstruction Task Force (START). The official website outlines that "START is working to expand Canada's whole-of-government capacity for deploying civilian experts to fragile states. This includes the management of the Canadian Police Arrangement (CPA) and the deployment of other Government of Canada expertise." ${ }^{155}$ Recent indications demonstrate that by 2010 the WGA has become an integral component of Canada's involvement in PSOs. ${ }^{156}$

\footnotetext{
${ }^{148}$ For discussion see: Stepputat Integrated National Approaches to International Operations: The Cases of Denmark, UK, and the Netherlands 37.

149 Ibid.

150 lbid. 38.

151 Strengthening of the Stabilisation Unit and Implimentation of the Cabinet Office Task Force Review of Stabilisation and Civil Effect (Third supplementary memorandum from the Ministry of Defence, the Foreign and Commonwealth Office and the Department for International Development December 2009) available at http://www.publications.parliament.uk/pa/cm200910/cmselect/cmdfence/224/224we28.htm at 1, UK Government UK Civilian Stabilisation Group, The Stabilsation Unit, available at http://www.stabilisationunit.gov.uk/index.php/civilian-stabilisation-group, (accessed 23 September 2010).

${ }^{152}$ See: Stepputat Integrated National Approaches to International Operations: The Cases of Denmark, UK, and the Netherlands 37.

${ }^{153}$ CIDA Canada's International Policy Statement (Canadian International Development Agency, 2005) available at http://www.acdi-cida.gc.ca/acdi-cida/acdi-cida.nsf/eng/JUD-2107401-GV3.

${ }^{154}$ For discussion see: Brown Greater Than the Sum of Its Parts?: Assessing "Whole of Government" Approaches to Fragile States 59.

${ }^{155}$ DFAIT Stabilization and Reconstruction Task Force (Start), Foreign Affairs and International Trade Canada, available at http://www.international.gc.ca/start-gtsr/index.aspx;
} 
The OECD peer review of Canada's development assistance was high in praise for Canada's whole-of-government approach to fragile states. ${ }^{157}$ The Review highlighted that "Canada's 2005 International Policy Statement broke new ground with an entirely new approach to Canada's international development assistance". ${ }^{158}$ The 2005 statement outlined Canada's first "integrated, or whole-of-government, approach, bringing together diplomatic, defence, development, trade and investment strategies." ${ }^{159}$ The approach has been applied in Canada's peace support operations in Afghanistan, Haiti and Sudan. The introduction to the Peer Review stressed that: ${ }^{160}$

\begin{abstract}
Global peace and security is a defining element of Canada's foreign policy ... In fragile states and countries in conflict, the whole-of-government approach is bringing together the Department of Foreign Affairs and International Trade (DFAIT), the Department of National Defence and the Canadian International Development Agency (CIDA) with some success. The approach is the outcome of a government-wide shared view and holds significant potential for policy coherence and co-ordinated programming across Canada's federal departments and agencies.
\end{abstract}

The Review recommended that it would like Canada to share lessons and good practice from implementing that approach into its programming in fragile states. They specifically noted the successes in Haiti illustrating that "collaboration across diverse organisational cultures can succeed and can be carried further with targeted corporate incentives."161

However, the Review found there were some gaps that required attention. One of those was a lack of an overarching national strategy or framework for these operations: $^{162}$

\footnotetext{
Canada needs an overall framework for policy coherence for development to make policies consistent and underpin Canada's whole-of-government approach. Such a framework should involve all relevant departments and agencies.
}

http://www.international.gc.ca/START-GTSR/civilian_deployment-deploiement_de_civils.aspx, (accessed 22 September 2010).

${ }^{156}$ See: Jeff Davis, "Feds' Go-to Team in Afghanistan Part of New Whole-of-Government Strategy " The Hill Times Online, no. April 19 (2010), http://www.thehilltimes.ca/page/view/afghan-04-19-2010.

${ }^{157}$ OECD OECD Peer Review of Canada (Development Assistance Committee (DAC), 2007) available at http://www.oecd.org/dataoecd/48/61/39515510.pdf (accessed 23 January 2011) 10.

158 lbid. 23

159 lbid.

160 Ibid. 10.

161 lbid. 23.

162 Ibid. 33. 
A further issue was that of policy coherence, the Review recommended that: ${ }^{163}$

Canada needs to articulate its approach to policy coherence for development to implement the whole-of-government approach more systematically, involving all relevant departments and agencies.

The Review demonstrated that Canada has firmly embedded the notion of whole-ofgovernment into its offshore peace operations. It found that the way this had been done was highly effective, although a few weaknesses were present in the overall framework for such operations which led to some issues with policy coherence.

The US on the other hand lagged behind the UK and Canada in developing an integrated, whole of government approache to respond to complex operations. ${ }^{164}$ Patrick and Brown outlined that US engagement with fragile states was "motivated almost entirely by national security concerns." 165 This was reinforced by the overwhelming influence of the US Department of Defence on White House thinking. This was most apparent in Iraq in 2003 as Washington transferred complete responsibility for the post-conflict phase to the Department of Defense. ${ }^{166}$ The turmoil that followed - including the breakdown of law and order, the disintegration of public services and the development of a full-scale insurgency clearly demonstrated the need to develop robust integrated responses to post-conflict complex environments. ${ }^{167}$

In response, the US State Department in August 2004 formed the Office of the Coordinator for Reconstruction and Stabilization (S/CRS). While this was a positive institutional step, it lacked appropriate resources, had inadequate authority over active operations, met bureaucratic resistance and entered into a list of intraagency rivalries. ${ }^{168}$ In a 2008 Report written by Officers at the United States Marine Corps, Command and Staff College, it was argued that: "While the Department of Defense has worked diligently toward developing necessary capabilities and skill sets, the U.S. lacks a "whole of government" approach. This failure to fully integrate operations and requirements erodes America's ability to conduct foreign missions." 169

\footnotetext{
163 Ibid. 13.

${ }^{164}$ Brown Greater Than the Sum of Its Parts?: Assessing "Whole of Government" Approaches to Fragile States 31.

165 Ibid. 32.

166 Ibid. 38.

167 lbid.

168 lbid.

${ }^{169}$ RD Harris and BR Lewis The Failure of Future U.S. Stability Operations Fueled by Flawed Strategic Policies (United States Marine Corps,Command and Staff College, Marine Corps Combat Development
} 
With the Obama administration entering office in 2009 the focus turned towards enhancing the civilian capacity in post conflict operations. In this pursuit, Secretary of State Hillary Rodham Clinton launched the Quadrennial Diplomacy and Development Review (QDDR) in July 2009 with the goal of "strengthening and elevating diplomacy and development cooperation as key pillars of U.S. foreign policy". ${ }^{170}$ This was taking place in the context of calls by Defense Secretary Robert Gates and Chairman of the Joint Chiefs Mike Mullen to enhance civilian capabilities in order to avoid the "militarisation" of U.S. foreign policy. ${ }^{171}$ Gates had stated in the Defense Department's January 2009 Quadrennial Roles and Missions Review Report that, "The Department supports institutionalizing whole-of-government approaches to addressing national security challenges." ${ }^{172}$ The document added that, "The desired end state is for U.S. Government national security partners to develop plans and conduct operations from a shared perspective." 173 It remains to be seen whether the US can implement robust whole of government reform or whether the existing institutional challenges will prevent any substantial, long-term change. ${ }^{174}$

\subsubsection{Australia}

Along with the UK and Canada, Australia has been a leader in developing whole of government strategies towards peace support operations. ${ }^{175}$ The October 2002 Bali bombings provided strong motivation for Canberra to place regional development at the top of its security agenda. ${ }^{176}$ This further contributed to the development of the notion of the so-called "arc of instability" which heavily influenced

Command,Marine Corps University, 2008) available at http://www.dtic.mil/cgi-

bin/GetTRDoc?AD=ADA508095\&Location=U2\&doc=GetTRDoc. pdf (accessed 22 March 2011.) 2.

${ }^{170}$ Frequently Asked Questions: Purpose of the QDDR, US Agency for International Development, available at http://www.usaid.gov/policy/qddr/faq.html, (accessed 23 September 2010), The Department of State's Quadrennial Diplomacy and Development Review, US Department of State, available at http://www.state.gov/r/pa/prs/ps/2009/july/125956.htm, (accessed 23 September 2010).

${ }^{171}$ Gordon Adams, "The Quadrennial Diplomacy and Development Review: Separating the U.S. Civilian and Defense Missions," Bullitin of the Atomic Scientists 1 February (2010),

http://www.thebulletin.org/web-edition/columnists/gordon-adams/the-quadrennial-diplomacy-anddevelopment-review-separating-the-.

172 Quadrennial Roles and Missions Review Report (Department of Defense, 2009) available at http://www.defense.gov/news/Jan2009/QRMFinalReport_v26Jan.pdf.

${ }_{173}$ Quadrennial Roles and Missions Review Report (Department of Defense, January 2009) available at http://www.defense.gov/news/Jan2009/QRMFinalReport_v26Jan.pdf 31.

${ }^{174}$ For discussion see: Adams, "The Quadrennial Diplomacy and Development Review: Separating the U.S. Civilian and Defense Missions."

${ }^{175}$ For a comprehensive analysis of Australia's whole of government approach to fragile states see: Brown Greater Than the Sum of Its Parts?: Assessing "Whole of Government" Approaches to Fragile States 76.

176 Ibid. 
Canberra's national security policy. ${ }^{177}$ The 2002 Ministerial Statement Australian Aid: Investing in Growth, Stability and Prosperity raised these issues, affirmimg, "The Australian aid program is playing an increasingly important role in whole of government efforts to respond to these critical issues." 178

This undoubtedly provided the conceptual underpinnings of the 2003 Regional Assistance Mission to Solomon Islands (RAMSI). RAMSI was noted as being one of the "most innovative whole of government operations" to that point. ${ }^{179}$ The mission met with initial success and leading into 2006 was hailed as a 'model of best practice'. ${ }^{180}$ Restoring the rule of law was rapidly accomplished with the overwhelming support of the local population. Subsequent problems after the 2006 elections, which led to violent riots in Honiara, were a clear signal that the enhanced coordination and integration was not sufficient and had to be deepened and widened. $^{181}$

In 2004, Sinclair Dinnen, reviewing the new development engagements, found that "More bits of the Australian government are now involved in development assistance than at any previous time in recent years." 182 However, Dinnen held a level of apprehension about the whole of government approach, stating, "It is also an approach that unless handled with sensitivity and skill could easily generate resentment and resistance among local officials." ${ }^{183}$ Dinnen observed that issues of coordination were critical, if not only to "avoid reproducing Canberra's bureaucratic rivalries in Port Moresby or Honiara". ${ }^{184}$ By 2004, the Australian Prime Minister's Office had taken a leading role in the development and steering of Australia's policy engagements in the region. ${ }^{185}$ Dinnen claimed that one undesirable outcome of this was that officials lacking extensive regional and development experience were

\footnotetext{
177 See: Robert Ayson, 'The Arc of Instability and Australia's Strategic Policy,' Australian Journal of International Affairs 61, no. 2 (2007), Graeme Dobell, "The 'Arc of Instability': The History of an Idea," in History as Policy: Framing the Debate on the Future of Australia's Defence Policy, (ed). Ron Huisken and Meredith Thatcher (Canberra: Australian National University Press, 2007).

${ }^{178}$ Australian Aid: Investing in Growth, Stability and Prosperity (AusAid: The Australian Government's Overseas Aid Program, 2002) available at

http://www.ausaid.gov.au/publications/pubout.cfm?id=6624_6294_3682_4822_12758.

${ }_{179}$ Brown Greater Than the Sum of Its Parts?: Assessing "Whole of Government" Approaches to Fragile States 76.

180 See: Michael Fullilove, 'RAMSI and State Building in Solomon Islands,' Defender (2006).

${ }^{181}$ See: Mary Louise O'Callaghan, "RAMSI: The Challenges Ahead " (paper presented at the Solomon Islands: Where to now?, State, Society and Governance in Melanesia Project and The Pacific Centre, College of Asia and the Pacific, Australian National University 5 May 2006) available at http://rspas.anu.edu.au/papers/melanesia/conference_papers/060505_solomons_ocallaghan.pdf (accessed 11 January 2011).

182 Sinclair; Dinnen Lending a Fist? Australia's New Interventionism in the Southwest Pacific (Discussion Paper 2004/5, State Society and Governance in Melanesia Project, RSPAS; ANU, 2004) available at http://dspace.anu.edu.au/handle/1885/42136 4.

${ }_{183}$ Ibid.

184 Ibid

185 Ibid.
} 
making key decisions. ${ }^{186}$ This may have contributed to the subsequent problems in Honiara in 2006.

By 2007, the literature shows that at least at the rhetorical level the whole of government approach had been widely embraced by Australian agencies. In 2006, the Australian government published the White Paper on their overseas aid program: Australian Aid: Promoting Growth and Stability. ${ }^{187}$ This White Paper was the most comprehensive Australian document to articulate the links between regional security, stability and development. It was developed with extensive consultation between the Australian Department of Foreign Affairs and Trade (DFAT), the Prime Minister's office, the cabinet, AusAID, and the Treasury department, as well as input from Australian NGOs. ${ }^{188}$ The document emphasised that Canberra would endeavour to further integrate and broaden Australian engagement in development in the AsiaPacific region. This would be achieved through a focus on policy coherence and whole-of-government approaches to aid delivery, and by broadening participation beyond government. ${ }^{189}$ While the 2006 White Paper frequently used the term "whole of government" (11 times), according to Patrick and Brown, it failed to address the need for a whole-of-government approach covering the "entire range of foreign policy and overseas aid." 190 Indeed, they noted that by 2007 there was still a substantial distance in translating the "policy coherence rhetoric into practice." 191

In 2008, the Australian Senate Standing Committee on Foreign Affairs, Defence and Trade published a 417-page analysis of Australia's involvement in peacekeeping operations (PKOs). Within this Report, the Committee evaluated the whole of government activities of the Australian government. ${ }^{192}$ The committee's two key overarching recommendations were directed at developing and improving the Australian whole-of-government policy and coordination of engagement in peacekeeping. ${ }^{193}$ They observed that despite the 'dramatic changes' in Australia's PKOs, particularly often as a lead country in the region, "there is no policy document that presents a whole-of-government approach to peacekeeping", concluding, "The

\footnotetext{
186 Ibid.

${ }^{187}$ Australian Aid: Investing in Growth, Stability and Prosperity

${ }^{188}$ Brown Greater Than the Sum of Its Parts?: Assessing "Whole of Government" Approaches to Fragile States 80, AusAid Australian Aid: Promoting Growth and Stability (The Australian Government's

Overseas Aid Program, 2006) available at http://www.ausaid.gov.au/publications/pdf/whitepaper.pdf ix.

189 AusAid Australian Aid: Promoting Growth and Stability 62.

190 Brown Greater Than the Sum of Its Parts?: Assessing "Whole of Government" Approaches to Fragile States 80.

191 Ibid. 82.

192 The term 'whole of government' was mentioned 96 times in the report.

${ }^{193}$ Government Australia's Involvement in Peacekeeping Operations executive summary, recommendations 37 and 38 . 
committee believes that it is time for such a document." ${ }^{194}$ In addition, the committee listed a wide number of recommendations for the government, many related to deepening whole of government approaches to these operations.

The Australian Senate Standing Committee provided an examination of the coordination between agencies in peacekeeping operations. At the strategic level, they noted that Australia's peacekeeping engagements are developed on a case-bycase basis. ${ }^{195}$ The following formal mechanisms are used to formulate whole-ofgovernment policy and to coordinate Australia's involvement in peacekeeping operations: $^{196}$

- the National Security Committee of Cabinet (NSC) and the Secretaries Committee on National Security (SCONS) provide policy direction and development;

- $\quad$ the Strategic Policy Coordination Group (SPCG) at the deputy secretary level provides strategic oversight and direction across agencies; and,

- standing interdepartmental committees (IDCs) address specific peacekeeping operation issues.

The Prime Minister chairs the NSC, which sets policy. It is placed at the highest level of government and meets regularly - on a daily basis if required. The SPCG includes the Department of Foreign Affairs and Trade (DFAT), the Department of Prime Minister and Cabinet and the Department of Defence as the core agencies. It is chaired by $P M \& C$, but any member of the committee may call a meeting if required. The SPCG committee meets on a monthly basis, although more frequently if required. ${ }^{197}$ The interdepartmental committees provide the whole-of-government framework for policy formulation and coordination of an individual peace support operation.

While Australia's policy and organisational framework appears to have been well designed, the Senate Report identified that there were several key weaknesses. Part VI of the report notes that:

- government agencies and the government as a whole do not have effective processes for converting lessons from a peacekeeping operation into policy or practice-due in large measure to inadequate evaluation mechanisms, particularly the absence of effective performance indicators;

\footnotetext{
194 Ibid. 19.

195 Ibid. 167.

196 Ibid.

197 Ibid.
} 
- current reporting practices can be improved to provide greater transparency and accountability-indeed the fragmentary reporting on Australia's engagement in peacekeeping provides an incomplete account of these activities;

- there is a compelling argument for a white paper on Australia's engagement in peacekeeping; and

- considerable scope exists to make the Asia-Pacific Centre on Civil-Military Cooperation an internationally recognised institute and for it to have an integral role in developing a culture of learning and improvement in those involved in peacekeeping.

In what appeared to be an ambitious response to some of the concerns raised by the Senate Report, there has been a significant push by Australia to increase the effectiveness and efficiency of their whole-of-government working. Two of the primary methods for delivering this have been the enhanced focus of the Asia-Pacific Civil-Military Centre of Excellence and the National Security College (NSC). Both institutions are aimed at increasing Australia's whole-of-government security approach. At the launch of the NSC in April 2010, Australia's Prime Minister Kevin Rudd, said "the National Security College at ANU will enhance collaborative leadership in the national security community and build trusted networks within and outside government."198 The Founding Director of the College, Professor Michael L'Estrange explained that, "Our aim is to build up the analytic skills and collaborative leadership attitudes among the members of the national security community in government, and to provide a range of academic courses and research which will be accessible for people inside and outside government." ${ }^{199}$ The NSC is a deliberate attempt by central government to drive culture change throughout the Australian (and New Zealand) security sector. Under no illusions of the resistance that it will inevitably receive, the government has quite intentionally placed 'heavy hitters' on the NSC Board to demonstrate their determination to succeed. ${ }^{200}$

\subsection{Benefits}

Chapter Two highlighted that many governments had recognised the benefits of integrated whole-of-government approaches in domestic governance. This greatly assisted in stimulating the development of initiatives to handle the gradual

\footnotetext{
198 "Prime Minister Launches National Security College", (24 April 2010), available at http://news.anu.edu.au/?p=2100, (accessed 30 January 2011). 
convergence of the diplomatic, defence and development policy agendas in peace support operations. ${ }^{201}$

A 2009 paper by the Swiss Centre for Security Studies provided an additional pragmatic argument for a coherent whole-of-government approach. They referred to their mission in Sudan, noting that any commitment by Swiss agencies was seen as inherently "Swiss". ${ }^{202}$ Therefore, successes or failures by any individual Swiss agency reflected on and influenced all other Swiss agencies involved. Consequently, there was "an inherent interest in coordination and mutual assistance towards enhancing the overall performance of all agencies." ${ }^{203}$ This is a very useful benchmark for what New Zealand has recently been attempting to construct within the so-called "NZ Inc framework for offshore operations". ${ }^{204}$ What will be seen in Chapter 7 is that the focus for 'NZ Inc', which is driven by the New Zealand Ministry of Foreign Affairs and Trade, is inherently trade focused and has yet to be fully exploited in peace support operations.

Based on the literature, this thesis argues that aside from a 'singular brand' noted above, there are specific benefits that a whole-of-government approach can bring to peace support operations. These mirror the benefits drawn from the literature on domestic implementation of the concept. Namely, there are four overarching advantages - the reduction of departmental silos, increasing policy coherence, maximising efficiency, and addressing complex social problems.

\subsubsection{Reduction of Departmental Silos}

The silozation of the security sector is perhaps more noticeable than that of the remainder of the public sector. This is largely due to the stark difference between disciplined and non-disciplined forces. Militaries are by their nature hierarchical and risk adverse - especially in the protection of information. This has manifested itself in entrenched cultures that are somewhat guarded towards the media and not predisposed to working collaboratively with civilian agencies. As the nature of the operating environment has evolved in the past few decades, militaries have begun to

\footnotetext{
${ }^{201}$ Anderson, 'Wiring up Whitehall: Ensuring Effective Cross -Departmental Activity,' 2.

202 Simon J A Mason (CSS) Towards a Swiss "Whole of Government" Approach in Sudan: 2005-2008 1. 203 Ibid.

${ }^{204}$ See Chapter 5.
} 
grapple with the realisation that they need to work in intimate partnerships with civilian agencies. ${ }^{205}$

Almost fortuitously, the recent increase of police being deployed alongside defence forces has rapidly begun to break down the barriers. This has seen its difficulties even though police, as disciplined forces, are much more closely related than development agencies for example. There is a growing literature on the collaboration between militaries and police in these operations. As was highlighted in the Australian Senate Report: ${ }^{206}$

\begin{abstract}
To this stage, the committee has looked at [Police and Military] training as though each organisation operated as a silo, as a distinct entity with separate training and predeployment programs. Today's peacekeeping operations, however, with their multidimensional and multifaceted nature, require coordination and cooperation between the different elements of a peacekeeping operation:
\end{abstract}

The report posits that although the police and defence forces have distinct functions in a peace support operation, they may need to support and rely on each other to achieve the mission's objective. Addressing the Panel, Lieutenant General Gillespie stated with reference to operations in Timor-Leste and Solomon Islands that: ${ }^{207}$

Then, as now, most military patrols will have a policeman with them so that powers in terms of law and order for arrest and detention remain where they should be, which is with the police force. If you are trying to bring a nation along to be a law-abiding nation, it ought to learn that police do policing and that the military are about something else.

The message that Lt Gen Gillespie put across was that each department has their specific roles but will often occupy the same space. Thus, interoperability between the two forces is critical. Lt Gen Gillespie stressed that, rather than develop identical skills, their efforts should be directed at "ensuring there are no security capability gaps." 208 This has been a useful development as Australia, like New Zealand, looks to develop its effectiveness in peace support operations. The next step is drawing on these experiences and using them to break down the silos between militaries and the growing number of civilian agencies involved in such operations.

\footnotetext{
${ }^{205}$ See: Benjamin de Carvalho Kristin M. Haugevik Civil-Military Cooperation in Multinational and Interagency Operations: Discussion Paper on Operational Terminologies and Assessment for Multinational Experiment 5 [MNE5] (Security in Practice no. 2 [A Publication in the NUPI Series on Security in Practice], Norwegian Institute of International Affairs, 2007) available at http://www.reliefweb.int/rw/lib.nsf/db900sid/PANA-79SJ2P/\$file/nupi_may2007.pdf?openelement (accessed 30 January 2011) 7.

206 Government Australia's Involvement in Peacekeeping Operations 147.

207 Ibid. 148.

208 Ibid. 


\subsubsection{Policy Coherence}

An efficient whole-of-government approach to peace support operations will necessarily reflect policy coherency amongst stakeholder agencies. The case studies in the 2006 OECD report Whole-of-Government Approaches to Fragile States identified that governments, "recognised the need for, and the benefits of, WGAs." 209 The report found that the main benefits flowed from ensuring coherency in policies across the various agencies. The report argued that whole-of-government approaches need to "go beyond providing a collection of independent policies guided by departmental mandates." 210 The report also stressed that coherent policies and activities should have greater legitimacy in the eyes of recipient states and as a result be more likely to receive a positive response. ${ }^{211}$

However, Brown et al provided strong argument that there is much work to be done to achieve policy coherence in peace operations. They highlight that governments often avoid honest debate over the goals of policy coherence in peace operations, in part because they are reluctant to confront the "divergent motivations for their efforts." 212 The benefit of policy coherence is to join-up the unique resources and skills of various departments in addressing security and governance obstacles to development in these operations. ${ }^{213}$

\subsubsection{Efficiency}

A coherent whole-of-government approach enables the exploitation of synergies, such as through information-sharing, joint analysis, activities that complement each other, and sharing the costs of infrastructure. ${ }^{214}$ The OECD report reasoned that the advantages of enhanced policy coherence amongst a whole-ofgovernment approach in peace operations were clear: ${ }^{215}$

... more coherent policies and activities can contribute to the overall objective of long-term development and stability in fragile states at a lower overall fiscal cost. In

\footnotetext{
209 OECD Whole of Government Approaches to Fragile States 18.

210 Ibid.

211 Ibid

212 Brown Greater Than the Sum of Its Parts?: Assessing "Whole of Government" Approaches to Fragile States 6.

213 Ibid. 12

214 Simon J A Mason (CSS) Towards a Swiss "Whole of Government" Approach in Sudan: 2005-2008.

215 OECD Whole of Government Approaches to Fragile States 18.
} 
addition, the risk of these objectives either being compromised, or simply not being met, is reduced.

In an environment strongly driven by the global effects of the economic crisis, governments are increasingly looking to leverage the most value from their engagements abroad. The OECD has identified that while there are significant 'frontend' costs involved with joining-up, the long-term economic benefits will far outweigh the short-term loss. ${ }^{216}$ As these relationships and experiences develop, there will be an identification of where governments can exponentially increase value for money.

\subsubsection{Addressing Complexity in Peace Support Operations}

A fundamental feature of contemporary peacekeeping is the complexity of the operating environment. Indeed, the New Zealand government labels the operations in Afghanistan, Timor-Leste, and Solomon Islands as 'complex peace support operations'. ${ }^{217}$ The OECD report argued that, "attempts to deal with precarious states have proven quite complex and problematic."218 The report described that development agencies realise that successful long-term development in fragile states is impossible when these states cannot deliver the collective requirements of basic security and effective governance. Furthermore, both development and military agencies are patently aware that short-term, ad hoc responses in which national and international policies lack coherence and co-ordination will not succeed. As a result, the focus has now turned to improving peace building capacities through better whole-of-government operational responses. As with domestic governance however, there are a number of key barriers to successful implementation of a whole-ofgovernment approach.

\footnotetext{
${ }^{216}$ Ibid. 7.

${ }^{217}$ MFAT Security: Peace Support Operations [Webpage], available at http://www.mfat.govt.nz/ForeignRelations/1-Global-Issues/International-Security/4-Peacekeeping-Operations.php, (accessed 04 January 2011).

${ }^{218}$ OECD Whole of Government Approaches to Fragile States 17. 


\title{
3.5 Barriers
}

The literature shows that there are some key challenges to effective whole-ofgovernment implementation in peace support operations. Providing overview of these challenges, the OECD report emphasised that: ${ }^{219}$

\begin{abstract}
Overall, the challenge to most of these partnerships is that they have comparatively little history. For the practitioners involved, most activities therefore have a pioneering character in which actors are still adapting to each others idiosyncrasies, arising from differing organisational cultures, professional skills sets, mandates and legal statutes. These are then compounded by a lack of consensus or clarity over roles and responsibilities of each partner and lines of accountability.
\end{abstract}

The report provides a coherent list of the primary challenges that arose from their case studies. Those challenges included the importance of political interests and priorities as well as the constitutional and political context of a donor country. There is an additional requirement to balance diverse rationales and perspectives of actors involved, as well as to clarify their roles in order to establish who takes the lead. There is a requirement to bridge differences in organisational culture among actors. In addition, the lack of incentives for departments to work collaboratively with each other needs to be addressed. They argue that often there are strong disincentives to work in close partnership with other government agencies. The whole-of-government approach can have substantial resource implications in both financial and human terms. The Report stressed that in many cases donor governments had not matched their ambitions for an integrated approach with sufficient resources. ${ }^{220}$

The barriers identified by the OECD highlight that there are specific structural issues that challenge the implementation of a whole-of-government approach. Brown et al emphasise that a high-level remit from the government is essential to generate momentum for interdepartmental collaboration. ${ }^{221}$ Finn Stepputat drew a set of challenges from his analysis on UK whole-of-government efforts. These included: ${ }^{222}$

- Lack of an agreed general plan

- $\quad$ Lack of agreed cross-governmental planning format

\footnotetext{
219 Ibid. 23.

220 Ibid.

${ }^{221}$ Brown Greater Than the Sum of Its Parts?: Assessing "Whole of Government" Approaches to Fragile States 19.

${ }^{222}$ Stepputat Integrated National Approaches to International Operations: The Cases of Denmark, UK, and the Netherlands 42 .
} 
- $\quad$ Lack of agreed persons or organizations with the overarching responsibility to lead and drive the process of cross-governmental coordination forward.

There is an inherent difficulty in gaining cross-departmental collaboration and buy-in when they have competing interests and varying raisons d'être. In this respect, concerns have been expressed that a whole-of-government approach can be misused as an excuse to interfere in and instrumentalise other agencies for goals outside their mandate. ${ }^{223}$ In addition, it can lead to a diffusion of responsibility and a confusion of roles as well as additional bureaucratisation and excessive coordination costs. $^{224}$ This ties in with the enhanced difficulties in accurately delineating lines of accountability and responsibility.

A further challenge, and possibly the greatest, is the clash of institutional cultures. Studies illustrate that there is a lack of knowledge about organisational identities, traditions, images, cultures, and fundamental goals that constitute and constrain their activities in peace support operations. ${ }^{225}$ Michael Pugh has noted that a key obstacle to closer cooperation in multinational and interagency cooperation is "the sheer scale and fragmentation of actors, activities, and perceptions in the civilian sector." ${ }^{226}$ Benjamin and de Carvalho argued that stereotyping and prejudices due to lack of knowledge and information represent root obstacles to civil-military cooperation. ${ }^{227}$ They claimed that another overall challenge "is lack of knowledge about one another's security concerns." ${ }^{228}$ They contend that for civilian actors, the threat of becoming a target in the conflict sometimes makes cooperation with the military necessary. The circular argument comes in that working with the military could also make the civilians legitimate targets.

A critical dilemma for militaries is the security risk connected with sharing operational information with civilian actors. Civilian personnel at times have been accused of being too naïve about the security risks in conflict areas, and have been

\footnotetext{
${ }^{223}$ Simon J A Mason (CSS) Towards a Swiss "Whole of Government" Approach in Sudan: 2005-2008 1. 
criticised for refusing to cooperate with military structures. ${ }^{229}$ The last challenge outlined by Benjamin and de Carvalho was the relevant actors' lack of knowledge about one another's diverging working procedures in the planning, action, and assessment-phases of an operation. ${ }^{230}$ On top of these fundamental issues, there are natural issues with the divergent languages and operational terminologies used by the varying agencies.

\subsection{Conditions and Factors}

Drawing on the above benefits and barriers, there is an opportunity to delineate a set of overarching factors and conditions required to implement a successful whole-of-government approach to peace support operations.

The first requirement is a national strategy for managing whole-of-government engagement in peace support operations. Such a framework would consist of three elements:

1. A clear understanding of the rationale for engagement in peace support operations, which is shared by all relevant government actors;

2. a joint policy statement explaining the underlying principle for collaborative working in these operations, together with the outcomes and how these will be achieved; and

3. a commitment to establish an effective dialogue between the key actors involved in a whole-of-government approach, and to work on bridging differences in organisational cultures. ${ }^{231}$

The framework would provide early engagement of all relevant actors (including those at the field level) and classify their roles and objectives in a whole-ofgovernment approach.

In addition to a national whole-of-government framework for peace support operations, there is a requirement for country specific whole-of-government strategies. This reflects the notion illustrated in the literature that there is no 'one size

\footnotetext{
229 Ibid.

230 Ibid.

${ }^{231}$ See: OECD Whole of Government Approaches to Fragile States 8.
} 
fits all' approach to these missions. The success of such a framework requires the highest level of political commitment. If possible, the process should be driven at the Prime Ministerial level and engages the relevant ministers within a whole-of government-approach. ${ }^{232}$

Whole-of-government approach is also made difficult by the disruption to the lines of accountability. Successful implementation will depend on cross-departmental accountability to be collectively designed and continually monitored. Flowing from this is a requirement for accurate and ongoing indicators of success.

There is also a requirement to drive culture change across the relevant government departments. The Australian National Security College is a useful example of an attempt to drive high-level culture change through the introduction of Executive Development courses to improve the ability to operate in a collaborative manner. ${ }^{233}$ A further method to drive this change is strategic use of performance management and reviews to provide tangible benefits to work across boundaries.

\subsection{Conclusion}

There has been a concerted effort in the past decade to achieve better results and enhance the value of the combined contributions to peace support operations. The United Kingdom and Canada led the way in researching and developing methods to increase coordination and collaboration between civilian and military components. Canada's 'Three D's' approach was an early example of a desire to provide more efficient and effective management of Canada's increasing presence in such operations. Australia was also an early advocate of the requirement to place civilians into the forefront of operations as demonstrated by the Police-led mission in Solomon Islands. Australia has reinforced the desire to leverage enhanced value of its offshore operations by the development of two world-leading institutions in the Civil-Military Centre of Excellence and the National Security College. These ambitious Centres, which are inherently designed to drive culture change across the whole-of-government, are strong indicators that Australia has invested in this concept.

\footnotetext{
232 Ibid.

${ }^{233}$ See: "Prime Minister Launches National Security College". 
The benefits of taking a whole-of-government approach to these operations have been well publicised. This includes the reduction of departmentalism, consistency of policy across departments as well as increased efficiency and an opportunity to identify and exploit synergies. Moreover, it is argued that this can all be achieved in complex operating environments. While this may be accurate, there are some overwhelming difficulties faced when attempting to construct such an approach. The structural issues of who takes the lead and who is therefore responsible, or where additional resources will come from are difficult - though these can be addressed in the short-term with effective management. The more complex issues however, are less to do with machinery of government and more to do with institutional cultures. In order to institute an efficient and effective whole-ofgovernment approach in the security sector, as with all sectors, there is a necessity to drive culture change across government departments tasked with national security. 


\section{Chapter 4: The Whole-of-Government Approach in New Zealand}

This chapter aims to critically review the New Zealand literature on the wholeof-government approach. It will examine how and why the approach was incorporated into New Zealand public sector reform. It will then look to outline the impact of the approach in domestic affairs. This chapter's rationale is that the domestic whole-of-government experience is instructive for the use of the approach in peace support operations. In this respect, value can be added to New Zealand's peace support operations by building on the experiences of domestic implementation. Moreover, value is gained from an understanding of not only how the concept operates domestically in New Zealand; but how it is implemented in the previous two chapters. It is only then that a detailed picture can be presented with which to evaluate New Zealand's whole-of-government approach to peace support operations.

The research questions that guided this section are:

- What is the background of the WGA?

- What is the background to New Zealand's whole of government approach?

- What has been the impact of the WGA as a service delivery strategy?

- What are the conditions and factors required to facilitate a WGA in New Zealand?

- What impedes a WGA in New Zealand?

\subsection{New Zealand Public Sector Reform}

New Zealand was not alone in implementing the new public management reforms of the 1980's and 1990's. The difference was the width and breadth of the domestic reforms. Jonathan Boston and Chris Eichbaum observed in 2005 that since the mid-1980s, those reforms attracted world-wide recognition, interest and commendation: ${ }^{234}$

\footnotetext{
Regarded as the most radical, comprehensive and innovative example of the 'new public management', the 'New Zealand model' has been closely scrutinised by reformist governments in numerous developed and developing countries and has inspired many of the public management changes during the past two decades
}

${ }^{234}$ Jonathan Boston, "State Sector Reform and Renewal in New Zealand: Lessons for Governance" 
As New Zealand moved away from those reforms, there was an increased focus towards policy outcomes as opposed to solely benchmarking policy on narrowly defined outputs. Moreover, outcomes would form the foundation of and be clearly articulated as policy was designed rather than based on an aggregation of outputs after the fact. ${ }^{235}$

In 2001, the Clark Labour Government commissioned a review of the public management system. A Ministerial Advisory Group, including Public Service chief executives, external commentators and a representative of the Public Service Association conducted the Review of the Centre of the New Zealand state sector over a four-month period in 2001. ${ }^{236}$ Their major finding was that the public management system, as it stood provided "a reasonable platform to work from, but some significant shifts in emphasis are needed to better respond to the needs of the future." ${ }^{237}$ One of these shifts was designed to resolve the fragmentation of the public sector. This had been caused by a noted increase of agencies and the subsequent proliferation of Ministerial portfolios leading to an excessive number of votes. They also emphasised that in some areas, the weakness was caused by "an overemphasis on vertical accountabilities at the expense of whole of government approaches." 238

The Review of the Centre, however, was not the first official mention of the notion of the whole of government. A survey of the official literature suggests that the first use of the term in Parliament came within a 1999 Select Committee Report. The Inquiry into Defence Beyond 2000, chaired by the Hon Derek Quigley, used the term several times when referring to procurement: ${ }^{239}$

We are in no doubt that advice on major capability procurement must be based on whole-of-Government policies and priorities, which must take precedence over single-service equipment wish-lists.

Quigley and the Committee rejected the 'in-house' nature of the formulation of defence policy in favour of a "whole of government" and a "whole of society"

\footnotetext{
235 Ibid.

${ }^{236}$ Report of the Advisory Group on the Review of the Centre (Presented to the Ministers of State Services and Finance, 2001) available at http://www.ssc.govt.nz/display/document.asp?DocID=2776 (accessed 31 October 2010).

237 Ibid. 4.

238 Ibid.

${ }^{239}$ New Zealand Government Inquiry into Defence Beyond 2000 (Foreign Affairs, Defence and Trade Committee, 1999) available at http://www.defence.govt.nz/pdfs/archive-publications/inquiry-defencebeyond-2000.pdf (accessed 6 October 2010) 71.
} 
approach. $^{240}$ The Select Committee's findings provided a strong base for the incoming Labour government's defence policy and were broadly adopted. ${ }^{241}$

Further early official use of the concept came in the lead up to the turn of the century. One of the central issues was that of the so-called ' $\mathrm{Y} 2 \mathrm{~K}$ bug'. The Minister of the State Services Commission, Hon Maurice Williamson, recommended a new committee be established, comprised of the chief executives of government agencies and representatives from the $\mathrm{Y} 2 \mathrm{~K}$ Commission, to respond to any incidents that may arise over the millennium period. ${ }^{242} \mathrm{Mr}$ Williamson argued that the role of the committee would be to coordinate a "whole of government" response to such incidents. ${ }^{243}$ The Minister recommended that the committee should comprise representatives of "chief executive level" from the Prime Minister's department, Cabinet, the SSC, Police, the Foreign Affairs Ministry, Treasury and the Y2K Commission. $^{244}$

Another came in the nascent field of 'e-government'. ${ }^{245}$ The Minister of State Services, Hon Trevor Mallard, highlighted the emerging theme in December 2000, where he said that: ${ }^{246}$

What was made clear to me is that if government is to deliver the type of value to New Zealanders that they will expect in the future, we require an all-of-government approach to the way information and communications technologies are put to use.

In fact, an article in the Waikato Times earlier that year illustrated that the term had already firmly entered the Minister's thinking, "There's probably quite a bit of money being wasted ... I do accept that there's not a decent 'whole-of-government' perspective."'"247

\footnotetext{
${ }^{240}$ See: Derek Quigley, The War against Defence Restructuring: A Case Study on Changes Leading to the Current Structure of New Zealand Defence (Canberra: Australian National University, 2006).

${ }^{241}$ See: Zhivan Jared Alach, "Facing New Challenges: Adapting the NZDF and ADF to the Post-Cold War Security Environment" (submitted in fulfilment of the requirements for the degree of Doctor of Philosophy, University of Auckland, 2006), Hon Matt Robson Defence Beyond 2000 Underpins the Government's Defence Policy, available at http://www.beehive.govt.nz/node/10503,

242 Tom Pullar-Strecker "Some State Agencies Falling Behind on Y2k," NZ Infotech Weekly 20 September, 1999.

243 Ibid.

244 Ibid.

${ }^{245}$ For an examination of e-government in New Zealand see: Rose O'Neill, "E-Government Transformation of Public Governance in New Zealand" (Victoria University of Wellington 2009).

${ }^{246}$ Hon Trevor Mallard, "Opening Address to Government Online Conference" (6 December, 2000), available at http://www.scoop.co.nz/stories/PA0012/S00078.htm.

${ }^{247}$ NZPA "Govt Web Sites Fail Test," Waikato Times, Edition 2, page 16, March 16, 2000. 
The accomplished journalist Colin James noted an early use of the concept in January 2001, specifically referring to the Deputy Prime Minister (and Minister for Economic Development) Jim Anderton; James observed that: ${ }^{248}$

This "whole of Government" approach emerged last year during development of $\mathrm{Mr}$ Anderton's cherished Tai Rawhiti project to try to reverse the East Coast's economic decline. He aims to transplant it into whole sectors, of which timber is first.

An article in the New Zealand Herald dated November 42000 tells the story, with an element of uncertainty of the new concept, "Invited by Gisborne Mayor John Clarke to look at East Coast regional development, [Anderton] hit on a taskforce approach backed by the "whole-of-government."'249

These combined references illustrate that the concept entered the New Zealand political mainstream from about 1999. By the time that the Review of the Centre was conducted in 2001, there was increasing use and a growing understanding of the concept. In this respect, the Review provided a valuable contribution in detailing, in plain English, the existing framework and rationale behind it. In doing so, it clearly delineated the inherent weaknesses in the existing system and provided a clearly expressed platform for public management reform. It promoted the whole of government approach as a desired objective across all government departments and firmly embedded the notion in official thinking.

An underlying theme was a requirement for integrated service delivery. A central question for the Advisory Group was whether the State Sector was as effective as it should be in providing services to the community. ${ }^{250}$ Another issue that emerged consistently through the review was the "extent of inter-agency cooperation required in the delivery of some services, and the difficulty of achieving coordinated "whole of Government" action."251

The following diagram taken from the RotC provides a discrete summary of the state as at 2001 and the new direction they believed was required. ${ }^{252}$

\footnotetext{
${ }^{248}$ Colin James "Dialogue: Clark and Co Doing Their Best to Prod the Economy," New Zealand Herald January 31, 2001, available at http://www.nzherald.co.nz/nz/news/article.cfm?c_id=1\&objectid=170444 (accessed 6 October 2010).

249 Editorial "Back to the Future, with 2000," The New Zealand Herald 4 November, 2000, available at http://www.nzherald.co.nz/nz/news/article.cfm?c_id=1\&objectid=158608 (accessed 6 October 2010).

${ }_{250}$ Report of the Advisory Group on the Review of the Centre 20.

251 Ibid.

252 Ibid. 19.
} 
Figure 2: The nature of the changes we think are needed is as follows:

\begin{tabular}{|c|c|c|}
\hline Current State & & New Directions \\
\hline $\begin{array}{l}\text { Service Delivery } \\
\text { impediments to inter-agency initiatives } \\
\text { citizens face multiple entry points to } \\
\text { government } \\
\text { poorly developed mechanisms for } \\
\text { devolving responsibility }\end{array}$ & citizen focused & $\begin{array}{l}\text { Service Delivery } \\
\text { responsive, adaptive system } \\
\text { more seamless face of government } \\
\text { technologically sophisticated } \\
\text { better connected with Māori, } \\
\text { communities }\end{array}$ \\
\hline $\begin{array}{l}\text { Tackling fragmentation / } \\
\text { Improving alignment } \\
\text { multiple agencies } \\
\text { plethora of coordination mechanisms } \\
\text { emphasis on specification } \\
\text { ambiguous leadership }\end{array}$ & $\begin{array}{l}\text { relationships } \\
\text { based }\end{array}$ & $\begin{array}{l}\text { Tackling fragmentation / } \\
\text { Improving alignment } \\
\text { fewer agencies, better connections } \\
\text { more purposeful collaboration } \\
\text { clearer leadership - mandated, flexible } \\
\text { long term relationships the norm } \\
\text { fostering trust }\end{array}$ \\
\hline $\begin{array}{l}\text { People and culture } \\
\text { emphasis on individual agencies } \\
\text { passive leadership development }\end{array}$ & $\begin{array}{l}\text { collaborative } \\
\text { people centred }\end{array}$ & $\begin{array}{l}\text { People and culture } \\
\text { greater sense of the State sector whole } \\
\text { opportunity for collective engagement } \\
\text { more proactive leadership development } \\
\text { strong unifying sense of values }\end{array}$ \\
\hline
\end{tabular}

\subsection{Implementation of the Approach in New Zealand}

While the Review of the Centre provided a list of recommendations for Government, there was recognition in the Review that it would take a degree of patience to develop efficient policy and practice. The Report held that to achieve significant change, "There are no simple solutions, or single levers that can be pulled. Progress will be made through finding flexible and responsive ways of working that reflect the particular challenges of each situation." 253 The process would require a certain change in official thinking in combination with in-depth research to establish when, where, how and why the new approach should be implemented.

Since the Review, the whole of government approach has become standard in policy rhetoric. A Google search of "whole of government" within the New Zealand government domain in October 2010 drew over 15,000 hits. ${ }^{254}$ A closer analysis of much of the rhetoric shows that often the term has been used without clear description of what is meant by its use - leading some to describe a 'gap' between

\footnotetext{
253 Ibid. 21.

${ }^{254}$ In total, there were 15,300 hits. Google "Whole of Government" Site:.Govt.Nz, available at http://www.google.co.nz/search?q=\%22whole+of+government\%22+site:.govt.nz\&hl=en\&lr=\&cr=country $\mathrm{NZ \& biw}=1280 \&$ bih=834\&tbs $=$ ctr:countryNZ\&ei=X0iuTJHUK5KinQeeou2BBg\&start=50\&sa=N, (accessed 8 October 2010). 
executive rhetoric and reform changes in practice. ${ }^{255}$ To assess this, it is useful to analyse responses into two paths of action - formal and informal.

\subsubsection{Formal Responses}

A direct outcome of the Review of the Centre was the introduction of new and amending legislation. In December 2003, the Public Finance (State Sector Management) Bill 2003 was introduced into Parliament. The Minister of Finance at the time, Michael Cullen, asserted that: ${ }^{256}$

\footnotetext{
The Public Finance [State Sector Management] Bill is designed to strengthen the public service, make it more transparent and flexible, allow a more integrated response to complex social problems involving a number of state agencies and invigorate the culture of the state sector.
}

Bob Gregory assessed that the legislation was aimed at strengthening 'whole of government' strategic capacity, "by overcoming problems of excessive structural 'fragmentation and 'siloization', and the weakening of longer-term executive and managerial capability, and the attenuation of a coherent state sector ethos." ${ }^{257}$ The Bill made amendments to three existing Acts (the State Sector Amendment Act 2004, the Public Finance Amendment Act 2004 and the State Owned Enterprises Act 2004) and created a new Act - the Crown Entities Act 2004. On 25 January 2005, all four Acts came into effect.

The legislative changes were designed to strengthen integration, build capability and provide stronger leadership on values and standards as well as developing future leaders in the wider public sector. ${ }^{258}$ The Crown Entities Act was intended to achieve better alignment between Crown entities and government objectives. In addition, the new legislation was geared towards more effective wholeof-government coordination and increased integration of Crown entities into the rest of the state sector. ${ }^{259}$ These changes also had an integral role in cementing the government's intention to drive the whole-of-government collaboration. As will be

\footnotetext{
${ }^{255}$ Gregory, "Theoretical Faith and Practical Works: De-Autonomizing and Joining-up in the New Zealand State Sector."

${ }^{256}$ Hon Dr Michael Cullen, "Setting the Benchmark for Public Management" (3 December 2003), available at http://www.beehive.govt.nz/release/setting-benchmark-public-management, (accessed 31 December 2010).

${ }^{257}$ Gregory, "Theoretical Faith and Practical Works: De-Autonomizing and Joining-up in the New Zealand State Sector," 138.

258 Jonathan Boston, "State Sector Reform and Renewal in New Zealand: Lessons for Governance". 259 Ibid.
} 
seen later, this was not restricted to domestic affairs - it was formative in the implementation of the approach in New Zealand's peace support operations.

Bob Gregory wrote that the changes reflected the "contemporary fascination" with collaborative government and argued that they would not be a panacea for the weaknesses of the NPM reforms. His argument stemmed from the belief that the political influence of the neo-liberal reforms of the 1980s and 1990s, which was based on the desire to reduce the ability of the state to 'intervene' in the social and economic marketplace, endured in New Zealand. He argued that the centre had shifted to the right because of the vulnerability of the deregulated New Zealand economy to globalisation and the portability of international capital. ${ }^{260}$ The 2004 reforms, Gregory claimed, "indicated no resolve on the part of the centre-left government to radically reverse that intention." 261

More recently, the National Government has been active in continuing the development of an integrated public sector. On 11 December 2010, Minister of State Services, Hon Tony Ryall announced the passing under urgency of the Research, Science and Technology Bill, the National Library of New Zealand (Te Puna Mātauranga o Aotearoa) Amendment Bill, and the Public Records Amendment Bill. Ryall argued that the legislation was "an important step towards improved service delivery at a reduced cost, and a more future-proofed State sector". ${ }^{262}$ The stated aim of the Bill was to "amalgamate a number of existing agencies to achieve gains in terms of financial efficiencies, effectiveness, and future viability of agencies". ${ }^{263}$ The Bills merge the Ministry of Research, Science and Technology and the Foundation for Research, Science and Technology into the new Ministry of Science and Innovation, and the National Library and Archives New Zealand into the Department of Internal Affairs. ${ }^{264}$ It was claimed that once the transitions were complete, the three structural changes (including the Ministry of Agriculture and Forestry and Food Safety Authority) would deliver approximate savings of $\$ 25$ million over the period to $2013 / 14 .^{265}$

\footnotetext{
${ }^{260}$ Gregory, "Theoretical Faith and Practical Works: De-Autonomizing and Joining-up in the New Zealand State Sector," 152.

261 lbid.

${ }^{262}$ Minister of State Services Hon Tony Ryall, "State Sector Management Bill Passed" (11 December 2010), available at http://www.scoop.co.nz/stories/PA1012/S00207/state-sector-management-billpassed.htm, (accessed 02 January 2011).

263 State Sector Management Bill 2010 193-1, Explanatory note.

264 Hon Tony Ryall, "State Sector Management Bill Passed".

265 Ibid. 
This is in direct line with the National Government's focus on reducing expense of the public sector while seeking better value for money. The Research, Science and Technology Bill received little attention by the media although the structural changes were significant. The lack of media may not be surprising; the Bill was fully supported by all parties in parliament (except the Green Party). ${ }^{266}$ In effect, the changes are in line with the former Labour government's desire to increase collaboration and integration in the public sector. The only disagreement from the opposition came in the merger of Archives New Zealand and the National Library into the Department of Internal Affairs. Labour stated in their Minority Report: 267

\footnotetext{
We believe that this merger will undermine vital components of our constitutional and democratic infrastructure by reducing their independence, the influence of the Chief Archivist and National Librarian and the confidence of the New Zealand public in these institutions.
}

Labour's opposition therefore came in a constitutional argument rather than opposition to the desire for increased efficiency and reduction of expense.

While vastly different in content and scope, the 2004 and 2010 legislative changes are interesting in examining the differences in the language used to 'sell' the legislation to the public. This is salient when assessing the underlying motivation for government to promote a whole-of-government approach. Cullen's 2003 press release spoke of 'transparency' and of 'complex social problems', as well as 'values, and cultures' - there was no mention of economic factor. ${ }^{268}$ In contrast, Ryall's 2010 press release referred to 'reduced costs', and the need to 'deliver services in existing baselines' and to 'future proof service delivery' - with no mention of social factors. ${ }^{269}$ The difference between these is clear with respect to the message: the National government is concerned with promoting a perception of efficient economic management of the public sector where the Labour party was concerned with perception of good management of increasingly complex social issues. Of particular note for this thesis is that this difference in language has been replicated in New Zealand's peace support operations. While there had been awareness by the National government of the complexity of the operating environment, there is an enhanced focus on 'value for money' in which the whole-of government approach is

\footnotetext{
${ }^{266}$ The Research, Science, and Technology Bill passed by 103 votes to 6 with the Greens opposing. The remaining bills passed by 65 to 54 with Labour and the Greens opposing.

${ }^{267}$ Education and Science Committee State Sector Management Bill Commentary $(193-2,2010)$ available at http://www.parliament.nz/NR/rdonlyres/D77162A7-14F0-4CAC-9BE56A8E03E23BCB/170250/DBSCH_SCR_4917_StateSectorManagementBill1932_7957_.pdf (accessed 02 January 2011) 4.

${ }^{268}$ Cullen, "Setting the Benchmark for Public Management".

269 Hon Tony Ryall, "State Sector Management Bill Passed".
} 
the tool of choice. Both Parties are using the same tool - though justifying that use in very different terms.

The 2010 changes were not simply a return to rational choice economic neoliberalism of the 1980s. While the National Party is much more comfortable than Labour using the language of economics (terms like value for money, efficiency and cost reduction have become mantras), they are in fact much closer to the underlying public management theme of the previous government than may be expected. Both National and Labour spoke about integrated approaches to public management within the press releases of their structural changes. National refers to 'outcomes' rather than 'outputs' as established by Labour. ${ }^{270}$ Many of the recent policy changes by the Government have been focused towards whole-of-government reforms to increase efficiency. ${ }^{271}$ Justice Minister Simon Power and Maori Affairs Minister Pita Sharples outlined a clear example in late 2009 when announcing a whole-ofgovernment approach to addressing the drivers of crime: ${ }^{272}$

\footnotetext{
Though responsibility for reducing crime sits with justice-sector agencies, many of the tools to address the drivers of crime are in other sectors, such as health, education, parenting support, housing, recreation, and economic, social and community development.

The focus will be on improving outcomes by tackling fragmentation, ensuring ministerial and chief executive co-ordination and leadership of the work programme, improving value for money, and improving the relationship between government and the community.
}

Aside from the economic reference to 'value for money', this statement could well have been written by Ministers in the previous Government. Focused on outcomes, it articulated the requirement for linkages between agencies when dealing with complex social issues and the need to reduce fragmentation.

\footnotetext{
${ }^{270}$ See: Hon John Key, "Prime Minister's Speech Notes on Benefit Reform" (23 March, 2010), available at http://www.johnkey.co.nz/archives/910-Prime-Ministers-speech-notes-on-benefit-reform.html, (accessed 02 January 2011), Hon John Key, "Opening Address to Local Government New Zealand Annual Conference" (26 July, 2010), available at http://www.johnkey.co.nz/archives/1001-Openingaddress-to-Local-Government-New-Zealand-Annual-Conference.html, (accessed 02 January 2011), Judith Collins Bill English, "NZ's First Ppp Prison to Be Built at Wiri" (14 April 2010), available at http://www.beehive.govt.nz/release/nz039s-first-ppp-prison-be-built-wiri, (accessed 02 January 2011). ${ }^{271}$ See for example: Paula Bennett, "High Trust Contracting Roll-out Continues" (3 March 2010), available at http://www.beehive.govt.nz/release/high-trust-contracting-roll-out-continues, (accessed 02 January 2011).

${ }^{272}$ Hon Simon Power and Hon Dr Pita Sharples, "Drivers of Crime a Whole-of-Government Priority" (17 December 2009), available at http://www.beehive.govt.nz/release/drivers-crime-whole-governmentpriority, (accessed 02 January 2011). 
It is clear that the National-led government is focused upon raising productivity and cost reduction of the public sector - though arguably that has been somewhat stimulated by the global financial crisis. What has not been very well articulated by the National government is how reducing costs and placing an emphasis on service delivery at the 'front-lines' will in-practice lead to improved outcomes when dealing with complex 'wicked problems'. However, this may also be inherent in their argument - to focus on efficiency at the service delivery level under increasingly tight budgets demands closer integration and collaboration between departments and sectors. The question is how to move from policy to implementation?

\subsubsection{Informal Responses}

In 2008, the Institute of Policy Studies (IPS) at Victoria University of Wellington undertook a project looking into collaboration within government. The Better Connected Services for Kiwis incorporated both academic and practitioner perspectives on what was happening at the service delivery level (or 'front lines' in contemporary phrasing) in the New Zealand public sector. ${ }^{273}$ Emphasis was placed on the practical experience of front-line staff and managers and this was the first original published research in New Zealand on what is happening with interagency service delivery. One of the key discoveries was that ad hoc collaboration, rather than institutionalised frameworks, were responsible for much of the current whole of government activity at the service delivery level. As will be seen in the next chapter, the IPS findings have specific relevance to New Zealand's whole-of-government approach to peace support operations.

The IPS research established that there was significant support throughout the New Zealand public sector for increased collaboration. This was defined as not just 'co-existence' (working alone), 'communication' (talking together), 'co-operation' (getting together) or 'co-ordination' (working together), but a further step: namely 'collaboration' (sharing work). ${ }^{274}$ It was contended that one mode was not inherently superior to the others, but that the nature of the work involved and the goal sought would determine which was most appropriate. However, working collaboratively was desirable when the so-called 'wicked issues' and 'complex problems' were being dealt with. In these cases the 'standard operating procedures' were not sufficient and

\footnotetext{
${ }^{273}$ Better Connected Services for Kiwis Institute of Policy Studies, Victoria University of Wellington, available at http://ips.ac.nz/events/completed-activities/joiningup.html, (accessed 11 October).

${ }^{274}$ Derek Gill Bill Ryan, Elizabeth Eppel and Miriam Lips 'Managing for Joint Outcomes: Connecting up the Horizontal and the Vertical,' Policy Quarterly 4, no. 3 (2008): 15.
} 
no one person or agency had all the knowledge or resources. The project found that, "since 'no system will connect you up', 'the right kinds of connections with the right kinds of people have to be created'.."275

The research team learnt that the problem of working together effectively to achieve results was multifaceted and defied attempts to produce simple cookbook of key steps. ${ }^{276}$ Rather, the real successes often came through ad hoc responses after an "a ha" moment of realisation that existing responses were inadequate. ${ }^{277} \mathrm{~A}$ "public entrepreneur" was often pivotal in this. These individuals are willing to step outside of the existing constraints and use their horizontal and vertical networks to achieve results. ${ }^{278}$ They were aided by senior figures, the so-called "guardian angels", who recognised and supported the ability of these entrepreneurs. The final part in this was the "fellow travellers", who were like-minded people that saw themselves working as part of the network on a common problem. ${ }^{279}$

In outlining these factors, the project observed that current 'joined-up working' overwhelmingly relied on "creative and energetic" individuals rather than institutionalised frameworks. They found that the public entrepreneurs did not see themselves as having the solutions, but identified issues that no single agency could solve and built an interagency network to develop new perspectives and approaches to addressing them. ${ }^{280}$ These individuals' personalities, leadership style, and record of accomplishment, provided the essential building blocks to set up an interagency process. ${ }^{281}$ However, the project also discovered that: ${ }^{282}$

\footnotetext{
In practice, there is only limited organisational support for this approach, although there is a lot said about collaboration, joined-up government, and inter-sectoral working. What is lacking is a system-wide understanding of what is involved, when it might be worth the effort, and how it should be initiated and supported.
}

The research found that these entrepreneurs were reliant on their guardian angels, but such individuals were not always forthcoming:

\footnotetext{
275 Ibid.

${ }^{276}$ Derek Gill Elizabeth Eppel, Miriam Lips, Bill Ryan Better Connected Services for Kiwis: Discussion Document for Managers and Front-Line Staff on Better Joining up the Horizontal and the Vertical (Institute of Policy Studies, School of Government, Victoria University of Wellington 2008) available at http://ips.ac.nz/events/completed-activities/joiningup/Connected\%20Services\%20ver\%2010.pdf.

277 Ibid. 6.

278 Ibid.

279 lbid

280 lbid. 24

${ }^{281}$ Ibid.

282 Ibid. 
Frustration and discouragement were traced back to 'risk-averse organisations and managers', senior managers who are 'busy managing upwards and not for outcomes', the dangers of 'putting your head above the parapet', the 'culture of busy-ness', and so on. A 'lack of leadership', a 'lack of permission' and a 'lack of reward' were also identified.

Therefore, many of the significant problems with increased collaboration were judged not to do with structures or budgetary silos, but were often the 'soft issues'. These were issues such as organisational cultures, values and routines, professional beliefs, as well as institutional values and preferences. ${ }^{283}$ These findings were reinforced by Australian policy analysis in 2007: 284

\footnotetext{
In the past, the outcomes we are now looking to achieve from whole of government activity were mostly pursued through organisational restructuring and machinery of government changes. What is new is that today's whole of government approaches tend to look primarily to the development of organisational cultures, capabilities and relationships that support, model, understand and aspire to whole of government solutions.
}

The value of the IPS research is that it clearly identifies the challenges involved with whole of government working at the service delivery level. Add to this the growing literature on the requirement for culture change throughout the levels of government, there is an opportunity to outline a set of factors and conditions for a more effective whole-of-government approach.

\subsection{Conclusion}

In 2000, Brewer and Seldon wrote, "Organizational performance is a socially constructed phenomenon that is subjective, complex, and particularly hard to measure in the public sector". ${ }^{285}$ Measurement is made somewhat more difficult when approaching complex social issues that require multiple-agency responses over extended timeframes. This is no different to the measurement of management of the contemporary complex peace support operations. Brewer and Seldon state, quite accurately, that: ${ }^{286}$

\footnotetext{
283 Bill Ryan, 'Managing for Joint Outcomes: Connecting up the Horizontal and the Vertical.'

284 Briggs, "A Passion for Policy," 9.

285 Gene A. Brewer and Sally Coleman Selden, 'Why Elephants Gallop: Assessing and Predicting Organizational Performance in Federal Agencies,' Journal of Public Administration Research and Theory 10, no. 4 (2000): 688. 286 Ibid.
} 
Previous research has tended to focus on narrow, efficiency-related measures of performance ... Such narrow measures of performance can produce misleading conclusions about organizational effectiveness. Finally, researchers typically impose their own definitions of organizational effectiveness. Yet they should not impose an arbitrary set of indicators; rather, they should ask "effectiveness from whose perspective"?

The 2001 Review of the Centre and subsequent 2004 legislation set the scene and provided the direction for public management into the $21^{\text {st }}$ century. These changes were clearly aimed at the structural weaknesses in the NPM reforms. The legislation was critical in shaping the government's agenda in addressing the increasingly complex 'wicked problems'. The changes were directed at enhancing the potential of the public sector to respond to these challenges by increased integration, collaboration and institutional culture changes towards a whole of government approach.

What does appear to have been lacking, if the IPS research is accurate, is a concentration on how to implement these changes more effectively at the service delivery level. While there are formal whole of government procedures at the senior levels (Cabinet, the DESC system, and inter-departmental committees for example), the front-line staff and managers lack institutional assistance and tangible incentives to join-up. Again, this is the same in external operations; the Domestic and External Security Coordination system is arguably an efficient whole-of-government tool for policy development - where there is a requirement for extensive investigation is how well agencies and individuals join-up at the service delivery level.

The various legislative changes made by the National Government indicate an intention to strengthen service delivery by a rhetorical concentration on the 'font lines'. Ministers have turned the terms 'efficiency' and 'front line' into mantras as they have justified job losses and restructuring within the wider public sector. The wholeof-government approach is being used as a tool to drive efficiency - much as the previous Labour government sold the whole-of-government approach as a tool to resolve complex issues. What is less certain is whether the current government will be more successful at identifying the correct methods or management instruments to achieve their aims.

The literature indicates that key obstacles to effective and efficient whole-ofgovernment approach are the 'soft' issues - such as the organisational cultures, 
values, and routines. As public organisations have evolved, they have gradually adapted to internal and external pressure. In a process of institutionalisation, they have developed individual cultural features reflected by their informal norms and values. ${ }^{287}$ To attempt to encourage a rapid transformation of those norms and values will be difficult. To add to the difficulty, there is no 'one size fits all' approach to resolve this problem.

Research has indicated that organisational culture significantly affects the performance of public organisations. ${ }^{288}$ Meyers et al have outlined that the use of management instruments will be more effective in organisations with a goal oriented or customer oriented culture, than in organisations where such a culture is less dominant. $^{289}$ This is very salient, for example, when looking at a WGA to peace support operations where the institutional culture of discipline forces is starkly different from that of civilian agencies.

This research contends that in order to achieve an effective whole-ofgovernment approach institutional cultures of differing agencies need not assimilate but should instead be complementary. ${ }^{290}$ To do so, agencies need to understand the culture of the agencies they are working with - what is their raison d'être, what is their structure, how do they operate, what is their capability and capacity. Individuals within those agencies must understand how they can be of value to the partner organisation in order to leverage the most value from the collaboration. This requires a distinct change in mindset towards a culture of openness and information sharing.

One possible management instrument that may expedite the process, especially so that it permeates through to the front lines, is to ensure that evaluation of officials at all levels takes into account their ability to 'join-up' where required. In theoretical terms, this is referred to as principal agent theory. A branch of economic organisational theory, it advocates the use of result based management incentives and tools to increase agencies' performance. ${ }^{291}$

\footnotetext{
${ }^{287}$ Selznick, Leadership in Administration, cited in, Lægreid, "Democracy and Administrative Policy: Contrasting Elements of NPM and Post-NPM".

288 See: Koen Verhoest Falke Meyers, Eva Beuselinck, "Performance of Public Sector Organizations: Do Management Instruments Matter?" (paper presented at the A performing public sector: the second transatlantic dialogue", Leuven, België, 1-3 June 2006) available at

http://soc.kuleuven.be/io/performance/paper/WS5MS5_Meyers_Verhoest_Beuselinck.pdf (accessed 02 January 2011), Brewer and Selden, 'Why Elephants Gallop: Assessing and Predicting Organizational Performance in Federal Agencies.'

${ }^{289}$ Falke Meyers, "Performance of Public Sector Organizations: Do Management Instruments Matter?".

290 See: Andrea Barbara Baumann, 'Clash of Organisational Cultures? The Challenge of Integrating Civilian and Military Efforts in Stabilisation Operations,' RUSI 153, no. 6 (2008).

${ }^{291}$ See for detailed analysis: Falke Meyers, "Performance of Public Sector Organizations: Do Management Instruments Matter?".
} 
Typically, government employees are assessed by use of an annual (or biannual) performance appraisal. This is what drives their remuneration and career progress. If joint-working and whole-of-government requirements are not explicitly articulated in these appraisals, there is no direct value to the individual employee to meet what is arguably a Government priority. Put simply, individual annual performance appraisals require clearly articulated goals and measurements for their cross-departmental activities so officials are rewarded and recognised for joint working. The IPS research found that certain individuals - the 'public entrepreneurs' were able to identify where they could gain value from networking in order to 'get the job done'. However, by providing real incentives to join-up it is more likely that a greater number of officials will look to see where they can gain value from doing so. While this research does not contend that that is a simple instrument to design and implement, it has the ability to shape thinking towards a whole of government approach. 


\section{Chapter 5: New Zealand's Whole-of-Government Approach to Peace Support Operations}

\subsection{Introduction}

This chapter aims to critically review the whole-of-government approach to New Zealand's peace support operations. It will examine how and why the approach was incorporated into these operations. It will then turn to an examination of the impact of the approach. To do this, the roles of the key departments tasked with New Zealand's offshore operations will be analysed. Within this there will be specific focus on how the whole-of-government approach has affected the drive for increased efficiency and effectiveness. This chapter will build on the argument posted in the previous chapters that a critical factor required for efficient and effective whole-ofgovernment working is culture change.

The research questions that guided this section are:

- What is the background of the WGA in NZ'S PSOs?

- How has the concept been implemented in NZ's PSO's?

- What are the weaknesses or barriers?

- What is required to add value?

\subsection{Overview}

Into the late 1990s, New Zealand's focus on external security began to shift towards the growing instability in the Pacific. By the time of the September 11 attacks in the United States, Australian and New Zealand analysts were alive to the potential links between poverty, conflict, and insecurity. ${ }^{292}$ Those attacks provided a blunt education to those who were not cognisant of the risk of leaving weak and failing states to flounder. The international assistance subsequently provided by New Zealand in the following years was to a large degree motivated by the need to prevent insecurity spilling across international borders and impacting global, regional or national security. During that period, New Zealand has undergone a significant evolution in the nature and management of its assistance to these so-called 'complex' operations.

\footnotetext{
${ }^{292}$ Brown Greater Than the Sum of Its Parts?: Assessing "Whole of Government" Approaches to Fragile States 77.
} 
Since 2001, New Zealand has been involved in complex peace support operations in Timor-Leste, Afghanistan and Solomon Islands. They are termed complex due to the understanding that the assistance required is not merely the traditional notion of security - most often on the form of military assistance. The assistance required runs across all pillars of civil society - economic, law and justice, governance and public administration. As was earlier cited in this thesis, the OECD Fragile States Group argued that successful development in fragile environments strongly relied on "well-sequenced and coherent progress across the political, security, economic and administrative domains". ${ }^{293}$ The outcome of that argument is that failure of one of these pillars risks failure of the others. The interdependence of these domains is analogous to the interdependence of the domains that are required to address the domestic 'wicked problems'. It is not surprising then that officials working towards effective and efficient management of foreign operations have picked up the same tools that have been used to approach management of entrenched domestic issues.

This has been the experience of New Zealand. As these operations have progressed, a growing number of New Zealand departments and agencies began taking on international responsibilities in addition to their domestic portfolios. The question that follows from this is how the whole-of-government approach is being used to coordinate the growing number of agencies involved in today's complex security environment?

\subsection{Whole-of-Government Approach to External Security}

There are a number of government agencies responsible for New Zealand's external security. The following provides an account of the development of the wholeof-government approach in security policy and practice in New Zealand. It illustrates the Domestic and External Security Coordination (DESC) structure that is used for coordinating the efforts of security-related agencies. The DESC system mandates responsibility for external security at four levels:

- The Cabinet Committee on Domestic and External Security Co-ordination (DES) and External Relations and Defence Committee (ERD)

\footnotetext{
${ }^{293}$ OECD Whole of Government Approaches to Fragile States 13. 
- The Officials Committee for Domestic and External Security Co-ordination (ODESC);

- The Security Risk Group (DPMC), and;

- The individual agencies involved in national security.

\subsubsection{Cabinet and Cabinet Committees}

New Zealand's has a unicameral Westminster style of government. The Cabinet, which is chaired by the Prime Minister, makes high-level policy decisions and sets direction. Often, Cabinet delegates power to act on specific areas to the relevant Cabinet Committees. Decisions made by those Committees must be tabled at the next Cabinet meeting - and all Ministers are bound under the convention of collective responsibility to publicly support all decisions. Structurally, this is an effective and efficient whole-of-government system at the senior strategy level of government. In effect, this system, which has been operating for decades, is an example of where 'whole-of-government' has been operating.

When an issue arises where the United Nations or a host Government may request New Zealand to assist in a complex peace support operation, Cabinet and its Cabinet Committees, is the executive decision-making body.

Domestic and External Security Co-ordination (DES)

The Cabinet Committee on Domestic and External Security Co-ordination (DES) is the central decision-making body of executive government for issues involving intelligence, security, and crisis management. ${ }^{294}$ The Prime Minister chairs the committee, and its members are drawn from those Ministers with portfolio responsibilities for key agencies involved in national security or depending on the needs of any specific crisis. The Committee's Terms of Reference are: ${ }^{295}$

\footnotetext{
${ }^{294}$ Managing Threats to Domestic Security (Report of the Controller and Auditor-General, 2003) available at http://www.oag.govt.nz/2003/domestic-security/docs/domestic-security.pdf (accessed 10 January 2011) 31.

${ }^{295}$ DPMC Cabinet Committees Cabinet Committee on Domestic and External Security Co-Ordination (DES), Department of the Prime Minister and Cabinet, available at

http://www.dpmc.govt.nz/cabinet/committees/des.html, (accessed 11 January 2011).
} 
To co-ordinate and direct the national response to a major crisis or to circumstances affecting national security (such as a natural disaster, biosecurity problem, health emergency, or terrorist/military threat) within New Zealand or involving New Zealand's interests overseas;

To consider issues of oversight, organisation and priorities for the New Zealand intelligence community and any issues which, because of their security or intelligence implications, the Prime Minister directs be considered by the committee;

To consider policy and other matters relating to domestic and external security coordination.

This committee has power to act where there is a need for urgent action and/or operational or security considerations demand it.

\section{External Relations and Defence Committee (ERD)}

The External Relations and Defence Committee meet every second week to consider policy and other matters relating to foreign affairs, international trade, development assistance, and defence. ${ }^{296}$ The Committee comprises Ministers form Defence, Disarmament and Arms Control, Foreign Affairs, Police and Trade. The Committee maintains authority over ongoing issues relating to external security.

Decisions of the committees under power to act are reported to the next Cabinet meeting as appropriate. ${ }^{297}$ Again, structurally, this system provides for an efficient whole-of-government repose to an urgent issue at the senior level of government.

\subsubsection{ODESC}

Under the Cabinet Committees sits the Officials Committee for Domestic and External Security Coordination (ODESC). As outlined by the Auditor General, this Committee facilitates a whole-of-government approach to national crises and issues affecting security, such as New Zealand's peace support operations. ${ }^{298}$ ODESC is a chief executive level forum in which agencies come together to establish whole-of-

\footnotetext{
${ }^{296}$ DPMC Cabinet Committees Cabinet External Relations and Defence Committee (ERD), Department of the Prime Minister and Cabinet, available at http://www.dpmc.govt.nz/cabinet/committees/erd.html, (accessed 11 January 2011).

${ }^{297}$ DPMC Cabinet Committees Cabinet Committee on Domestic and External Security Co-Ordination (DES),

${ }^{298}$ Managing Threats to Domestic Security 31. 
government approaches to national security. It provides strategic policy advice to the Prime Minister and exercises policy oversight in the areas of intelligence and security, terrorism, maritime security and emergency preparedness. ${ }^{299}$ It comprises a generic committee with flexible membership, which mainly deals with response and recovery issues for specific events or issues. ODESC has two standing committees ODESC(P) for continuing policy, planning and preparedness, and ODESC(I) for intelligence matters.

Membership of ODESC comprises Chief Executives from the Ministry of Foreign Affairs and Trade, the Defence Force, Ministry of Defence, NZ Security Intelligence Service, Government Communications Security Bureau, NZ Police, Ministry of Civil Defence \& Emergency Management, Treasury and others as and when necessary. The Chief Executive of DPMC chairs the group. ${ }^{300}$

\subsubsection{The Department of the Prime Minister and Cabinet}

The Department of Prime Minister and Cabinet (DPMC) is one of the central agencies responsible for coordinating and managing public sector performance. ${ }^{301}$ It serves the Executive (the Prime Minister, the Governor-General, and Cabinet) through the development of impartial advice and support services that assist government decision-making at both strategic and operational levels. ${ }^{302}$ DPMC comprises apolitical officials who do not change with a change in the administration. The Rt Hon Sir Geoffrey Palmer has argued that: ${ }^{303}$

\footnotetext{
The injection of these elements of political management into the relationship between ministers and the public service has added another layer of checks in the system of inputs to decision making that must be taken into account. The result has been to add complexity to the process and to increase the time taken to make decisions, but it also means there is less chance of unintended political consequences flowing from the decisions when they are taken.
}

\footnotetext{
${ }^{299}$ Security \& Risk Group, Department of the Prime Minister and Cabinet, available at http://www.dpmc.govt.nz/dess/index.htm, (accessed 09 January). 300 Ibid.

${ }^{301}$ DPMC About DPMC, Department of the Prime Minister and Cabinet, available at http://www.dpmc.govt.nz/dpmc/index.htm, (accessed 09 January).

${ }^{302}$ NZDF Statement of Intent for the Period 1 July 2006 to 30 June 2009 (New Zealand Defence Force, 2006) available at http://www.nzdf.mil.nz/downloads/pdf/public-docs/nzdfsoi2006.pdf (accessed 08 January 2011).

${ }^{303}$ Geoffrey Palmer, 'The Cabinet, the Prime Minister and the Constitution: The Constitutional Background to Cabinet,' New Zealand Journal of Public and International Law 4, no. 1 (2006): 14.
} 
Within DPMC, the key security related body is the Security and Risk Group (SRG). ${ }^{304}$ The SRG is responsible for national security threats that affect New Zealand and its interests, both domestic and foreign. SRG coordinates the activities of central government agencies in preparing for and responding to security crises, emergencies and natural disasters. The SRG provides leadership and coordinates central government activities aimed at protecting New Zealand's domestic and external security, including intelligence, counter-terrorism preparedness, emergency/crisis management and defence operations. ${ }^{305}$ It oversees agencies that have operational responsibilities for managing security risks, and has a central role in overseeing the preparation of overarching national security strategies.

The SRG provides advice and support to ODESC and convenes interdepartmental watch groups to monitor major issues and to provide oversight for interagency action. In the event of a crisis or emergency affects New Zealand's interests, a watch group is formed of senior officials from relevant departments to monitor and advise the government on the situation. The SRG monitors the development of overarching national strategies and provides leadership in creating policy and coordinating the interagency response to actual events. The SRG coordinated the whole of government approach to respond to events such as the Fiji coups, the September 11 attacks, the Timor-Leste crisis and the possibility of conflict between India and Pakistan. ${ }^{306}$

In 2010 the Chief Executive of DPMC, Maarten Wevers, indicated that two of DPMC's business units, the National Assessments Bureau and the SRG would be moving premises. They would be collocating with staff from the GCSB to "improve the performance of and coordinate the government's security and intelligence agencies." ${ }^{307}$ It was stressed that the move would be one of a number of steps being taken, including "working more closely together and better aligning the activities of a number of agencies, which have external, and domestic security responsibilities." ${ }^{308}$ Another of these steps has been the SRG taking the lead on the development of a national security framework. ${ }^{309}$ The 2010 DPMC Statement of Intent detailed that the

\footnotetext{
${ }^{304}$ The Security and Risk Group, formally the Domestic and External Security Group, was renamed in 2010.

${ }^{305}$ NZDF Statement of Intent for the Period 1 July 2007 to 30 June 2010 (New Zealand Defence Force, 2007) available at http://www.nzdf.mil.nz/downloads/pdf/public-docs/2007/NZDF-SOI-07-08.pdf (accessed 09 January 2011).

306 Security \& Risk Group,

307 DPMC Statement of Intent 2010-2014 (Department of the Prime Minister and Cabinet, 2010) available at http://www.dpmc.govt.nz/dpmc/publications/soi-dpmc-2010-14.pdf (accessed $10 \mathrm{January}$ 2011) 5 .

308 Ibid.

309 Ibid. 
work will delineate the "foundations and organisational arrangements for managing national security issues, and will support the process of determining which security issues are of national significance." ${ }^{310}$ This is a clear indication of government priority to better synthesise the collective roles of the departments tasked with the maintenance of New Zealand's security sector. It very neatly reflects the argument cited by Christensen and Lægreid in Chapter Two, of the "importance of governments' avoiding contradictory outcomes and ensuring that information is shared between agencies." ${ }^{311}$

DPMC and especially SRG form a vital link in efficient and effective whole-ofgovernment approach to national security at the policy and programme development level. The SRG is central in this endeavour; it coordinates policy advice and provides oversight for the variety of departments engaged in national security. It is located within walking distance of all these departments in Wellington - which promotes effective and efficient socialisation of relevant individuals. The following figure provides an overview of New Zealand's security and intelligence structural framework.

Below the senior strategy levels of New Zealand governance are the individual departments - of the bottom three levels public management. ${ }^{312}$ These departments merge the bureaucratic, (policy and programme development), organisational (programme management) and the local (service delivery) levels. Within a whole-of-government approach, each of these levels are required to work horizontally across departments - rather than solely within their vertical hierarchy. Traditionally, it has been the military who has taken the lead in New Zealand's external security. Traditionally, it could be argued that within the disciplined hierarchical structure of a military, working horizontally is an anathema. However, it was the New Zealand Defence Force who was the first to outwardly promote joinedup approaches to peace support operations.

\footnotetext{
310 Ibid.

${ }^{311}$ See Chapter 2.2, page 11: Lægreid The Whole-of-Government Approach - Regulation, Performance, and Public-Sector Reform.

${ }^{312}$ See for a detailed breakdown of levels of public governance, Hyde, 'How to Make the Rhetoric of Joined-up Government Really Work.'
} 


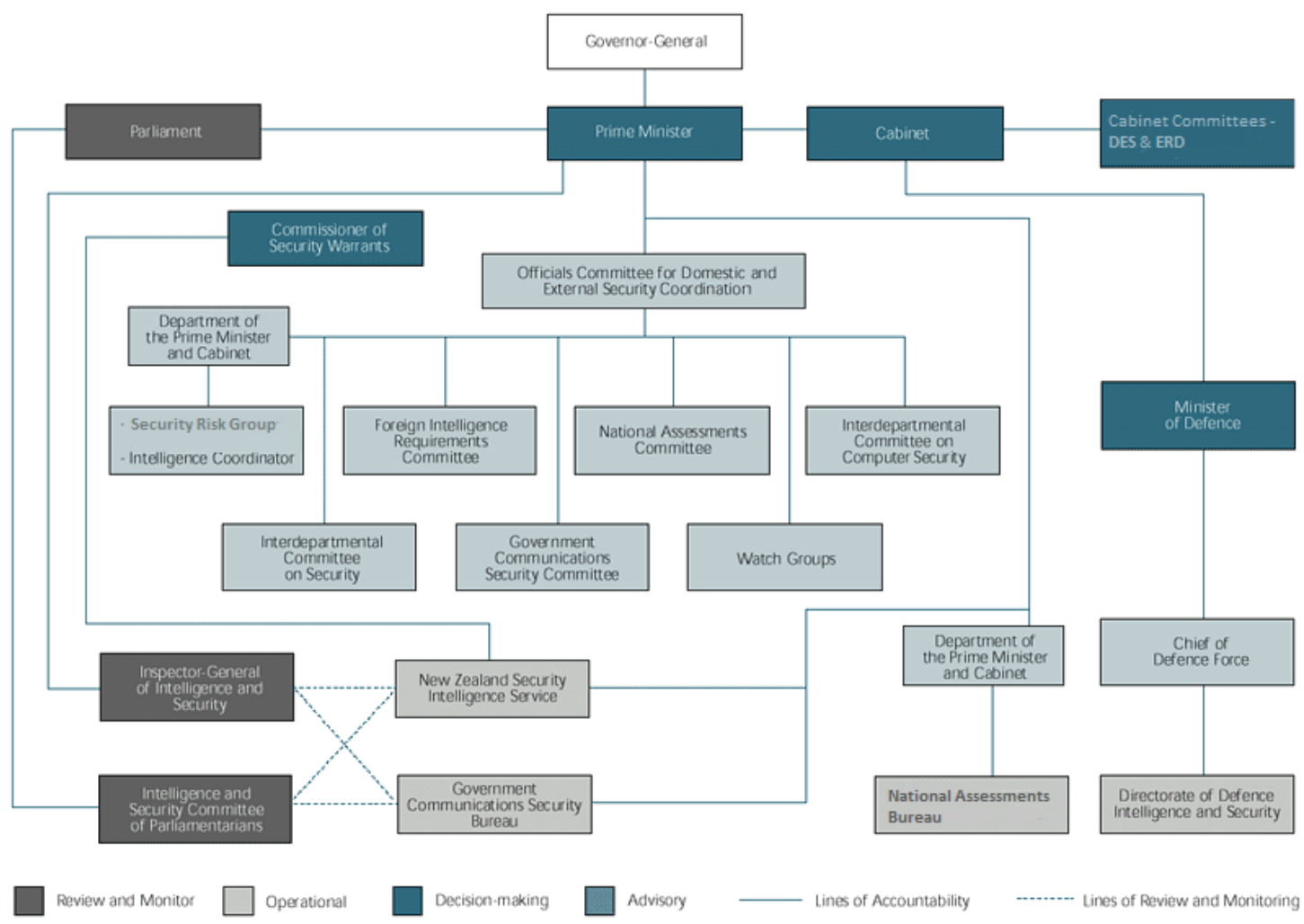

Figure 3: An Overview of New Zealand's Security and Intelligence Arrangements ${ }^{313}$

\subsubsection{New Zealand Defence Force}

The first public indication that a whole-of-government approach was entering the discourse of foreign and security policy came in November 2000. The New Zealand Defence Force Capability Review conducted at that time declared that: ${ }^{314}$

Defence is one aspect of New Zealand's foreign and security policy (see DPF) New Zealand can best contribute to regional security and global peace by promoting a comprehensive security approach which utilises policies and resources based on a "whole of government" approach.

The Defence Policy Framework (DPF) referred to above had been published the previous June (2000). It had stated that: ${ }^{315}$

\footnotetext{
${ }^{313}$ Adapted and updated from the original: Securing Our Nation's Safety: How New Zealand Manages Its Security and Intelligence Agencies, Department of the Prime Minister and Cabinet, available at http://www.dpmc.govt.nz/dpmc/publications/securingoursafety/overview.html, (accessed 11 January). ${ }^{314}$ New Zealand Defence Force Capability Reviews Phase One - Land Forces and Sealift (The New Zealand Ministry of Defence 2000) available at http://www.defence.govt.nz/reports-publications/nzdfcap-rev/introduction.html.

${ }^{315}$ The Government's Defence Policy Framework (The New Zealand Government, 2000) available at http://www.defence.govt.nz/reports-publications/defence-policy-framework/defpol-frmwrk.html (accessed 04 January 2011) 1. 
Defence policy and foreign policy are a partnership aimed at securing New Zealand's physical, economic, social and cultural well being, and meeting our regional and global responsibilities.

This demonstrated an understanding and desire for the traditionally foreign focused elements of New Zealand government to work in partnership. It is evident that it was an evolving concept at that time and demonstrated that the NZDF was trying to settle on the definition between a 'whole-of-government' and the 'comprehensive approach'. What these statements did not articulate was the requirement to incorporate the non-security focused elements of the government apparatus in order to achieve government security outcomes.

By 2006 the NZDF had refined its definition of the whole-of-government approach. Building on the definition provided in the 2004 Australian Connecting Government Report, ${ }^{316}$ the following succinctly expresses the clear objectives of the notion as well as its justification: ${ }^{317}$

\begin{abstract}
Whole of Government denotes government departments and public service agencies working across portfolio boundaries to achieve a shared goal (or outcome) and an integrated government response to particular issues or situations. Whole of Government expects the State sector to work like a single, integrated organisation, rather than a collection of seemingly independent service providers. Whole of Government approaches work on the assumption that responses (to problems) will be more effective if we combine the efforts of all relevant agencies into a single coordinated strategy.
\end{abstract}

While borrowed from the Australian's, it was useful as it was the first clearly articulated definition of the whole-of-government approach in the New Zealand security sector.

The concept was mentioned in NZDF public documentation over the next several years without much fanfare. ${ }^{318}$ However, as the government moved towards managing for outcomes rather than outputs the use of whole-of-government language markedly increased. This was reflected in the 2005 NZDF Statement of

\footnotetext{
${ }^{316}$ Connecting Government: Whole of Government Responses to Australia's Priority Challenges 2.

${ }^{317}$ NZDF Statement of Intent for the Period 1 July 2006 to 30 June 2009.

318 The 2003 Annual Report outlined with regard to the new military capabilities, "These capabilities are being developed in the context of a whole-of-government approach to security. They will provide options to respond to a range of future security challenges including both conventional threats and emerging challenges such as trans-national threats." See also:

NZDF Foundations of New Zealand Military Doctrine (NZDDP-D) (First Edition, New Zealand Defence Force, 2004) available at http://www.nzdf.mil.nz/downloads/pdf/public-docs/nzddp_2004_web.pdf (accessed 08 January 2011) 6-5, 8.31.
} 
Intent (SOI) where there was a more focused move to asserting the relationship between NZDF and the common and shared outcomes of other public agencies. The SOI signalled, "The relationship that the NZDF has with these other departments and agencies, under the Whole-of-Government approach, is taking on increased importance." ${ }^{319}$ It was the first public document that outlined in a structured way the summary of relationships between NZDF and other agencies. This is a clear indication that NZDF had begun to demonstrate and justify outcomes based on its coordination and collaboration with other departments.

In the 2006 SOI, the NZDF raised the issue of how it would evaluate whole of government outcomes as set by government. It was stressed that the Operational Preparedness Reporting System (OPRES) used to measure the preparedness of the force elements of the NZDF to undertake operations was not suitable for measuring whole of government outcomes. ${ }^{320}$ The SOI argued that the achievement of Defence Outcomes under the approach was often reliant on the contributions from many public departments that had an interest in wider security issues. The NZDF believed that to adequately measure wider security outcomes, higher-level indicators and impact measures were required to encompass input from all relevant sources: ${ }^{321}$

The MoD, DPMC,MFAT, NZ Police, NZ Customs Service, Immigration Service of the Department of Labour, and other departments and agencies involved in the greater "security of New Zealand and its people", and actual decision-making by the Cabinet, all have a significant part to play in determining the coordinated and aggregated indicators and impact measures at this (higher) level.

It will be some time before a robust, truly Whole-of-Government approach on this can be achieved. In the meantime the NZDF will continue to identify the indicators and impact measures that are applicable to Defence contributions to national security - in its widest sense.

This illustrates that NZDF was cognisant of and wanted to outline that they could not be solely responsible for setting or accounting for New Zealand's security outcomes. It was also interesting to note NZDF's admission that New Zealand did not currently have a "robust, truly Whole-of-Government approach on this" and that it would take some time to achieve it.

\footnotetext{
${ }^{319}$ NZDF Statement of Intent for the Period 1 July 2005 to 30 June 2008 (New Zealand Defence Force, 2005) available at http://www.nzdf.mil.nz/downloads/pdf/public-docs/nzdfsoi2005.pdf (accessed 08 January 2011) 36.

${ }^{320}$ NZDF Statement of Intent for the Period 1 July 2006 to 30 June 200923.

321 Ibid. 
What NZDF believed was required was a clear set of indicators and impact measures to be developed that could proved effective and efficient accountability of whole of government working. The development of such indicators appears to have begun in 2009. The above paragraphs, which had been repeated in the 2007 and 2008 SOls were altered in 2009 where the second paragraph read: ${ }^{322}$

\begin{abstract}
While it will be some time before a robust, truly Whole of Government approach on this can be achieved, the Ministry of Defence, in conjunction with the NZDF, is promoting moves in this direction and a project on this, sponsored by the MoD, is progressing.
\end{abstract}

That project, which was being performed on behalf of the Domestic and External Security Committee (DESC), was designed to develop a set of measurable New Zealand Security Sector Outcomes. ${ }^{323}$ The project was put on hold pending completion of the 2010 Defence Review/Defence White Paper although the 2010 SOI highlighted that the project would re-commence and draw on the work of the Defence Review. It was noted that: 324

the intent is that all departments/agencies of government that contribute to the security of New Zealand will be able to show, in measurable terms, how they contribute to the developed set of security outcomes.

The development of a collective set of outcomes and indicators is a vital step. Joint inter-departmental targets to which each relevant department can contribute will reinforce commitment to policy coherence, while an integrated results framework would enable an effective monitoring progress and assess impact. ${ }^{325}$

The NZDF was early to recognise the importance of using a whole-ofgovernment approach in reaching their outcomes. They continually promoted the approach in public documentation throughout the decade and by 2009 had begun work with the Ministry of Defence in designing a set of government security outcomes.

\footnotetext{
${ }^{322}$ NZDF Statement of Intent 2009 - 2012 (New Zealand Defence Force, 2009) available at http://www.nzdf.mil.nz/downloads/pdf/public-docs/2009/soi/nzdf-soi-2009-12.pdf (accessed 22 March 2011) 44.

${ }^{323}$ NZDF Statement of Intent 2010 - 2013 (G55 SOI (2010), New Zealand Defence Force, 2010) available at http://www.nzdf.mil.nz/public-documents/soi/default.htm (accessed 08 January 2011). 324 Ibid.

${ }^{325}$ See for similar findings with regard to New Zealand's whole-of-government approach to development: OECD New Zealand (2010) Dac Peer Review: Main Findings and Recommendations (Organisation for Economic Co-operation and Development, 2010) available at http://www.oecd.org/document/54/0,3746,en_21571361_44315115_46730038_1_1_1_1,00.html (accessed 09 January 2011).
} 
The official literature shows that the approach began to take a larger role on the strategic thinking of NZDF around 2006. It was around the same time that it also took hold within the Ministry of Foreign Affairs and Trade. Once MFAT had fully embraced the concept, they quickly took ownership of it and took the external lead.

\subsubsection{The New Zealand Ministry of Foreign Affairs and Trade}

The whole-of-government approach began to be mentioned in official MFAT documentation from the early 2000s, although it became more prominent from 2004. In the only mention of the concept in the 2003 Annual Review, MFAT described that it was "deeply involved" in the development of New Zealand Trade and Enterprise. A key interest in this process, they outlined, "was ensuring that the basis was laid for effective whole-of-government approaches in New Zealand's offshore representation." 326 The 2004 Annual Report took account of global security issues, stating that, "The Government appointed its first Ambassador for Counter-Terrorism to coordinate and focus a whole-of-government approach to the international campaign against terrorism." ${ }^{327}$

The 2004 Statement of Intent observed that the new "managing for outcomes" environment for state sector planning reflected the Government's requirement for broader, more strategic management and the priority it attaches to a whole-ofgovernment effort. ${ }^{328}$ The SOI outlined that Government outcomes for MFAT were set across the security field, in support of economic growth and innovation, to strengthen the international system, to contribute to poverty elimination and to protect New Zealanders abroad. ${ }^{329}$ It is evident that MFAT recognised that it would be required to work across agencies to achieve wide sweeping outcomes. Like NZDF, MFAT highlighted a necessity for efficient coordination between departments and agencies.

\footnotetext{
${ }^{326}$ MFAT Annual Report 2002-2003 (The New Zealand Ministry of Foreign Affairs and Trade, 2003) available at http://www.mfat.govt.nz/Media-and-publications/Publications/Annual-report/index.php (accessed 08 January 2011) 70.

${ }^{327}$ MFAT Annual Report 2003-2004 (The New Zealand Ministry of Foreign Affairs and Trade, 2004) available at http://www.mfat.govt.nz/Media-and-publications/Publications/Annual-report/index.php (accessed 08 January 2011) 5.

${ }^{328}$ MFAT Statement of Intent 2004-2005 (New Zealand Ministry of Foreign Affairs and Trade, 2004) available at http://www.mfat.govt.nz/Media-and-publications/Publications/Statement-of-intent/index.php (accessed 08 January 2011) 5.

329 Ibid. 
The 2004 SOI provided a description of one of the key pillars in this enhanced coordination of government agencies working abroad. The External Relations and Defence network, which the Chief Executive of MFAT chaired, was comprised of over 30 agencies involved in managing and implementing the Government's external policies. ${ }^{330}$ The Chief Executives of those departments and agencies meet every six months to ensure there is effective inter-agency information flow and coherent policy development on work with an external dimension. ${ }^{331}$ The Network comprises numerous inter-agency sub-groups on specific issues, ranging from cooperation with the New Zealand Defence Force in peace support operations, to joint activities with New Zealand Trade and Enterprise to advance the internationalisation of New Zealand business. ${ }^{332}$

The SOI stated that in December 2003 the ERD Chief Executives "restated their commitment to cooperate, consult, collaborate and coordinate with the aim of delivering a more cohesive effort in international activities." ${ }^{333}$ This came at a time when a growing number of government agencies had begun establishing an offshore presence. In order to maximise the impact of this combined presence, MFAT took ownership of supporting and coordinating these interrelated commitments. The following year's SOI (2005) was the first to put this coordination into its current moniker - "NZ Inc". ${ }^{334}$ The new term covered the full spectrum of New Zealand's offshore commitments - from immigration to police liaison posts. Peace support operations were a sub-section of this larger grouping, though would take on increasing importance as the contributions to these operations became more civilian focused.

\footnotetext{
${ }^{330}$ Departments and agencies represented in the ERD network are Agriculture and Forestry and its Food Safety Authority, Conservation, Culture and Heritage, Customs, Defence, the Defence Force, Economic Development, Education, Environment, Fisheries, Foreign Affairs and Trade, Immigration Service, Inland Revenue, Internal Affairs, Labour, National Library, Pacific Island Affairs, Police, Prime Minister and Cabinet, Research Science and Technology, New Zealand Security Intelligence Service (NZSIS), Te Puni Kokiri, Tourism, Trade and Enterprise, Transport and the Treasury: Ibid. 331 Ibid.

${ }^{332}$ MFAT Post-Election Brief 2008 (NZ Ministry of Foreign Affairs \& Trade, 2008 ) available at http://www.mfat.govt.nz/downloads/media-and-publications/peb-nov2008.pdf (accessed 22 March 2011) 4.

${ }_{333}^{4.3}$ MFAT Statement of Intent 2004-2005 54.

${ }^{334}$ MFAT Statement of Intent 2005-2008 (New Zealand Ministry of Foreign Affairs and Trade, 2005) available at http://www.mfat.govt.nz/Media-and-publications/Publications/Statement-of-intent/index.php (accessed 08 January 2011) 15.
} 
By 2006 Cabinet had identified the trend of increasing offshore engagements by New Zealand agencies and were keen to maximise efficiency and effectiveness. MFAT defined this increased commitment in the 2006/7 Annual Review: ${ }^{335}$

\begin{abstract}
As international developments and cross-border issues continue to impact on domestic policy, more government agencies are deploying staff offshore. Staff from other government agencies now comprise one-third of all New Zealand-based staff at our overseas posts. One way in which New Zealand can multiply the reach and impact of its external engagement is through increased policy cohesion and cooperation among the agencies working offshore.
\end{abstract}

To increase New Zealand's effectiveness and efficiency, Cabinet directed that guidelines be prepared to "ensure agencies do not work in separate silo operations, but have mechanisms in place for identifying opportunities and responding with whole-of-government approaches and initiatives when this is in New Zealand's best interest." ${ }^{336}$ The 2007 Annual Review indicated that this request had been addressed by detailing the development of the formal Framework for NZ Inc Operations Offshore Charter. Supported by the ERD Network and endorsed by Government in May 2007, the framework consisted of a "shared outcome, values, set of relationship principles, and suggested practices for building more coherent and coordinated operations and strategic alignment among government agencies operating overseas." ${ }^{337}$ MFAT held that its precepts were largely common sense and had already been implemented at many posts where there were multi-agency interests in the bilateral relationship concerned. ${ }^{338}$ NZDF referred to the document in several publications, stating: ${ }^{339}$

\begin{abstract}
The mid-2008 issued "Framework for NZ Inc Operations Offshore Charter" reemphasise the benefits of maximising opportunities and minimising risks for New Zealand through whole of government approaches for advancing national interests and national identity offshore. NZDF Defence Attachés and Advisers are aware of this and will work closely with their respective Heads of New Zealand Missions to advance this approach.
\end{abstract}

The Charter provided that the head of a New Zealand mission in a country would be the senior New Zealand Government official responsible for ensuring NZ Inc

\footnotetext{
${ }^{335}$ MFAT Annual Report for the Year Ended 30 June 2007 (Ministry of Foreign Affairs and Trade, 2007) available at http://www.mfat.govt.nz/downloads/media-and-publications/annualreport/annualreport0607.pdf (accessed 22 March 2011) 6.

${ }^{336}$ Ibid. 20.

337 Ibid.

338 Ibid

${ }^{339}$ NZDF Statement of Intent 2009 - 201244. 
operates in a coherent and aligned way in that location. ${ }^{340}$ While this was a valuable development, the focus was not specifically on peace support operations although it would come to play an increasingly important role.

The 2006/7 Annual Review provided an indication of the development of the approach and MFAT's increased role in peace support operations. The Overview at the beginning of the Review stated that: ${ }^{341}$

Increasingly, responses to complex security situations have required the Ministry to work closely with other agencies on whole-of-government responses to inter-agency deployments. New Zealand continued to manage deployments to the Solomon Islands, Timor-Leste, and Afghanistan in 2006/07.

In the 2007/8 Annual Review, the importance was restated: ${ }^{342}$

New Zealand continued to contribute significantly to international peace support operations. Currently about 400 New Zealand Defence Force (NZDF) and 75 New Zealand Police personnel are deployed on 12 peace support missions in 14 countries. New Zealand's largest missions are in Timor-Leste, Afghanistan, and the Solomon Islands.

One way that MFAT has provided support and coordination for agencies involved in peace support operations in Timor-Leste and Solomon Islands is through weekly NZ Inc meetings chaired by the head of mission. All New Zealand agencies involved in the operation are invited to attend. This provides a very useful forum for sharing information and identifying synergies at the programme management level.

With the change of Government on 2008 the New Zealand Foreign Affairs and Trade Post-Election Brief - November 2008 indicated again the importance of coordination in New Zealand's peace support operations. The Brief illustrated that: ${ }^{343}$

Engagement in support of fragile states requires a balance between security, political and development interventions, and a corresponding need for coordination between, and within, governments. New Zealand has implemented a whole-of-Government approach to engagement in the three complex integrated operations in the Solomon Islands, Timor-Leste and Afghanistan.

\footnotetext{
340 Ibid.

${ }^{341}$ MFAT Annual Report for the Year Ended 30 June 2008 (Ministry of Foreign Affairs and Trade, 2008) available at http://www.mfat.govt.nz/downloads/media-and-publications/annual-report/ar-mfat-200708.pdf (accessed 22 March 2011) 11. 
MFAT outlined that they had developed a series of 'sub-sectoral Pacific security strategies' to inform the whole-of-government engagement in the Pacific by New Zealand agencies. This was a clear indication that these operations required a deeper and extended civilian component to compliment NZDF's contributions something that NZDF had been requesting since 2000.

The following several years saw a distinct shift in the National-led government's thinking towards more economic focus in management of MFAT. In response to the government's strong desire to get better outcomes and efficiencies from New Zealand agencies working offshore, MFAT began work on developing processes to enhance NZ Inc coordination. This flowed into a major review led by the Ministries offshore network that was scheduled for 2009/10.

The official literature shows that MFAT began using whole-of-government rhetoric from early in the decade. The use of the concept drove the formulation of NZ Inc as a collective identify offshore as well as the Framework for the effective and efficient coordination of $N Z$ Inc Operations Offshore. The External Relations and Defence Network, which is owned by MFAT, is a central component at the policy and programme development level. The sub-committees and inter-departmental teams that flow from the ERD further strengthen joined-up working. The Framework provides that New Zealand's head of mission in a country is responsible for ensuring NZ Inc runs effectively and efficiently. What the public literature is silent on is how well the 'front line' staff are working together within NZ Inc. A question that arises is whether the same barriers - the soft issues - that pervade joined-up working in domestic public management are an issue within NZ Inc offshore.

\subsubsection{The Requirement for a Whole-of-Government National Security}

\section{Statement}

In 2003, the report on Managing Threats to Domestic Security found that the DESC structure provided an effective mechanism for establishing a whole-ofgovernment response to domestic security matters. ${ }^{344}$ While this was a positive outcome, the Report also found the system would substantially benefit from an

\footnotetext{
${ }^{344}$ Managing Threats to Domestic Security 37.
} 
overarching strategic domestic security framework to guide the work of the many agencies involved; it argued that: ${ }^{345}$

A whole-of-government strategy for domestic security needs to be prepared to ensure that the efforts of the various agencies are being combined to achieve maximum effect. There is currently no such strategy, but DPMC is drawing up a national framework (or strategy) for domestic security. To be effective, this strategy will need to include a comprehensive description and assessment of the risks and threats facing New Zealand, and allocate to specific agencies the responsibility for countering these threats.

The key elements of a strategic framework would include: ${ }^{346}$

- a common understanding of what domestic security is;

- clear goals and objectives (identified through the use of risk, threat, and vulnerability assessments) for the medium-to-long term;

- clearly stated roles and responsibilities of various agencies and groups;

- content and quality aspects in line with international best practice; and

- periodic review to ensure that the framework continues to reflect the enduring risk environment.

While the requirement for this overarching framework was identified, to this point it has not been achieved. Regardless, the findings of the 2003 Report are instructive for an analysis of the DESC system's efficiency and effectiveness in external whole-of-government security responses. The DESC system provides a very high level of joined-up working at the Government and policy and program development levels. However, an overarching National Security Statement designed for both domestic and external security is required. The 2010 Defence Assessment emphasised this point: ${ }^{347}$

New Zealand does not have a formal national security policy, and it is not the purpose of this Assessment to construct one. We do, however, suggest that a national policy framework would be desirable.

\footnotetext{
345 Ibid. 35.

${ }^{346}$ Ibid.

${ }^{347}$ MoD Defence Assessment (Ministry of Defence, 2010) available at http://www.defence.govt.nz/pdfs/defence-review-2009-released-defence-assessment-july-2010.pdf (accessed 10 January 2010) 7.
} 
As was outlined in the introduction to this chapter, from the turn of the century the NZDF was alive to the fact that as New Zealand's external commitments have transformed, a growing number of New Zealand departments and agencies would be required to assist. The 2008 Doctrine Manual asserted that: ${ }^{348}$

The NZDF recognises that in today's complex security environment it is not the sole contributor to either the overall security of New Zealand or crises abroad. There are eleven other government agencies contributing to defence policy objectives or outcomes in New Zealand

Of particular note in the above statement is the articulation of the NZDF's raison d'être - the security of New Zealand. ${ }^{349}$ This is an obvious rationale for raising and maintaining armed forces. What is less clear is how the raison d'être for the traditionally domestically focused departments such as Police, Inland Revenue, Justice, Corrections, Immigration and Customs aligns with that of Defence (or Foreign Affairs and Trade). How does a department whose focus has been administration of taxes or the Courts in New Zealand integrate into a whole-ofgovernment operation offshore? A more nuanced question is why would they want to? On the face of it such operations do not advance their underlying objectives or targeted outcomes as provided by government. A National Security Statement that unambiguously outlines how those agencies contribute towards national security outcomes would therefore be constructive.

Indeed, the 2010 Murdoch Review proposed that a methodology and process to better define and integrate the government's national security goals would be addressed in 2010, though this has not been confirmed. ${ }^{350}$ This would provide clarity and delineate lines of accountability for the growing number of agencies involved in external operations. This is particularly salient for New Zealand's peace support operations where traditional security issues are often less relevant within the broader task of (re)constructing a functioning society. Agencies that have not been traditionally focused upon New Zealand's security are required to become involved and need clear direction for their involvement, clarified description of roles, and robust reward and accountability frameworks.

\footnotetext{
${ }^{348}$ NZDF Foundations of New Zealand Military Doctrine (NZDDP-D) (Development Branch, Headquarters New Zealand Defence Force, 2008) available at http://www.nzdf.mil.nz/downloads/pdf/public-docs/2008/nzddp-d-2008-ed-2.pdf 2-7.

${ }^{349}$ Article 2.4 of the Doctrine Manual outlines that the primary mission of the NZDF is to secure New Zealand against external threat, to protect our sovereign interests, including in the EEZ, and to be able to take action to meet likely contingencies in our strategic area of interest.

${ }^{350}$ NZSIS Annual Report for the Year Ended 30 June 20105. 
The 2010 Defence Assessment came to similar conclusions, recommending that an overarching national security policy for protecting New Zealand, our people, and our interests be developed which: ${ }^{351}$

- $\quad$ reflects New Zealand's core values;

- $\quad$ responds to the major security challenges and drivers of instability; and

- brings together the objectives of all ministries, agencies, and forces involved in protecting our national security.

A key element of such a document will be a clear description of how the whole-ofgovernment approach is to be applied in offshore operations. It will require unambiguous collective national level outcomes where each agency must be collectively (but not equally) accountable.

\subsection{Complex Peace Support Operations}

In 2007, the Minister of Foreign Affairs Winston Peters outlined in a Speech to the Swedish Institution of International Affairs in Stockholm, that, "New Zealand is currently looking to improve its whole-of-government framework, with the aim of increasing the effectiveness of our engagement with fragile and post-conflict states." ${ }^{352}$ In 2008, the incoming National-led Government quickly outlined its focus of value for money and efficiency in public policy. This was subsequently applied to the management of New Zealand's external operations. Rather than drastically revising or implementing a new system, the existing whole-of-government approach was supported and strengthened.

The whole-of-government approach to peace support operations has been evolving over the past decade. New Zealand continues to be involved in three complex peace support operations in Timor-Leste, Solomon Islands and Afghanistan. There is no 'one size fits' model when applying a whole-of-government approach to these operations. Though each of these operations has managed unique issues, they have all collectively informed and moulded the way that New Zealand conducts itself in these operations.

\footnotetext{
${ }^{351}$ MoD Defence Assessment 12.

${ }^{352}$ Minister of Foreign Affairs Hon Winston Peters, "Nz's Involvement in Global Peace Operations" (18 October, 2007), available at http://www.beehive.govt.nz/speech/nz\%E2\%80\%99s-involvement-globalpeace-operations, (accessed 10 January 2011).
} 


\subsubsection{Timor-Leste}

New Zealand's final contribution of the 1990s would set the tone for the coming decade. As East Timor moved towards independence, it became clear that the withdrawing pro-Indonesian militias were resorting to violence. ${ }^{353}$ New Zealand received popular domestic support to send troops to support the Timorese and prevent further atrocities. The New Zealand Defence Force was deployed under the auspices of the International Force for East Timor (INTERFET). They remained in East Timor moving under the United Nations Transitional Authority in East Timor (UNTAET) in late 2000 and United Nations Mission of Support to East Timor (UNMISET) in May 2002. At its peak in October 1999, the NZDF had 1,100 personnel in East Timor, which was New Zealand's largest overseas military deployment since the Korean War. ${ }^{354}$ However, it was not only NZDF that was involved; diplomatic staff were present and Police and were also called on to assist in the development of the nation. ${ }^{355}$

While the mission in newly independent Timor-Leste had all the hallmarks of success, the reality was far from that. New Zealand withdrew the core of its troops from May 2005 after UNMISET had successfully completed its mandate. The United Nations Security Council then established the United Nations Office in Timor-Leste (UNOTIL). ${ }^{356}$ As part of UNOTIL NZDF provided Military Training Advisors to mentor Border Patrol Units and facilitate meetings between the Units and the Indonesian Army. ${ }^{357}$ However, as Dili degenerated into violence in spectacular fashion in April 2006 there was a realisation that much of the work done in Timor had been superficial. ${ }^{358}$ The same issues of poor governance and corruption that plagued many of the South Pacific nations had clearly emerged in Timor-Leste. ${ }^{359}$ Australia and New Zealand were clear in their willingness for reengagement. The failure to build and support the core institutions in Timor-Leste reinforced the growing argument that more than just the security sector had to be focused on. Moreover,

\footnotetext{
353 James Dunn Crimes against Humanity in East Timor, January to October 1999: Their Nature and Causes (2001) available at http://www.etan.org/etanpdf/pdf1/dunn.pdf (accessed 22 March 2011).

${ }^{354}$ NZDF, "Ten Years in Timor," One Force, 3, October 2009, available at http://www.nzdf.mil.nz/news/publications/one-force/3/default.htm, (accessed 04 January 2011).

${ }^{355}$ See: Callum Martin, "New Zealand's Expeditionary Police: The Expanding Role of New Zealand Police in International Relations" (paper presented at the The Oceanic Conference on International Studies (OCIS), Auckland, New Zealand, 30 June - 2 July 2010) available at http://www.ocis.org.nz/ocis/files/Martin.doc (accessed 11 January 2011).

${ }^{356}$ NZDF, "Ten Years in Timor."

357 Ibid.

${ }^{358}$ Resolving Timor-Leste's Crisis (Asia Report N120, International Crisis Group, 2006) available at http://www.crisisgroup.org/ /media/Files/asia/south-east-asia/timorleste/120_resolving_timor_lestes_crisis.ashx (accessed 09 January 2011). ${ }^{359}$ See: Ibid. 
similar to responses to domestic 'wicked problems', these operations could not be short term engagements - they required long term commitment of both resources and capital. They also required a deep analysis of how the operations were being constructed and managed. To coordinate New Zealand's commitments across multiple agencies and extended periods, a whole-of-government approach was implemented and began to evolve.

\title{
5.4.2 Afghanistan
}

Similar complexity was found in New Zealand's deployment to Bamian Province in Afghanistan that began in 2003. On June 9 the Government announced that it had reconnaissance teams in Afghanistan looking at the possibility of taking over a Provincial Reconstruction Team (PRT). The Prime Minister stated: ${ }^{360}$

\begin{abstract}
It is now time to contribute to the reconstruction of Afghanistan. The Afghan provisional government is working with a number of countries to establish security and rebuild society across Afghanistan. A significant part of this effort is through the deployment of Provincial Reconstruction Teams. ... New Zealand intends to contribute to a PRT. If it proves to be within our capacities, that contribution will extend to leading a PRT.
\end{abstract}

Since March 2005, NZ Police joined the deployment and were tasked to provide training to the Afghan National Police. New Zealand incrementally increased its official development assistance to Afghanistan from $\$ 9.5$ million in 2009/2010 to $\$ 12$ 14 million from 2010-2015, focused on improving agriculture, rural livelihoods, education and health. ${ }^{361}$ From the outset the mission was designed to incorporate a civilian element, although the strategy and framework for doing this was not initially articulated.

Unlike previous models of 'peace-building', the PRT's were designed to merge the traditionally parallel roles of non-governmental organisations (NGOs) and the military. The concept was developed as an offshoot of the 'Coalition Humanitarian Liaison Cells'. These were small groups of military personnel tasked to assess and address humanitarian needs within in Afghanistan in 2002. During the early stages, these cells effectively established relationships with NGOs and UN aid

\footnotetext{
${ }^{360}$ Government assistance to Operation Enduring Freedom and Iraq, 9 June, 2003, http://www.beehive.govt.nz/release/government+assistance+operation+enduring+freedom+and+iraq ${ }^{361}$ New Zealand's Current Involvement in Afghanistan, New Zealand Ministry of Foreign Affairs and Trade, available at http://www.mfat.govt.nz/Countries/Middle-East/Afghanistan.php, (accessed 11 January).
} 
missions, enabling a robust appreciation of the reconstruction requirements. Their successes led to an expansion into the form of the first PRT in Gardez in January 2003. The idea was to get into areas where there was little or no Afghan governmental or development community presence and promote reconstruction. As of March 2010, there were 27 PRTs in Afghanistan each commanded by one of the ISAF member-states (USA command 12 of these PRTs).

The Provincial Reconstruction Team in Bamyan was designed as a tool for delivering the pillars of civil society. The basic structure of a PRT contains both military and civilian components working in unison. Military units focus on force protection and civil affairs, while civilians, such as police and aid staff, advise and train Afghan officials. PRTs are commanded by the military and generally staffed by between 60 to 100 personnel, though some, such as the Canadian PRT in Kandahar, are staffed by up to 350 .

With the new government taking office in late 2008, various reviews of the mission were commissioned. One of these was the Review of New Zealand Official Development Assistance Supported activities in Afghanistan. ${ }^{362}$ Simon Williamson, an independent consultant, was tasked to "assess the strategic direction and focus of the programme" in order to inform the next 3-5 years. ${ }^{363}$ At the outset, the review was cognisant of the widely reported assumption that much of the international engagement in Afghanistan lacked strategy. This was demonstrated in New Zealand where for the period under review it was found that "no clear, written strategy or programme framework exists" for the various NZ contributions. ${ }^{364}$ It was noted that NZPRT was the most significant development actor in Bamyan, though NZDF acknowledged that they were not expert in development. ${ }^{365}$ However, there was an absence of input by development professionals to the design of projects and NZPRT did not have a monitoring and evaluation framework in place. Due to this, the report found that the "extent to which projects have addressed the needs of development in a sustainable, relevant and effective way is unknown and therefore likely to be limited."366

One of the key recommendations to come out of the review was a need for a senior NZAID advisor to be permanently placed within NZPRT. To enable this to

\footnotetext{
${ }^{362}$ Simon Williamson Review of New Zealand Official Development Assistance Supported Activities in Afghanistan (Independent Advisor, 2009) 6.

${ }^{363}$ Ibid.

364 Ibid.

365 Ibid.

366 Ibid. 6 
work, the advisor would preferably have the same level of authority as the NZDF Senior National Officer. The advisor would also have a role in increasing coherence of all funds flowing through the PRT. This was a further admission that Defence professionals alone are not equipped to successfully carry out civil reconstruction there needs to be a whole-of-government approach that draws in relevant expertise from across the whole of government.

The experience in Afghanistan has been very useful in identifying the gaps in New Zealand's whole-of-government approach to the Provincial Reconstruction Team in Bayman. The Williamson Review found that a higher degree of strategic input was required from across government stakeholders at all levels of decision making and action. While the DESC system outlined earlier provides sound coordination at the senior level of governance, there was a particular lack of horizontal coordination at the programme management and service delivery levels in Wellington and Afghanistan.

\subsubsection{Solomon Islands}

In 2003, New Zealand also became deeply involved in the complex peace support mission in Solomon Islands. The Regional Assistance Mission in Solomon Islands (RAMSI) was novel in that it was police-led, reflecting a theme of the Brahimi Report in 2000. ${ }^{367}$ RAMSI was also focused upon building the pillars of society from the outset. As well as the contribution from NZ Police and NZDF, a number of New Zealand civilian personnel also serve with the Mission. ${ }^{368}$ The Mission was from the outset one of the first internationally that operated a whole-of-government approach to reconstruction.

Until 2006, RAMSI was being held as a 'model of best practice' and received a high level of admiration. ${ }^{369}$ Regrettably, the mission suffered a serious obstacle when there was violence during the 2006 elections. Mary Louise O'Callaghan lamenting the lack of cultural awareness of the Australian and New Zealanders emphasised that: ${ }^{370}$

\footnotetext{
367 'Report of the Panel on United Nations Peace Operations,' A/55/305-S/2000/809, United Nations General Assembly \& Security Council (New York: 2000), http://www.un.org/peace/reports/peace_operations/, (accessed 04 January 2011).

${ }^{368}$ MFAT Solomon Islands [Webpage], New Zealand Ministry of Foreign Affairs and Trade, available at http://www.mfat.govt.nz/Countries/Pacific/Solomon-Islands.php, (accessed 11 January 2011).

${ }^{369}$ See:Fullilove, 'RAMSI and State Building in Solomon Islands.'

370 O'Callaghan, "RAMSI: The Challenges Ahead " 5.
} 
The scene of the April 2006 protests outside parliament where the predominantly Australian and New Zealand PPF officers could be seen acting in a seeming vacuum from both the mood of the crowd and the senior ranking local RSIP officers present at the scene was a chilling illustration of the dangers of trying to rebuild someone else's country without being steeped in understanding of that culture and the dynamics of that community.

O'Callaghan was critical of the inability of the donor nations to better integrate themselves into the operating environment. The break down in law and order in 2006 was indicative of a failure by RAMSI to establish deep relationships with the Solomon's community - to gain their trust and importantly to encourage their 'ownership' of the mission. In order to do this, the staff at the front lines required better cultural, social and historical knowledge of the society they were meant to be assisting.

Although RAMSI was distinct from the mission in Timor-Leste in many ways, a number of the same problems plagued the intervention. In 2006 Matthew Allen highlighted several pervasive issues that challenged the effectiveness of the Mission: ${ }^{371}$

\footnotetext{
The [Participating Police Force] deliberate isolation from the community-the location of its base on the outskirts of Honiara, its refusal to consume locally produced foodstuffs, its reluctance to have its people walking the streets, the inability of the majority of its people to speak Pijin, the high rotation of rate of its officers through the provincial posts and through the operation as a whole-is inimical to this process of interaction and exchange.
}

For the NZ police, the same six-month rotations as in Timor-Leste were the norm. There was only limited language training and the pre-deployment and in-country cultural instruction was limited. The issues Mathew Allen refers to are vitally important in gaining and maintaining legitimacy for an operation - especially within the hearts and minds of the local population. ${ }^{372}$

\footnotetext{
${ }^{371}$ Matthew G Allen, 'Dissenting Voices: Local Perspectives on the Regional Assistance Mission to Solomon Islands,' Pacific Economic Bulletin 21, no. 2 (2006): 197.

${ }^{372}$ Martin, "New Zealand's Expeditionary Police: The Expanding Role of New Zealand Police in International Relations" 22. 


\subsubsection{Many Departments $\neq$ Whole-of-Government}

The inability to find rapid and enduring results in these operations has troubled officials. In 2008 Sinclair Dinnen looked to the justification for these operations and posited the question of whether the initial conceptualisation of "failed" and "fragile" states was adequate. ${ }^{373}$ As this was the foundation for the design and implementation of state (re)construction, he believed there was "Insufficient appreciation of the distinct forces that characterize post-colonial states". ${ }^{374}$ Dinnen argued that a lack of detailed understanding of the social and political forces and the fragmented settings in these nations has "tended to render external state-building projects, at best, ineffective, and, at worst, disruptive and destabilizing." ${ }^{375}$

Dinnen's observations have specific resonance when applied to an argument for the application of a whole-of-government approach to peace support operations. A key rationale behind the approach in domestic governance was to manage the wicked problems that transgressed multiple layers and sectors of society. Detailed ongoing research was required to understand the intricacies of these difficult social issues and long-term strategies and collective outcomes had to be designed and continually re-evaluated.

The complex issues that motivated the whole-of-government approach in domestic governance are conceptually no different to the complex issues donor nations are facing when entering peace support operations. While structural adaptations are a central component of addressing these complex operations, to best support and shape these structural changes, deeper cultural awareness of the host nation's culture is essential. Academics and practitioners such as David Kilcullen and Montgomery McFate, not without controversy, ${ }^{376}$ have been strong advocates for the extensive use of social scientists on the front lines in places such as Iraq and Afghanistan. ${ }^{377}$ The awareness is that there has been a stark lack of detailed social analysis of the operating environment. As noted by McFate, "One of the central epistemological tenets of anthropology is cultural relativism - understanding other

\footnotetext{
${ }^{373}$ Sinclair Dinnen, 'State-Building in a Post-Colonial Society: The Case of Solomon Islands,' Chicago Journal of International Law 9, no. 1 (2008): 52.

${ }^{374}$ Ibid.

375 Ibid.: 52.

376 See: Roberto J Gonzalez, "We Must Fight the Militarization of Anthropology," Chronicle of Higher Education 22, 2007, available at http://chronicle.com/weekly/v53/i22/22b02001.htm, (accessed 04 January 2011).

${ }^{377}$ David Kilcullen, The Accidental Guerrilla (Melbourne: Sage, 2009), Montgomery McFate, 'Anthropology and Counterinsurgency: The Strange Story of Their Curious Relationship,' Military Review March-April (2005).
} 
societies from within their own framework." ${ }^{378}$ Reinforcing Sinclair Dinnen's argument above, McFate concluded that: ${ }^{379}$

\begin{abstract}
While the consequences of a lack of cultural knowledge might be most apparent (or perhaps most deadly) in a counterinsurgency, a failure to understand foreign cultures has been a major contributing factor in multiple national-security and intelligence failures.
\end{abstract}

There is strong argument for effective and efficient coordination of government agencies involved in complex peace support operations. A whole-ofgovernment approach is arguably the tool to achieve this. To do this efficiently and effectively a whole-of-government approach to peace support operations requires not only engagement of multiple agencies and better use of expertise across departments, but also a deeper understanding of why and how. Enhanced cultural awareness of the operating environment will enable better identification of where to place resources and to more efficiently join-up.

There should be extensive education into the culture and history of the 'failed' state that is being assisted. In relation to Dinnen and McFate's arguments, staff that are being deployed to these operations require deeper knowledge of the operating environment. Specifically, there need to be an enhanced focus upon a higher level of education before and during deployment. This will require developing closer relationships with universities in New Zealand. Key academics should be identified and commissioned to undertake research that informs New Zealand's operations. It would be advantageous if those academics could spend extended time seconded to these operations in-country so they can train and provide advice to staff while on operation. Master Classes with universally accepted qualifications should be regularly available with officials gaining personal value through promotional opportunities or increased salary.

Cultural awareness of the operating environment needs to be supplemented by enhanced institutional cultural awareness. Institutional culture informs how organisations identify their interests and priorities; how they define problems and ways to solve them; and the value and meanings they attach the surrounding environment. ${ }^{380}$ Focusing on culture draws attention to the fact that effective wholeof-government approach may require more than the elimination of technical barriers

\footnotetext{
${ }^{378}$ McFate, 'Anthropology and Counterinsurgency: The Strange Story of Their Curious Relationship,' 26.

379 Ibid.: 25.

380 Baumann, 'Clash of Organisational Cultures? The Challenge of Integrating Civilian and Military

Efforts in Stabilisation Operations,' 72.

90
} 
or harmonisation of standard operating procedures. ${ }^{381}$ Andrea Baumann argued in 2008 that, "despite widespread consensus over the need for a holistic approach in theory, the implementation of comprehensive or whole-of-government strategies has given rise to debate, controversy and concern in practice." ${ }^{382}$ She argued that: ${ }^{383}$

\footnotetext{
... the mechanisms and structures aimed at improving co-operation between military and civilian organisations tasked with the implementation of a comprehensive response are unlikely to succeed if they merely brush over the fundamental cultural differences that exist between these organisations.
}

Baumann referred to a recent lecture by General John Craddock where he compared the interplay of civilian and military efforts to a soccer game "where each player has an assigned role, but 'due to the fluidity of the game, these roles are not distinct, rather the borders between those roles are often blurred." ${ }^{384}$ In providing additional insight to the analogy with regard to organisational culture, Baumann continued "without a better understanding of each individual player's rationale and motivation for playing his part in a specific way, it will be difficult to work with overlapping roles." 385

In order to leverage the most value out of these relationships, there needs there needs to be an assessment of where and how each department can complement the workings of the other agencies so they work together to reach collective outcomes. On a practical level, this may require a portion of 'predeployment training' to include officials from the various departments that will be working together in-theatre. Again, institutional culture needs to be a component of this training as this allows for a critical appreciation of best practices and perceived lessons learned. For example, Baumann argues that it has become a default policy recommendation that joint training will "lessen cultural divides by reducing misperception and building bridges between military and civilian personnel." However, what is also needed, according to Baumann, "is an understanding of why these cultural barriers exist in the first place and whether it always makes sense to tear them down." 387

\footnotetext{
381 Ibid

382 Ibid

383 Ibid.

384 Ibid.: 71.

385 Ibid.

386 Ibid.: 72.

387 Ibid.
} 
Another possibility is continual cross-departmental briefings - at all levels of decision-making and action - including the so-called front lines. A further tool, which some departments have used regularly, is secondments. MFAT and Defence for a long time have been seconding and moving staff between their departments. ${ }^{388}$ This provides for socialisation and education into the respective networks, cultures and practices of those agencies. This should be expanded into the more non-traditional security agencies that are becoming involved in peace support operations. It would also promote fluid movement of staff between agencies and provide opportunities for specialised staff to spend longer periods in recipient countries.

\subsection{Conclusion}

New Zealand's contributions to these complex peace support operations have been ongoing and multifaceted. There has been a continual evolution and sharpening of the whole-of-government approach. The literature and the collective experiences of the operations indicate that a true whole-of-government approach is more than just multiple agencies working 'together'. It requires a deep knowledge of why the agencies are working together and how they best 'fit together' in order to leverage the most value from the collaboration. In addition, there must be extensive education into the complex nature of the environment these agencies are working in - the history, social and cultural nature of the recipient country. This requires drawing on more expertise inside and outside of government to achieve this difficult level of capability.

In order to achieve these difficult tasks, any mission needs to be guided by a clear national statement of intent. In addition, individual whole-of-government country strategies need to be written that clearly state mutually agreed outcomes as well as an accountability framework. ${ }^{389}$ Moreover, this must project forward at least ten years. Sustained, deeper, long-term commitments need to be made from the outset. This would emphasise its strategic approach to its partners and help to ensure a cohesive approach in the field. It would also allow effective monitoring of the impact of the overall whole-of-government approach in a country. If this is established from the conceptualisation of these deployments, it allows long-term planning and specialist skills specific to the recipient nation to be incorporated into the training of

\footnotetext{
${ }^{388}$ The current Secretary of Defence John McKinnon had an extensive career in MFAT, as has Dr Brook Barrington, who is Deputy Secretary of Defence (Policy and Planning).

${ }^{389}$ In 2010 it was noted that such country strategies were beginning to be developed, see: OECD New Zealand (2010) Dac Peer Review: Main Findings and Recommendations. 
personnel. These enhanced skills would then benefit from longer deployment rotations. While there are significant front end costs in deepening the level of involvement in such ways, the long term benefits are found in the enduring viability of these states. ${ }^{390}$

The literature demonstrates the New Zealand Defence Force was an early supporter of a whole-of-government approach to security issues. They raised the notion at the turn of the century and continued to champion its use in public documents throughout the decade. While the Ministry of Foreign Affairs and Trade had used whole-of-government rhetoric in their public documents, it was not until 2006 when the notion took hold. MFAT subsequently took ownership of the approach abroad and sought, quite naturally, to use it as a tool to achieve the Ministries core objectives.

If government departments involved in New Zealand's complex peace support operations are utilise a whole-of-government approach there needs to be a common understanding of what that approach is. Furthermore, there needs to be an understanding of why they are doing it, the value to their organisation, and how it operates. To this end, if a Government priority is to operate a whole-of-government approach in these operations there is a requirement for a clear statement to that effect. This research argues that a National Security Policy is required that articulates the requirement for all departments, when called upon, to work collectively towards the government outcome of a safe and thriving New Zealand.

\footnotetext{
${ }^{390}$ Martin, "New Zealand's Expeditionary Police: The Expanding Role of New Zealand Police in International Relations" 24.
} 


\section{Chapter 6: Findings and Conclusions}

\subsection{Introduction}

An underlying question that can be extracted from this research is how does the notion of a whole-of-government approach add value to the service delivery of New Zealand's offshore engagements? This chapter seeks to begin to answer that question. In doing so it will propose a framework that the author argues will add value to New Zealand's peace support operations.

\subsection{Overview}

As stated in the introduction, one of the barriers in performing this research is the difficulty in locating comprehensive information about New Zealand's commitments to peace support operations. A significant reason for this is that there is no centralised source providing comprehensive information about New Zealand's whole-of-government contributions. ${ }^{391}$ As was found in the Australian Senate Report regarding Australia's operations, New Zealand's peace support operations have now widened well beyond the scope of the military. It is important that New Zealand's whole-of-government operations be accompanied by whole-of-government reporting. ${ }^{392}$ This will enable Parliament and the New Zealand public to identify the size and nature of the resources provided by government to peace operations. An appropriate agency, such as DPMC, should be mandated to perform public whole-ofgovernment reporting on New Zealand's contribution to peace support operations. This would require the department's annual report to include a description of all peace support operations, a list of the contributing government agencies, and, for each relevant agency: ${ }^{393}$

- a description of its role in the operation;

- the financial contribution to the operation during that reporting year;

- the peak number of personnel deployed by the agency during the reporting year and the date at which the peak occurred; and

- the number of personnel deployed as at the end of the reporting year.

\footnotetext{
${ }^{391}$ See recommendations from Australian Senate: Government Australia's Involvement in Peacekeeping Operations 341.

392 See: Ibid.

393 Ibid.
} 
In conjunction with accurate and clear public reporting, there is a requirement for publicly accessible indicators of success. The Introduction to this thesis outlined that one of the main the barriers to effective whole-of-government working in domestic public management was poor understanding of performance indicators. ${ }^{394}$ This research has found no public indication that New Zealand agencies involved in peace support operations have developed effective indictors for joined up working.

This research contends that performance indicators are needed by government to effectively assess the success or otherwise of contributions to peace support operations. In addition, they will ensure that lessons learnt from an operation are captured for future operations. In order to construct an indicator framework, there will need to be clearly articulated whole-of-government outcomes for these operations. As such, whole-of-government country strategies should be employed to guide this process, which in turn would be guided by a whole-of-government national security strategy. In relation to peace support operations, the OECD in 2006 called for a "joint policy statement by the key ministers, providing the rationale for whole-ofgovernment engagement in fragile states as well as the main objective". ${ }^{395}$ The added value for this, they highlighted, was that "governments could use such a policy statement as a means of accountability for higher-level officials to put joined-up working into operation in their respective organisations." 396

\subsection{What Should Whole-of-Government Look Like?}

The literature indicates that a whole-of-government approach is an efficient and effective tool for maximising value of public sector governance. Successive governments have embraced this and instructed that it be implemented in New Zealand's peace support operations. ${ }^{397}$ Nevertheless, other than an increase in contributions from multiple-agencies, it is not altogether clear that the whole-ofgovernment approach has been effectively implemented across all levels of decision making and action - from the Government strategy to the service delivery level. Put another way, what would an effective and efficient whole of government approach look like? Various question flow from this, such as:

\footnotetext{
${ }^{394}$ See Chapter 1.

${ }^{395}$ OECD Whole of Government Approaches to Fragile States 10.

396 Ibid.

${ }^{397}$ Hon Winston Peters, "Nz's Involvement in Global Peace Operations".
} 
- Are these operations, as a whole, well run? Where are their particular strengths or weakness;

- Is the quality of management across government departments as a whole improving, declining or stable;

- Does the government have the required management capacity to deliver on its outcomes agenda; and,

- How does a whole-of-government approach affect these three questions?

What would be instructive is an assessment framework that is able to evaluate and inform the whole-of-government approach in such operations. This would provide a clear picture of what a whole-of-government approach to peace support operations would look like. It would also serve to improve the performance of New Zealand's whole-of-government contribution to these operations.

With the development of the new "managing for outcomes" environment, whole-of-government brings added complexities to accountability and incentive mechanisms. ${ }^{398}$ The traditional association of decision making, accountability and performance management with vertical structures can restrain shared outcomes and responsibilities between organisations. ${ }^{399}$ To ensure success, performance management and incentives need to be specifically tailored to support a whole-ofgovernment approach. Currently, rewards for achieving organisational aims can be stronger than the incentives for horizontal achievements. With a strong focus on existing performance management, departments can often be tempted to ignore issues that require shared responsibility. ${ }^{400}$ Whole-of-government therefore requires shared performance indicators that must be aligned with incentives and reporting systems.

That said there are significant challenges in devising credible and useful performance indicators when assessing whole-of-government performance in peace support operations. Specific challenges that relate to whole-of-government collaboration in any sector include:

- Formalities (conflicting mandates, no Memorandum of Understandings (MoUs));

- Culture, mindset, prejudices;

\footnotetext{
398 Joined up Government: A Review of National and International Experiences 7.

399 Ibid.

${ }^{400}$ Mulgan, "Joined-up Government: Past, Present, and Future." 
- Bureaucratic rigidity (despite wiliness, no flexibility to adjust plans and budget);

- Funding (a zero-sum game, competing for funds);

- Priorities (may share the vision, but not how to reach goals);

- Resources (more funding goes to some departments, less for others);

- Leadership (who takes the lead).

These are also relevant to peace support operations. The Australian Senate Report found that: ${ }^{401}$

\footnotetext{
The task of measuring the effectiveness of the whole-of-government contribution means examining issues such as interoperability and [civil-military cooperation]. Such matters raise questions about who should assess this overall performance and how an agency's assessment of its performance feeds into a whole-of-government appraisal.
}

The same issues arise in New Zealand. The advantage for New Zealand however is the relatively minor size of New Zealand's contributions to peace support operations and the coherent shape and location of the bureaucracy. New Zealand's size is also a drawback however, as there is a relatively small public sector that is being given more to do and within the current global financial crisis, less to do it with. Regardless, prudent investment with clearly established long-term outcomes will inevitably provide added-value for less cost over the long-term. There would be considerable advantage in a central agency, possibly DPMC, taking the lead with assessment. DPMC has recently reinforced its oversight and direction-setting role in the intelligence sector. Assessment of the whole-of-government approach to peace support operations would be a natural extension of its mandate.

\subsubsection{Performance Indicators}

The first chapter highlighted that the key barriers for whole-of-government working are departmental silos, a lack of relevant data, lack of flexibility in funding arrangements, and poor understanding of performance indicators. ${ }^{402}$ While the former issues have been assessed throughout this research, performance indicators have not been specifically addressed.

\footnotetext{
${ }^{401}$ Government Australia's Involvement in Peacekeeping Operations 24.29.

${ }^{402}$ See also: Hyde, 'How to Make the Rhetoric of Joined-up Government Really Work.'
} 
Indicators are summary data that represent an issue of concern or measure change or progress toward achieving a desired outcome or objective. ${ }^{403}$ They may indicate areas that need further investigation or attention. Indicators consist of quantitative and qualitative data presented in a formalised way to describe past and current conditions in a system. ${ }^{404}$ Typically, a number of indicators are required to evaluate whether a desired outcome has been achieved. ${ }^{405}$ Indicators measure changes over time - they show trends and when monitored over a period and can illustrate whether things are improving, remaining static, fluctuating or declining with respect to the outcome they are being used to measure. ${ }^{406}$ Indicators should be easily interpretable measures that describe what is occurring with regard to a particular issue. They can be roughly divided into two groups - those that articulate the state of affairs with regard to the issue, and those that depict trends with specific spatial scales and time horizons. ${ }^{407}$ Indicators can also help track and assess performance at the organisational level.

When seeking to develop a set of performance indicators, Mark Schacter believes there are two fundamental questions in order to produce a credible and practical assessment framework for whole-of-government management: ${ }^{408}$

- Is it possible to reach a reasonable degree of consensus on the key ingredients of good public management at the whole-of-government level?

- Is it possible to produce a set of measures of manageable scope that, while not perfect, will be seen as good enough to support reliable and actionable assertions about the quality of public management across an entire government?

Again, the New Zealand public sector landscape is well socialised and relatively small. The DESC system enables the key players in the senior ranks to work closely

\footnotetext{
${ }^{403}$ Indicators for Monitoring Community Outcomes: Methodology and Process for Developing Indicators (Canterbury Region Community Plans Group, 2005) available at http://www.stats.govt.nz/browse_for_stats/government_finance/local_government/ /media/Statistics/Pub lications/Stats-by-Area/regional-statistics/canterbury-region-outcome-indicators-18-07-05.ashx (accessed 13 January 2011) 4.

404 Professor Ali Memon Choosing Community-Based Indicators to Monitor and Report Progress Towards Community Outcomes (PUCM LGA Report 4, Environmental Management Group Environment, Society and Design Division, Lincoln University, Canterbury, 2008) available at http://www.waikato.ac.nz/igci/pucm/lga/lgarpt4.pdf (accessed 13 January 2011) 8.

${ }^{405}$ Indicators for Monitoring Community Outcomes: Methodology and Process for Developing Indicators 4. 406 Ibid.

407 Profiles of Tools and Tactics for Environmental Mainstreaming: Indicators (International Institute for Environment and Development (IIED), 2009) available at http://www.environmentalmainstreaming.org/documents/EM\%20Profile\%20No\%2010\%20\%20Indicators\%20\%2820\%20November\%2009\%29.pdf (accessed 20 February 2011).

${ }^{408}$ Mark Schacter How Good Is Your Government? Assessing the Quality of Public Management (Mark Schacter Consulting, 2008) available at http://www.schacterconsulting.com/documents/howgood.pdf (accessed 14 January 2011) 4 
within the required agencies. In addition, there is an existing central agency, DPMC, which can provide oversight and guidance. Reaching consensus on the key ingredients of 'good public management' should be readily achievable. There should also be little difficulty in developing a set of measures of manageable scope to assess the quality of management of peace support operations. In order to provide this, a robust set of indicators would aspire to:

- Strengthen accountability when implementing commitments in peace support operations;

- Detect progress and achievements in the implementation of whole-ofgovernment approach in these operations;

- Detect gaps and weaknesses in the implementation of this approach;

- Facilitate subsequent policy making and prioritisation of actions, as well as possible benchmarking;

- Ensure consistency across departments;

- Motivate personnel;

- Facilitate clear communication about the implementation of the approach;

- Improve NZ Inc visibility.

The indicators would be required to inform decision-making and progress on several key themes that have been raised in this research. They specifically relate to developing:

- awareness and understanding of partner agencies' institutional cultures, capacity and capability;

- greater understanding of host nation social and institutional cultures and histories;

- a culture of collective responsibility towards achieving whole-of-government outcomes; and,

- whole-of-government country strategies that project and plan for long-term outcomes.

Indicators by themselves are only a component of a robust system of measurement. Schacter highlights that a performance measurement framework is abstract by its very nature. ${ }^{409}$ Practicable and constructive measurement requires simplification, particularly when dealing with a subject as large and multifaceted as the quality of 
public management in complex peace support operations. Schacter argues that "While the assessment framework must not ignore critical data, it must also not overwhelm users with fine detail, nor should it impose a heavy administrative burden." 410

\subsubsection{A Value-added Framework}

This thesis posits a framework which is divided into four categories, representing the four broad areas this research indicates should be the focus of a whole-ofgovernment approach to peace support operations:

\section{Institutional Cultures}

2. Social Cultures

3. Collective Responsibility

4. Social, Political and Economic Outcomes

This is not an exhaustive framework; that would require extensive consultation amongst all stakeholders over an extended timeframe. This is an initial framework based on the findings of this research conducted within the limited scope of a Master's thesis.

\section{1) Awareness of Institutional Cultures}

Public servants involved in peace support operations are mutually aware of and seek to compliment the institutional cultures, capabilities and capacity of other departments involved.

Performance Indicator 1: An enhanced understanding of institutional cultures, capacity and capabilities of New Zealand agencies.

- Develop programs for personnel to be educated in the capabilities, capacities and raison d'être of partner agencies.

- Develop programs and policies that promote the education into and adaptation of institutional cultures, mindsets, and prejudices (especially between military and civilian agencies).

- Create increased opportunities for more fluid sector-wide movement of personnel.

410 Ibid 
- Timings of deployment rotations are designed to increase the effectiveness of relationships in roles where close personal contact with partner agencies is required.

\section{2) Awareness of Social Cultures}

All deployed staff are educated in host nation culture and history.

Performance Indicator 2: A greater awareness and education into host nation cultures and history.

- Provide opportunities increased education and specialisation into the culture and history of the host nation.

- Early identification and commitment to specialist skills relevant to the host nation.

- Provide opportunity and incentive for language skills and relationships to be strengthened.

- Develop closer relationships with universities in order to leverage off relevant expertise and develop a culture of learning.

- Provide opportunities for academics to be seconded to operations so can assist with training and research in the host country.

- Lengths of deployment rotations are designed to increase the effectiveness of relationships in roles where close personal contact with host nationals is required.

\section{3) Collective Responsibility}

A culture of collective responsibility towards achieving whole-of-government outcomes.

Performance Indicator 3: An increased obligation and willingness to promote New Zealand's priorities and outcomes above individual agency's priorities and outcomes.

- The development of policies and the design and implementation of programs systematically incorporate the perspectives of all stakeholders.

- A transparent and interactive process of engagement with reinforced leadership and strengthened steering capacity.

- Increased flexibility in funding arrangements. 
- Individual performance appraisals are linked to collective contributions and results.

- Results-based performance information is routinely used as a foundation for continuous improvement of whole-of-government program/policy performance.

\section{4) Social, Political and Economic Outcomes}

New Zealand's peace support operations meet the needs and expectations of the host nation and achieve results desired by the New Zealand government.

Performance Indicator 4: The quality of results management meets the needs and expectations of the host nation.

- The host nation is central stakeholder and is continually consulted with regard to policy development and outcomes.

- The best interests of the host nation are at the forefront when developing measurable social and economic outcomes for peace support operations.

- The New Zealand government regularly reports on its performance against intended outcomes - using data that are complete, accurate and valid - in a manner that gives the host nation a basis for evaluating New Zealand's performance in relation to results.

Performance Indicator 5: The quality of results management achieves the expectations of the New Zealand government.

- A core set of measurable whole-of-government social and economic outcomes is defined and communicated. The contribution of public programs towards them is evaluated through performance measurement and assessment at the government-wide level.

- Measurable department-wide social and economic outcomes that are integrated with government-wide outcomes are defined and communicated. The contribution of public programs towards them is assessed through performance measurement and evaluation at the departmental level.

- Whole-of-government country strategies that project and plan for long-term outcomes. 
- Performance is regularly measured against intended outcomes - using data that are complete, accurate and valid - in a manner that gives Parliament a basis for holding the government accountable for performance in relation to results.

Performance Indicator 6: The quality of information provided to New Zealanders.

- Performance is publicly reported in a manner that gives New Zealanders a basis for holding the government accountable for performance in relation to results.

- Information on peace support operations is centrally located and publicly available.

- Government increases its ability to create and disseminate information so it is readily digestible by the general public.

\subsection{Conclusion}

This thesis has found that three main factors are required for successful implementation of a whole-of-government approach in peace support operations. Direction from Government is essential. A national security statement is a prerequisite to provide unambiguous strategic direction.

This must be followed by culture change across the growing number of agencies involved in these operations. The research found that this should be concentrated in two distinct but interrelated areas. The first is to develop a culture of shared understanding between public departments and agencies. This will provide better awareness of each agencies rationale for action and ways of doing business. In return there would be enhanced ability to leverage the most value out of these partnerships. The second is to drive a culture of shared understanding between the combined 'NZ Inc' contributions and the host nation. This would provide New Zealand officials with deeper awareness of the history and culture of the host state. The desired result is an enhanced ability to shape the assistance to the specific environment, individuals or programs.

The final requirement is for the development of performance indicators and measurement frameworks. Such tools would enable identification and achievement of government outcomes. Attached to this is the need to provide enhanced official reporting on the progress towards government outcomes. 
The findings of this thesis provide opportunity for further research. One of these is extensive case studies of the whole-of-government approach in New Zealand's peace support operations. This would require a high degree of declassification of official information. Therefore it would best lend itself to doctoral research. A further opportunity is to conduct thorough research into how to best drive culture change across the wider security sector. In addition, there is value in providing analysis into how the 'soft issues', such as institutional cultures and values, can be adapted to promote superior service delivery in complex operating environments. This requires research into how to drive a culture of learning and awareness of host state history and society. 


\section{Bibliography}

6, Perri. "Joined-up Government in the Western World in Comparative Perspective: A Preliminary Literature Review and Exploration." Journal of Public Administration Research and Theory 14 no. 1 (2004).

Adams, Gordon. "The Quadrennial Diplomacy and Development Review: Separating the U.S. Civilian and Defense Missions." Bullitin of the Atomic Scientists (2010), http://www.thebulletin.org/webedition/columnists/gordon-adams/the-quadrennial-diplomacy-and-development-reviewseparating-the-.

Alach, Zhivan Jared. "Facing New Challenges: Adapting the NZDF and ADF to the Post-Cold War Security Environment."(submitted in fulfilment of the requirements for the degree of Doctor of Philosophy), University of Auckland, 2006.

Allen, Matthew G. "Dissenting Voices: Local Perspectives on the Regional Assistance Mission to Solomon Islands." Pacific Economic Bulletin 21, no. 2 (2006): 194-201.

Anderson, Major Will. "Wiring up Whitehall: Ensuring Effective Cross -Departmental Activity." Journal of Security Sector Management 3, no. 3 (2005).

"The Asia Pacific Civil-Military Centre of Excellence [Website]." http://civmilcoe.gov.au/ (accessed 23 January 2011).

AusAid, The Australian Government's Overseas Aid Program, "Australian Aid: Promoting Growth and Stability," (2006), http://www.ausaid.gov.au/publications/pdf/whitepaper.pdf.

"Australian Aid: Investing in Growth, Stability and Prosperity ", AusAid: The Australian Government's Overseas Aid Program, (2002), http://www.ausaid.gov.au/publications/pubout.cfm?id=6624 6294368248221275

Ayson, Robert. "The Arc of Instability and Australia's Strategic Policy." Australian Journal of International Affairs 61, no. 2 (2007): 215 - 31.

Baumann, Andrea Barbara. "Clash of Organisational Cultures? The Challenge of Integrating Civilian and Military Efforts in Stabilisation Operations." RUSI 153, no. 6 (2008).

Bennett, Paula, "High Trust Contracting Roll-out Continues" (3 March 2010), available at http://www.beehive.govt.nz/release/high-trust-contracting-roll-out-continues, (accessed 02 January 2011).

"Better Connected Services for Kiwis ". http://ips.ac.nz/events/completed-activities/joiningup.html (accessed 11 October).

Bill English, Judith Collins, "NZ's First Ppp Prison to Be Built at Wiri" (14 April 2010), available at http://www.beehive.govt.nz/release/nz039s-first-ppp-prison-be-built-wiri, (accessed 02 January 2011).

Bill Ryan, Derek Gill, Elizabeth Eppel and Miriam Lips "Managing for Joint Outcomes: Connecting up the Horizontal and the Vertical." Policy Quarterly 4, no. 3 (2008).

Bogdanor, Vernon. "Introduction." In Joined-up Government, edited by Vernon Bogdanor. Oxford: Oxford University Press, 2005. 
Brewer, Gene A., and Sally Coleman Selden. "Why Elephants Gallop: Assessing and Predicting Organizational Performance in Federal Agencies." Journal of Public Administration Research and Theory 10, no. 4 (2000).

Briggs, Lynelle. "A Passion for Policy." In A Passion for Policy: Essays in Public Sector Reform, edited by John Wanna. Canberra: ANU E Press, 2007.

Brown, Stewart Patrick and Kaysie, International Peace Academy, "Greater Than the Sum of Its Parts?: Assessing "Whole of Government" Approaches to Fragile States," (2007), http://www.cgdev.org/content/publications/detail/13893/.

Cedric de Coning, Helge Lurås, Niels Nagelhus Schia and Ståle Ulriksen, Norwegian Institute of International Affairs, Department of Security and Conflict Management, "Norway's Whole-ofGovernment Approach and Its Engagement with Afghanistan," (2009), http://english.nupi.no/Publications/Books-and-reports/2009/Norway-s-Whole-of-GovernmentApproach-and-its-Engagement-with-Afghanistan.

CIDA, Canadian International Development Agency, "Canada's International Policy Statement," (2005), http://www.acdi-cida.gc.ca/acdi-cida/acdi-cida.nsf/eng/JUD-2107401-GV3.

Collier, Lisa Chauvet and Paul, Centre for the Study of African Economies, Department of Economics, Oxford University, "Development Effectiveness in Fragile States: Spillovers and Turnarounds," (2004), http://www.jica.go.jp/cdstudy/library/pdf/20071101 09.pdf.

Committee, Education and Science, "State Sector Management Bill Commentary," (2010), http://www.parliament.nz/NR/rdonlyres/D77162A7-14F0-4CAC-9BE56A8E03E23BCB/170250/DBSCH SCR 4917 StateSectorManagementBill1932 7957 .pdf, (accessed 02 January 2011).

Coning, Cedric de, Danish Institute for International Studies, "The United Nations and the Comprehensive Approach," (2008), http://www.diis.dk/graphics/Publications/Reports\%202008/Report-200814 The United Nations and the Comprehensive Approach.pdf.

"Connecting Government: Whole of Government Responses to Australia's Priority Challenges," Management Advisory Committee, Commonwealth of Australia, (2004), http://www.apsc.gov.au/mac/connectinggovernment.htm, (accessed 04 January 2011).

Cullen, Hon Dr Michael, "Setting the Benchmark for Public Management" (3 December 2003), available at http://www. beehive.govt.nz/release/setting-benchmark-public-management, (accessed 31 December 2010).

Davies, Jonathan. "The Limits of Joined up Government: Towards a Political Analysis." Public Administration 87, no. 1 (2009): 80-96.

Davis, Jeff. "Feds' Go-to Team in Afghanistan Part of New Whole-of-Government Strategy " The Hill Times Online, no. April 19 (2010), http://www.thehilltimes.ca/page/view/afghan-04-19-2010.

"The Department of State's Quadrennial Diplomacy and Development Review." http://www.state.gov/r/pa/prs/ps/2009/july/125956.htm (accessed 23 September 2010).

DFAIT. "Stabilization and Reconstruction Task Force (Start)." http://www.international.gc.ca/startgtsr/index.aspx; http://www.international.gc.ca/START-GTSR/civilian deploymentdeploiement de civils.aspx (accessed 22 September 2010).

Dinnen, Sinclair. "State-Building in a Post-Colonial Society: The Case of Solomon Islands." Chicago Journal of International Law 9, no. 1 (2008). 
Dinnen, Sinclair;, State Society and Governance in Melanesia Project, RSPAS; ANU, "Lending a Fist? Australia's New Interventionism in the Southwest Pacific," (2004), http://dspace.anu.edu.au/handle/1885/42136.

Dobell, Graeme. "The 'Arc of Instability': The History of an Idea." In History as Policy: Framing the Debate on the Future of Australia's Defence Policy, edited by Ron Huisken and Meredith Thatcher. Canberra: Australian National University Press, 2007.

Dovey, Lyne, State Services Commission, "Achieving Better Social Outcomes in New Zealand through Collaboration: Perspectives from the United States," (2003), http://www.ssc.govt.nz/upload/downloadable files/Working Paper 16.pdf, (accessed 24 January 2011).

DPMC. "About DPMC." http://www.dpmc.govt.nz/dpmc/index.htm (accessed 09 January).

DPMC. "Cabinet Committees Cabinet Committee on Domestic and External Security Co-Ordination (DES)." http://www.dpmc.govt.nz/cabinet/committees/des.html (accessed 11 January 2011).

DPMC. "Cabinet Committees Cabinet External Relations and Defence Committee (ERD)." http://www.dpmc.govt.nz/cabinet/committees/erd.html (accessed 11 January 2011).

DPMC, Department of the Prime Minister and Cabinet, "Statement of Intent 2010-2014," (2010), http://www.dpmc.govt.nz/dpmc/publications/soi-dpmc-2010-14.pdf, (accessed 10 January 2011).

Dunleavy, Patrick, 2020 Public Services Trust, "The Future of Joined-up Public Services," (2010), http://clients.squareeye.com/uploads/2020/documents/esrc dunleavy.pdf.

Dunn, James, "Crimes against Humanity in East Timor, January to October 1999: Their Nature and Causes," (2001), http://www.etan.org/etanpdf/pdf1/dunn.pdf, (accessed 22 March 2011).

Editorial "Back to the Future, with 2000," The New Zealand Herald 4 November, 2000, available at http://www.nzherald.co.nz/nz/news/article.cfm?c id=1\&objectid=158608 (accessed 6 October 2010).

Eide, Espen Barth, Anja Therese Kaspersen, Randolph Kent, and Karen von Hippel, Independent Study for the Expanded UN ECHA Core Group, "Report on Integrated Missions: Practical Perspectives and Recommendations," (May 2005), http://www.isn.ethz.ch/isn/DigitalLibrary/Publications/Detail/?ots591=0C54E3B3-1E9C-BE1E-2C24A6A8C7060233\&lng=en\&id=28276.

Elizabeth Eppel, Derek Gill, Miriam Lips, Bill Ryan Institute of Policy Studies, School of Government, Victoria University of Wellington "Better Connected Services for Kiwis: Discussion Document for Managers and Front-Line Staff on Better Joining up the Horizontal and the Vertical," (2008), http://ips.ac.nz/events/completedactivities/joiningup/Connected\%20Services\%20ver\%2010.pdf.

Eppel, Elizabeth, School of Government, Victoria University of Wellington, "Better Connected Services for Kiwis: Achieving Outcomes by Joining Up: A Liturature Review," (2008), http://ips.ac.nz/events/completedactivities/joiningup/Integrated\%20 Government $\% 20$ Services\%20lit\%20review\%20outline $\% 20 \%$ 20v4\%20revised\%20May2008.doc.

Falke Meyers, Koen Verhoest, Eva Beuselinck. "Performance of Public Sector Organizations: Do Management Instruments Matter?" In A performing public sector: the second transatlantic dialogue". Leuven, België, 2006. 
"Foundations of New Zealand Military Doctrine (NZDDP-D)," Development Branch, Headquarters New Zealand Defence Force, (November 2008), http://www.nzdf.mil.nz/downloads/pdf/publicdocs/2008/nzddp-d-2008-ed-2.pdf.

"Frequently Asked Questions: Purpose of the QDDR." http://www.usaid.gov/policy/qddr/faq.html (accessed 23 September 2010).

Friis, Cedric de Coning and Karsten. "How to Conceptualise 'Comprehensive Approach'?" In Comprehensive Approach: Challenges and Opportunities in Complex Crisis Management, edited by Karsten Friis and Pia Jarmyr. Oslo: Norsk Utenrikspolitisk Institutt (NUPI), 2008.

Fullilove, Michael. "RAMSI and State Building in Solomon Islands." Defender (2006): 31-35.

"Getting Better at Managing for Shared Outcomes: A Resource for Agency Leaders," Prepared by the Managing for Shared Outcomes Development Group for the Managing for Outcomes Programme Office, (2004), http://www.ssc.govt.nz/upload/downloadable files/mfsoresource.pdf.

Goff, Phil, "Meeting the Challenges of Security and Development" (27 June, 2005), available at http://www. beehive.govt.nz/release/meeting+challenges+security+and+development, (accessed 21 September 2010).

Gonzalez, Roberto J. "We Must Fight the Militarization of Anthropology." Chronicle of Higher Education 2007.

Google. "'Whole of Government" Site:.Govt.Nz."

http://www.google.co.nz/search?q=\%22whole+of+government $\% 22+$ site:.govt.nz\&hl=en \&lr=\&cr =countryNZ\&biw=1280\&bih=834\&tbs=ctr:countryNZ\&ei=X0iuTJHUK5KinQeeou2BBg\&start=50 \&sa=N (accessed 8 October 2010).

"The Government's Defence Policy Framework ", The New Zealand Government, (2000), http://www.defence.govt.nz/reports-publications/defence-policy-framework/defpol-frmwrk.html, (accessed 04 January 2011).

Government, Australian, The Senate: Standing Committee on Foreign Affairs, Defence and Trade, "Australia's Involvement in Peacekeeping Operations," (2008).

Government, New Zealand, Foreign Affairs, Defence and Trade Committee, "Inquiry into Defence Beyond 2000," (1999), http://www.defence.govt.nz/pdfs/archive-publications/inquiry-defencebeyond-2000.pdf, (accessed 6 October 2010).

Government, UK. "UK Civilian Stabilisation Group." http://www.stabilisationunit.gov.uk/index.php/civilian-stabilisation-group (accessed 23 September 2010).

Gray, Alison, Review of the Centre - Regional Co-ordination Workstream, "Integrated Service Delivery and Regional Co-Ordination: A Literature Review," (2002), http://www.msd.govt.nz/documents/about-msd-and-our-work/publicationsresources/archive/2003-integrated-service-delivery-regional-coordination-literature-review.pdf.

Gregory, Robert. "Theoretical Faith and Practical Works: De-Autonomizing and Joining-up in the New Zealand State Sector." In Autonomy and Regulation: Coping with Agencies in the Modern State edited by Tom Christensen and Per Lægreid. Cheltenham: Edward Elgar, 2006.

Gross, Eva, Danish Institute for International Studies, "The Eu and the Comprehensive Approach," (2008), http://www.diis.dk/graphics/Publications/Reports\%202008/R2008$13 \mathrm{EU}$ and the Comprehensive Approach.pdf. 
Helen Clark, (Prime Minister), "Clark: NZ and Peaceful Conflict Resolution" Suzanne Mubarak International Peace Movement, Khafre Hall, Cairo International Convention Centre (29 November, 2007), available at http://www.scoop.co.nz/stories/PA0711/S00588.htm.

Hon Tony Ryall, Minister of State Services, "State Sector Management Bill Passed" (11 December 2010), available at http://www.scoop.co.nz/stories/PA1012/S00207/state-sector-managementbill-passed.htm, (accessed 02 January 2011).

Hon Winston Peters, Minister of Foreign Affairs, "Nz's Involvement in Global Peace Operations" Speech to the Swedish Institution of International Affairs in Stockholm, Sweden (18 October, 2007), available at http://www.beehive.govt.nz/speech/nz\%E2\%80\%99s-involvement-global-peaceoperations, (accessed 10 January 2011).

Hood, Christopher. "The Idea of Joined-up Government: A Historical Perspective." In Joined-up Government, edited by Vernon Bogdanor. Oxford: Oxford University Press, 2005.

Hunt, Sue, Australian National University, Asia Pacific School of Economics and Government, "Wholeof-Government: Does Working Together Work?," (2005).

Hyde, Jim. "How to Make the Rhetoric of Joined-up Government Really Work." Australia New Zealand Health Policy 5 (2008)

"In Larger Freedom: Towards Development, Security and Human Rights for All ", (September 2005), http://www.un-ngls.org/orf/UNreform/UBUNTU-1.pdf.

"Indicators for Monitoring Community Outcomes: Methodology and Process for Developing Indicators," Canterbury Region Community Plans Group, (2005), http://www.stats.govt.nz/browse for stats/government finance/local government/ /media/Stati stics/Publications/Stats-by-Area/regional-statistics/canterbury-region-outcome-indicators-1807-05.ashx, (accessed 13 January 2011).

Jakobsen, Peter Viggo, Danish Institute for International Studies, "A Work in Slow Progress: Nato's Comprehensive Approach to Crisis Response Operations," (2008), http://www.diis.dk/graphics/Publications/Reports\%202008/Report 200815 NATO Comprehensive Approach Crisis Response Operations.pdf

James, Colin "Dialogue: Clark and Co Doing Their Best to Prod the Economy," New Zealand Herald January 31, 2001, available at http://www.nzherald.co.nz/nz/news/article.cfm?c id=1\&objectid=170444 (accessed 6 October 2010).

Jobbagy, Z. "A Literature Survey on Effects-Based Operations." PhD Study on measuring militaryeffects and effectiveness, TNO Physics and Electronics Labratory, 2003.

"Joined up Government: A Review of National and International Experiences," State Government of Victoria State Services Authority, (2007), http://www.ssa.vic.gov.au/CA2571410025903D/WebObj/OccPaper JoinedupGovernment/\$File IOccPaper JoinedupGovernment.pdf.

Jonathan Boston, Chris Eichbaum. "State Sector Reform and Renewal in New Zealand: Lessons for Governance." In Conference on Repositioning of Public Governance - Global Experiences and Challenges. Taipei, 2005.

Jorgensen, Colonel M.P. "A Strategy for Effective Peace-Building: Canada's Whole-of-Government Approach in Afghanistan." Canadian Forces College, 2008.

Juillet, Herman Bakvis and Luc, Canada School of Public Service, "The Horizontal Challenge: Line Departments, Central Agencies and Leadership," (2004), http://www.cspsefpc.gc.ca/pbp/pub/pdfs/P124 e.pdf, (accessed 04 January 2011). 
Key, Hon John, "Opening Address to Local Government New Zealand Annual Conference" (26 July, 2010), available at http://www.johnkey.co.nz/archives/1001-Opening-address-to-LocalGovernment-New-Zealand-Annual-Conference.html, (accessed 02 January 2011).

Key, Hon John, "Prime Minister's Speech Notes on Benefit Reform" (23 March, 2010), available at http://www.johnkey.co.nz/archives/910-Prime-Ministers-speech-notes-on-benefit-reform.html, (accessed 02 January 2011).

Kilcullen, David. The Accidental Guerrilla. Melbourne: Sage, 2009.

Kristin M. Haugevik, Benjamin de Carvalho, Norwegian Institute of International Affairs, "Civil-Military Cooperation in Multinational and Interagency Operations: Discussion Paper on Operational Terminologies and Assessment for Multinational Experiment 5 [MNE5]," (2007), http://www.reliefweb.int/rw/lib.nsf/db900sid/PANA79SJ2P/\$file/nupi may2007.pdf?openelement, (accessed 30 January 2011).

Lægreid, Tom Christensen \& Per. "Democracy and Administrative Policy: Contrasting Elements of NPM and Post-NPM." In EGPA Annual Conference 'The Public Service: Public Service Delivery in the Information Age', Study Group VI: Governance of Public Sector Organizations. Malta, 2009.

Lægreid, Tom Christensen and Per, Stein Rokkan Centre for Social Studies, "The Whole-ofGovernment Approach - Regulation, Performance, and Public-Sector Reform," (2006), https://bora.uib.no/bitstream/1956/1893/1/N06-06\%20Christensen-L\%C3\%A6greid.pdf, (accessed 9 September 2010).

Lægreid, Tom Christensen and Per. "The Whole-of-Government Approach to Public Sector Reform." Public Administration Review 67, no. 6 (2007): 1059.

Laswell, H D. Politics: Who Gets What, When and How. Cleveland: Meridan, 1936.

Lewis, RD Harris and BR, United States Marine Corps,Command and Staff College, Marine Corps Combat Development Command,Marine Corps University, "The Failure of Future U.S. Stability Operations Fueled by Flawed Strategic Policies," (2008), http://www.dtic.mil/cgibin/GetTRDoc?AD=ADA508095\&Location=U2\&doc=GetTRDoc.pdf, (accessed 22 March 2011.).

Ling, Tom. "Delivering Joined-up Government in the UK: Dimensions, Issues and Problems." Public Administration 80 (2002): 615-42.

Majumdar, Debiprosad. "Collaboration among Government Agencies with Special Reference to New Zealand: A Literature Review." Social Policy Journal of New Zealand, no. 27 (2006).

Mallard, Hon Trevor, "Opening Address to Government Online Conference" (6 December, 2000), available at http://www.scoop.co.nz/stories/PA0012/S00078.htm.

"Managing Threats to Domestic Security," Report of the Controller and Auditor-General, (2003), http://www.oag.govt.nz/2003/domestic-security/docs/domestic-security.pdf, (accessed 10 January 2011).

Mark Burton, (Minister of Defence), "New Zealand's Role in the Global Defence Community" Speech to RSA National Council meeting (16 June, 2004), available at http://www.beehive.govt.nz/node/20017.

Martin, Callum. "New Zealand's Expeditionary Police: The Expanding Role of New Zealand Police in International Relations." In The Oceanic Conference on International Studies (OCIS). Auckland, New Zealand, 2010. 
McFate, Montgomery. "Anthropology and Counterinsurgency: The Strange Story of Their Curious Relationship." Military Review March-April (2005): 24.

Memon, Professor Ali, Environmental Management Group Environment, Society and Design Division, Lincoln University, Canterbury, "Choosing Community-Based Indicators to Monitor and Report Progress Towards Community Outcomes," (2008), http://www.waikato.ac.nz/igci/pucm/lga/lgarpt4.pdf, (accessed 13 January 2011).

MFAT, The New Zealand Ministry of Foreign Affairs and Trade, "Annual Report 2002-2003," (2003), http://www.mfat.govt.nz/Media-and-publications/Publications/Annual-report/index.php, (accessed 08 January 2011).

MFAT, The New Zealand Ministry of Foreign Affairs and Trade, "Annual Report 2003-2004," (2004), http://www.mfat.govt.nz/Media-and-publications/Publications/Annual-report/index.php, (accessed 08 January 2011).

MFAT, Ministry of Foreign Affairs and Trade, "Annual Report for the Year Ended 30 June 2007," (2007), http://www.mfat.govt.nz/downloads/media-and-publications/annualreport/annualreport0607.pdf, (accessed 22 March 2011).

MFAT, Ministry of Foreign Affairs and Trade, "Annual Report for the Year Ended 30 June 2008," (2008), http://www.mfat.govt.nz/downloads/media-and-publications/annual-report/ar-mfat-2007-08.pdf, (accessed 22 March 2011).

MFAT, NZ Ministry of Foreign Affairs \& Trade, "Post-Election Brief 2008," (2008), http://www.mfat.govt.nz/downloads/media-and-publications/peb-nov2008.pdf, (accessed 22 March 2011).

MFAT. "Security: Peace Support Operations [Webpage]." http://www.mfat.govt.nz/Foreign-Relations/1Global-Issues/International-Security/4-Peacekeeping-Operations.php (accessed 04 January 2011).

MFAT. "Solomon Islands [Webpage]." http://www.mfat.govt.nz/Countries/Pacific/Solomon-Islands.php (accessed 11 January 2011).

MFAT, New Zealand Ministry of Foreign Affairs and Trade, "Statement of Intent 2004-2005," (2004), http://www.mfat.govt.nz/Media-and-publications/Publications/Statement-of-intent/index.php, (accessed 08 January 2011).

MFAT, New Zealand Ministry of Foreign Affairs and Trade, "Statement of Intent 2005-2008," (2005), http://www.mfat.govt.nz/Media-and-publications/Publications/Statement-of-intent/index.php (accessed 08 January 2011).

MoD, Ministry of Defence, "Defence Assessment," (2010), http://www.defence.govt.nz/pdfs/defencereview-2009-released-defence-assessment-july-2010.pdf, (accessed 10 January 2010).

Moseley, Alice. "Joined-up Government: Rational Administration or Bureaucratic Politics?" In Public Administration Committee Annual Conference. University of Glamorgan, 2009.

Mulgan, Geoff. "Joined-up Government: Past, Present, and Future." In Joined-up Government, edited by Vernon Bogdanor. Oxford: Oxford University Press, 2005.

"New Zealand's Current Involvement in Afghanistan." http://www.mfat.govt.nz/Countries/MiddleEast/Afghanistan.php (accessed 11 January).

"New Zealand Defence Force Capability Reviews Phase One - Land Forces and Sealift ", The New Zealand Ministry of Defence (2000), http://www.defence.govt.nz/reports-publications/nzdf-caprev/introduction.html. 
Niels Nagelhus Schia, Ståle Ulriksen, A Publication in the NUPI Series on Security in Practice, "Multidimensional and Integrated Peace Operations," (2007),

http://www.humansecuritygateway.com/documents/NUPI multidimensionalandintegratedpeace ops.pdf, (accessed 23 January 2011).

"NSC Board: Our People." http://nsc.anu.edu.au/about us.php (accessed 30 January 2011).

NZDF, New Zealand Defence Force, "Foundations of New Zealand Military Doctrine (NZDDP-D)," (2004), http://www.nzdf.mil.nz/downloads/pdf/public-docs/nzddp 2004 web.pdf, (accessed 08 January 2011).

NZDF, Development Branch, Headquarters New Zealand Defence Force, "Foundations of New Zealand Military Doctrine (NZDDP-D)," (2008), http://www.nzdf.mil.nz/downloads/pdf/publicdocs/2008/nzddp-d-2008-ed-2.pdf.

NZDF, New Zealand Defence Force, "Statement of Intent 2009 - 2012," (2009), http://www.nzdf.mil.nz/downloads/pdf/public-docs/2009/soi/nzdf-soi-2009-12.pdf, (accessed 22 March 2011)

NZDF, New Zealand Defence Force, "Statement of Intent 2010 - 2013," (2010), http://www.nzdf.mil.nz/public-documents/soi/default.htm, (accessed 08 January 2011).

NZDF, New Zealand Defence Force, "Statement of Intent for the Period 1 July 2005 to 30 June 2008," (2005), http://www.nzdf.mil.nz/downloads/pdf/public-docs/nzdfsoi2005.pdf, (accessed 08 January 2011).

NZDF, New Zealand Defence Force, "Statement of Intent for the Period 1 July 2006 to 30 June 2009," (2006), http://www.nzdf.mil.nz/downloads/pdf/public-docs/nzdfsoi2006.pdf, (accessed 08 January 2011).

NZDF, New Zealand Defence Force, "Statement of Intent for the Period 1 July 2007 to 30 June 2010," (2007), http://www.nzdf.mil.nz/downloads/pdf/public-docs/2007/NZDF-SOI-07-08.pdf, (accessed 09 January 2011).

NZDF. "Ten Years in Timor." One Force, October 2009.

NZPA "Govt Web Sites Fail Test," Waikato Times, Edition 2, page 16, March 16, 2000.

NZSIS, New Zealand Security Intelligence Service, "Annual Report for the Year Ended 30 June 2010," (2009), http://www.security.govt.nz/reports/ar10/nzsis-ar10.pdf, (accessed 10 January 2011).

O'Callaghan, Mary Louise. "RAMSI: The Challenges Ahead " In Solomon Islands: Where to now? State Society and Governance in Melanesia Project and The Pacific Centre, College of Asia and the Pacific, Australian National University 2006.

O'Neill, Rose. "E-Government Transformation of Public Governance in New Zealand." Doctor of Philosophy in Public Management, Victoria University of Wellington 2009.

OECD, Organisation for Economic Co-operation and Development, "New Zealand (2010) Dac Peer Review: Main Findings and Recommendations," (2010), http://www.oecd.org/document/54/0,3746,en 215713614431511546730038111 1,00.ht $\underline{\mathrm{ml}}$, (accessed 09 January 2011).

OECD, Development Assistance Committee (DAC), "OECD Peer Review of Canada " (2007), http://www.oecd.org/dataoecd/48/61/39515510.pdf, (accessed 23 January 2011). 
OECD, Development Assistance Committee (DAC) Fragile States Group (FSG), "Whole of Government Approaches to Fragile States," (2006), http://www.oecd.org/dataoecd/15/24/37826256.pdf, (accessed 22 March 2011.).

Palmer, Geoffrey. "The Cabinet, the Prime Minister and the Constitution: The Constitutional Background to Cabinet." New Zealand Journal of Public and International Law 4, no. 1 (2006): 1-36.

Phil Goff, (Leader of the Opposition), "New Zealand's Contribution to a World Free of Nuclear Weapons" Speech to the Wellington Branch of the New Zealand Institute of International Affairs (May 31, 2010), available at http://www.labour.org.nz/news/new-zealand\%E2\%80\%99s-contributionworld-free-nuclear-weapons.

Phil Goff, (Minister of Defence), "Meeting Contemporary Security Challenges" Speech notes for addrss to New Zealand Defence Force Command and Staff College. Trentham (12 July, 2007), available at http://www.beehive.govt.nz/node/30047.

Phil Goff, (Minister of Defence), "New Zealand's Defence Policy" Opening address of the Chief of Army's Contemporary War Fighting Seminar (30 August, 2007), available at http://www.beehive.govt.nz/node/30478.

Pollitt, Christopher. "Joined-up Government: A Survey." Political Studies Review 1, no. 1 (2003): 34-49.

"Prime Minister Launches National Security College", (24 April 2010), available at http://news.anu.edu.au/?p=2100, (accessed 30 January 2011).

"Profiles of Tools and Tactics for Environmental Mainstreaming: Indicators," International Institute for Environment and Development (IIED), (2009), http://www.environmentalmainstreaming.org/documents/EM\%20Profile\%20No\%2010\%20\%20Indicators\%20\%2820\%20November\%2009\%29.pdf, (accessed 20 February 2011).

Pugh, Michael. "Civil-Military Relations in International Peace Operations." In Peace Support Operations. Lessons Learned and Future Perspective, edited by Gabriel Thomas Bernauer Jürg M, Kurt R Spillmann, Andreas Wenger. Bern: Peter Lang, 2001.

Pullar-Strecker, Tom "Some State Agencies Falling Behind on Y2k," NZ Infotech Weekly 20 September, 1999.

"Quadrennial Roles and Missions Review Report ", Department of Defense, (2009), http://www.defense.gov/news/Jan2009/QRMFinalReport v26Jan.pdf.

"Quadrennial Roles and Missions Review Report ", Department of Defense, (January 2009), http://www.defense.gov/news/Jan2009/QRMFinalReport v26Jan.pdf.

Quigley, Derek. The War against Defence Restructuring: A Case Study on Changes Leading to the Current Structure of New Zealand Defence. Canberra: Australian National University, 2006.

"Report of the Advisory Group on the Review of the Centre," Presented to the Ministers of State Services and Finance, (2001), http://www.ssc.govt.nz/display/document.asp?DoclD=2776, (accessed 31 October 2010).

"Report of the Advisory Group on the Review of the Centre," Presented to the Ministers of State Services and Finance, (November 2001), http://www.ssc.govt.nz/display/document.asp?DocID=2776, (accessed 31 October 2010).

"Report of the Panel on United Nations Peace Operations," United Nations General Assembly \& Security Council (New York: 2000), http://www.un.org/peace/reports/peace operations/, (04 January 2011). 
"Resolving Timor-Leste's Crisis," International Crisis Group, (2006), http://www.crisisgroup.org/ /media/Files/asia/south-east-asia/timorleste/120 resolving timor lestes crisis.ashx, (accessed 09 January 2011).

"Review of the Centre Integrated Service Delivery: Regional Co-Ordination - Final Workstream Report," State Services Commission, Ministry of Social Development, (2003), http://www.ssc.govt.nz/upload/downloadable files/integrated-service-delivery-final-workstreamreport.pdf, (accessed 29 January 2011).

Robson, Hon Matt. "Defence Beyond 2000 Underpins the Government's Defence Policy." http://www. beehive.govt.nz/node/10503

Røste, Rannveig, "Innovation in the Public Sector: Studies of Innovation in the Public Sector, a Theoretical Framework," (2005), http://www.step.no/publin/reports/d16litteraturesurvey.pdf, (accessed 27 February 2011).

Schacter, Mark, Mark Schacter Consulting, "How Good Is Your Government? Assessing the Quality of Public Management," (2008), http://www.schacterconsulting.com/documents/howgood.pdf, (accessed 14 January 2011).

"Securing Our Nation's Safety: How New Zealand Manages Its Security and Intelligence Agencies." http://www.dpmc.govt.nz/dpmc/publications/securingoursafety/overview.html (accessed 11 January).

"Security \& Risk Group." http://www.dpmc.govt.nz/dess/index.htm (accessed 09 January).

Selden, Gene A Brewer and Sally Coleman. "Why Elephants Gallop: Assessing and Predicting Organizational Performance in Federal Agencies." Journal of Public Administration Research and Theory 10, no. 4 (2000).

Selznick, P. Leadership in Administration. New York: Harper \& Row, 1957.

Sharples, Hon Simon Power and Hon Dr Pita, "Drivers of Crime a Whole-of-Government Priority" (17 December 2009), available at http://www.beehive.govt.nz/release/drivers-crime-wholegovernment-priority, (accessed 02 January 2011).

Simon J A Mason (CSS), David Lanz (swisspeace), Center for Security Studies (ETH Zurich) and Swisspeace, "Towards a Swiss "Whole of Government" Approach in Sudan: 2005-2008," (2009), http://www.swisspeace.ch/typo3/fileadmin/user upload/pdf/publications by staff/Swiss-WGAin-Sudan-18Mar09.pdf.

Smith, Edward A, "Effects Based Operations Applying Network Centric Warfare in Peace, Crisis, and War," http://www.iwar.org.uk/rma/resources/ebo/Literature_survey_on_Effects-

Based Operations.pdf, (accessed 23 January).

SSC, State Services Commission: New Zealand Government, "Factors for Successful Coordination - a Framework to Help State Agencies Coordinate Effectively," (2008), http://www.ssc.govt.nz/state-services-coordination.

State Sector Management Bill 2010 193-1.

State, US Department of. "A Whole-of-Government Approach to Prevent, Resolve, and Transform Conflict." http://merln.ndu.edu/archivepdf/nss/state/71036.pdf (accessed 21 September).

Stepputat, Finn, Danish Institute for International Studies, "Integrated National Approaches to International Operations: The Cases of Denmark, UK, and the Netherlands," (2009), 
http://www.isn.ethz.ch/isn/Digital-Library/Publications/Detail/?ots591=EB06339B-2726-928E0216-1B3F15392DD8\&lng=en\&id=99492.

Straw, Jack, UK Foreign and Commonwealth Office, "UK International Priorities: A Strategy for the Fco," (December 2003), http://www.sovereignty.org.uk/siteinfo/newsround/FCOStrategyFullFinal.pdf.

"Strengthening of the Stabilisation Unit and Implimentation of the Cabinet Office Task Force Review of Stabilisation and Civil Effect," Third supplementary memorandum from the Ministry of Defence, the Foreign and Commonwealth Office and the Department for International Development (December 2009), http://www.publications.parliament.uk/pa/cm200910/cmselect/cmdfence/224/224we28.htm.

Theodoulou, S. Z. and Cahn, M. A. Public Policy. The Essential Readings. Englewood Cliffs, NJ: Prentice Hall, 1995.

Unit, The Stabilisation. "About Us." http://www.stabilisationunit.gov.uk/index.php/about-us (accessed 23 September 2010).

Verhoest, Per Lægreid and Koen, ed. Governance of Public Sector Organizations: Proliferation, Autonomy and Performance: Palgrave Macmillan 2010.

Williamson, Simon, Independent Advisor, "Review of New Zealand Official Development Assistance Supported Activities in Afghanistan," (2009).

Wilson, James Q. Bureaucracy: What Government Agencies Do and Why They Do It. New York: Basic Books, 1989

"Wiring It Up: Whitehall's Management of Cross-Cutting Policies and Services," A Performance and Innovation Unit Report, (2000), (accessed 22 March 2011).

World Bank, Independent Evaluation Group, "Engaging with Fragile States: An leg Review of World Bank Support to Low-Income Countries under Stress," (2006), http://www.worldbank.org/ieg/licus/docs/licus ce.pdf. 